\title{
Fatigue life prediction of GFRP composite material at coupon and component level
}

Praveenkumar Munagala

West Virginia University

Follow this and additional works at: https://researchrepository.wvu.edu/etd

\section{Recommended Citation}

Munagala, Praveenkumar, "Fatigue life prediction of GFRP composite material at coupon and component level" (2005). Graduate Theses, Dissertations, and Problem Reports. 4177.

https://researchrepository.wvu.edu/etd/4177

This Thesis is protected by copyright and/or related rights. It has been brought to you by the The Research Repository @ WVU with permission from the rights-holder(s). You are free to use this Thesis in any way that is permitted by the copyright and related rights legislation that applies to your use. For other uses you must obtain permission from the rights-holder(s) directly, unless additional rights are indicated by a Creative Commons license in the record and/ or on the work itself. This Thesis has been accepted for inclusion in WVU Graduate Theses, Dissertations, and Problem Reports collection by an authorized administrator of The Research Repository @ WVU. For more information, please contact researchrepository@mail.wvu.edu. 


\title{
Fatigue Life Prediction of GFRP Composite Material at Coupon and Component Level
}

\author{
By \\ Praveenkumar Munagala

\begin{abstract}
A Thesis Submitted to the
College of Engineering and Mineral Resources

West Virginia University

in Partial Fulfillment of the Requirements

for the Degree of

Master of Science in Mechanical Engineering
\end{abstract}

Kenneth H. Means, Ph.D., Chair

Hota GangaRao, Ph.D.

Bruce Kang, Ph.D.

Department of Mechanical and Aerospace Engineering

Morgantown, West Virginia

2005

Keywords: Fatigue Life Prediction, GFRP, Single Cell Deck, Multi-cell Deck, Coupon, Internal Strain Energy, Energy Release Rate. 


\section{ABSTRACT \\ Fatigue Life Prediction of GFRP Composite Material at Coupon and Component Level}

\section{Praveenkumar Munagala}

Fiber Reinforced Polymer (FRPs) composites are gaining acceptance as alternate materials to conventional materials of construction for civil and military infrastructure applications. The primary reasons for better acceptance are: high strength and stiffness to weight ratio, resistance to fatigue and corrosion, easy installation, low maintenance costs and good vibration characteristics. Glass FRPs are the most widely used composites because of favorable initial and maintenance costs with good mechanical and chemical properties. In order to use glass FRPs for infrastructural applications, they must be tested at both coupon and component level under static and fatigue loads.

In this study unidirectional, bidirectional glass fabric reinforced polymer (GFRP) composites were tested under fatigue loads to determine their fatigue life. The experimental fatigue life of FRP coupons was compared with the predicted fatigue life which was evaluated based on the internal strain energy model proposed by GangaRao and Natarajan (2003). It was found from the strain energy model that the power law accurately describes the relationship between energy release rate, $\Delta U$ and normalized strain, $\mathrm{x}$ (applied strain to ultimate strain) as $\Delta U=a x^{b}$, where ' $\mathrm{a}$ ' and ' $\mathrm{b}$ ' are the fatigue coefficients.

Further rectangular single cell and multi-cell GFRP deck components (Prodeck 4) were also evaluated under fatigue to determine their strain energy loss per cycle. It was found that the fatigue coefficient ' $a$ ' depends on the energy release rate while ' $b$ ' depends on material constants such as damping and bond strength between fibers/fabrics and 
matrix. Coefficients ' $a$ ' and ' $b$ ' rely on other factors as well, which are: moment of inertia, strain energy at mean load, fiber architecture, edge effects (e.g., cutting of FRP component), stress concentration at web-flange junction and others. The normalized coefficient, ratio of ' $a$ ' over strain energy at mean load, was found to decrease with increasing percentage of mean fatigue strain for all the test specimens. The above power law is valid for single cell and multi-cell deck GFRP composites. From the experimental data of fatigue coefficients ('a' and ' $b$ ') of decks, the fatigue lives at different strain ranges of single cell deck were predicted. The predicted results correlated well with the experimental fatigue lives. 


\section{ACKNOWLEGEMENTS}

First of all, I would like to thank my parents and sister for their inspiration and support during the completion of this project. I am also greatly indebted for their love and affection.

I would like to express my sincere gratitude to Dr. Hota GangaRao for his invaluable support, guidance and knowledge along with my committee members Dr. Kenneth H. Means and Dr. Bruce Kang. This work would not have been completed without their encouragement, valuable suggestions and motivation.

I would also like to thank Vimala Shekar for her guidance, support and encouragement throughout the completion of my thesis.

Bill Comstock should be especially commended for helping me throughout the test setup along with David Turner, Jerry Nester in addition to my officemates for helping me in preparing the test specimens for my thesis and concluding this research.

Thanks to my roomies and friends for their support and encouragement, which made my life easier at Morgantown. 


\section{TABLE OF CONTENTS}

ABSTRACT

ACKNOWLEDGEMENTS iv

TABLE OF CONTENTS V v

LIST OF FIGURES ix

LIST OF TABLES Xi

CHAPTER 1

INTRODUCTION

$1.1 \quad$ General 1

1.2 Objectives 2

1.3 Scope 3

CHAPTER 2

LITERATURE REVIEW

$\begin{array}{lll}2.1 & \text { Introduction } & 4\end{array}$

2.2 Fatigue Damage in Composite Materials 4

$2.3 \quad$ Fatigue Life Prediction Models 6

2.3.1 Fatigue Life Models 6

2.3.2 Phenomenological Models 9

2.3.2.1 Residual Stiffness Models 9

2.3.2.2 Residual Strength Models 11

2.3.3 Progressive Damage Models 13

2.4 Fatigue Life Prediction of Composite Materials at Coupon Level 14

2.5 Fatigue Life Prediction of Composite Materials at Component Level 18 


\section{CHAPTER 3}

FATIGUE TEST ON GFRP COUPONS UNDER FATIGUE LOADING 22

$\begin{array}{lll}3.1 & \text { Introduction } & 22\end{array}$

3.2 Internal Strain Energy Curve 22

3.3 Experimental Procedure 24

$\begin{array}{lll}3.3 .1 & \text { Static Test } & 24\end{array}$

3.3.1.1 Description of Material 24

3.3.1.2 Static Test Results 25

3.3.1.3 Test Specimen Preparation 25

$\begin{array}{lll}\text { 3.3.1.4 Testing Equipment } & 27\end{array}$

$\begin{array}{lll}\text { 3.3.1.5 Test Procedure } & 28\end{array}$

3.3.2 Tension-Tension Fatigue Test 29

$\begin{array}{ll}\text { 3.3.2.1 Test Procedure } & 29\end{array}$

3.3.2.2 Steps to Determine Strain Energy Release Rate and

Fatigue Coefficients from Experimental Data 32

3.3.2.3 Tension-Tension Fatigue Test Results 33

3.3.2.4 Strain Energy Curves, Energy Release Rate and Determination of Fatigue Coefficients $\quad 36$

3.3.2.5 Comparison of MAT 1, MAT 2, MAT 3 Based on $\begin{array}{ll}\text { Fatigue Coefficients } & 45\end{array}$

3.3.2.5.1 MAT 1 vs MAT 2 45

3.3.2.5.2 MAT 2 vs MAT 3 45

3.4 Application of Strain Energy Model for Fatigue Life Prediction of 
$\begin{array}{ll}\text { GFRP Material } & 46\end{array}$

3.4.1 Model Development 46

3.4.2 Application of Theoretical Model 48

3.5 Synonymy of Energy Release Rate Between Composites and Metals 50

3.6 Conclusions $\quad 51$

\section{CHAPTER 4}

FATIGUE TEST ON SINGLE CELL DECK AND MULTI-CELL DECK

UNDER FATIGUE LOADING

4.1 Introduction $\quad 53$

4.2 Fatigue Tests on Single Cell Deck 53

4.2.1 Description of the Deck 53

4.2.2 Testing Equipment $\quad 54$

4.2.3 Support Conditions 56

4.2.4 Loading Conditions $\quad 56$

4.2.5 Static Test 56

$\begin{array}{lll}\text { 4.2.6 Fatigue Test } & 58\end{array}$

4.2.6.1 Test Results and Discussion $\quad 58$

4.2.6.2 Internal Strain Energy, Strain Energy Release Rate $\begin{array}{ll}\text { and Fatigue Coefficients } & 61\end{array}$

4.2.6.3 Application of Strain Energy Model for Single Cell Deck 65

4.3 Fatigue Tests on 4" thick Multi-Cell Bridge Deck 66

4.3.1 Cross-Section of the Deck 66

$\begin{array}{lll}\text { 4.3.2 Static Test } & 67\end{array}$ 
$\begin{array}{lll}\text { 4.3.3 } & \text { Fatigue Test } & 68\end{array}$

4.3.4 Test Results and Discussion $\quad 69$

$\begin{array}{lll}\text { 4.3.4.1 Test } 1 & 69\end{array}$

$\begin{array}{lll}\text { 4.3.4.2 } & \text { Test } 2 & 70\end{array}$

4.3.4.3 Strain Energy Release Rate and Fatigue Coefficients for a Multi-Cell Deck $\quad 73$

$\begin{array}{lll}4.4 & \text { Conclusions } & 76\end{array}$

4.4.1 Bending Fatigue Tests on Single Cell Deck 76

4.4.2 Bending Fatigue Tests on Multi-Cell Deck 77

\section{CHAPTER 5}

CONCLUSIONS AND RECOMMENDATIONS 79

$\begin{array}{lll}5.1 & \text { Conclusions } & 79\end{array}$

5.1.1 Fatigue Test on GFRP Composite Materials under Coupon Level 79

5.1.2 Bending Fatigue Tests on Single Cell Deck 81

5.1.3 Bending Fatigue Tests on Multi-Cell Deck $\quad 82$

$\begin{array}{lll}5.2 & \text { Recommendations } & 83\end{array}$

$\begin{array}{lr}\text { REFERENCES } & 84\end{array}$

APPENDIX A Normalized Coefficient (a/Uo) Results for GFRP Composites at Coupon Level and Component Level 90

APPENDIX B Fatigue Test on 3D Stitched GFRP Fabric 92

APPENDIX C Comparision of Strain Energy Loss Between GFRP

Coupons and Carbon Fabric Coupons 99

APPENDIX D Application of Strain Energy Model 99 


\section{LIST OF FIGURES}

Figure 2.1 Fatigue Damage Development of a Composite Laminate 5

Figure 3.1 Strain Energy Curve for GFRP Composite Specimen 23

Figure 3.2 Fiber Architecture of the Materials Studied 24

Figure 3.3 Static and Fatigue Test Specimen Configuration 26

$\begin{array}{lll}\text { Figure } 3.4 & \text { Instron } 8501 \text { Machine } & 27\end{array}$

Figure 3.5 Extensometer Connected to Specimen 28

Figure 3.6 Sine Waveform and Data Measurements 31

Figure 3.7 Waveform Editor (Block 1) 31

Figure 3.8 Waveform Editor (Block 2) 32

Figure 3.9 Tension-Tension Fatigue Failure Mode of MAT 1 34

Figure 3.10 Tension-Tension Fatigue Failure Mode of MAT 2

Figure 3.11 Tension-Tension Fatigue Failure Mode of MAT 3

Figure 3.12 S-N Curves for MAT 1, MAT 2 and MAT 3

$\begin{array}{lll}\text { Figure 3.13 Strain Energy Curves for MAT 1 } & 38\end{array}$

Figure 3.14 Strain Energy Curves for MAT 2 39

Figure 3.15 Strain Energy Curves for MAT 3 40

Figure 3.16 Variation of Strain Energy Release Rate with Normalized Strain for MAT 1

Figure 3.17 Variation of Strain Energy Release Rate with Normalized Strain for MAT 2

Figure 3.18 Variation of Strain Energy Release Rate with Normalized Strain for MAT 3

Figure 3.19 Comparision of Experimental and Predicted Fatigue Lives for MAT 1 and MAT 2 
Figure 3.20 Comparision of Experimental and Predicted Fatigue Lives for MAT 3

Figure 4.1 Cross-Section of the Single Cell Deck 54

Figure 4.2 Fatigue Test Set Up of a Single Cell Deck 55

Figure 4.3 Static Failure Mode Single Cell Deck under Bending 57

Figure 4.4 Fatigue Failure Mode of Single Cell Deck under Bending 60

Figure 4.5 Strain Energy vs Normalized Number of Cycles for a $\begin{array}{ll}\text { Single Cell Deck } & 64\end{array}$

Figure 4.6 Variation of Strain Energy with Normalized Strain for a Single Cell Deck 64

Figure 4.7 Comparision of Experimental and Predicted Fatigue Lives for Single Cell Deck $\quad 66$

Figure 4.8 Cross-Section of a Multi-Cell FRP Bridge Deck $\quad 67$

Figure 4.9 Fatigue Test Set Up of a Multi-Cell FRP Bridge Deck 68

Figure 4.10 Fatigue Failure Mode of Deck for Test 2

Figure 4.11 Strain Energy Curves for Multi-Cell Deck (Test 2) 74

Figure 4.12 Strain Energy Curves for Multi-Cell Deck (Test 1) 75

Figure 4.13 Strain Energy Release Rate vs Normalized Strain Curve to Determine Fatigue Coefficients ' $a$ ' and 'b' 


\section{LIST OF TABLES}

Table $3.1 \quad$ Properties of Materials Studied 25

Table 3.2 Summary of Fatigue Test Results for MAT 1, 2, 3

Table 3.3 Summary of Strain Energy Results for MAT 1, 2, 3

Table $3.4 \quad$ Fatigue Coefficients for MAT 1, 2, $3 \quad 45$

Table 4.1 Static Test Results for Single Cell Deck 57

Table 4.2 Stiffness and Strain Energy Values at Predetermined Number of Cycles for Single Cell Deck at 30\% of Ultimate Load 62

Table 4.3 Stiffness and Strain Energy Values at Predetermined Number of Cycles for Single Cell Deck at 50\% of Ultimate Load 62

Table 4.4 Stiffness and Strain Energy Values at Predetermined Number of Cycles for Single Cell Deck at $70 \%$ of Ultimate Load

Table 4.5 Energy Release Rate of Single Cell Deck for Different Percentage of Ultimate Strain

Table 4.6 Fatigue Coefficients for a Single Cell Deck $\quad 65$

Table 4.7 Stiffness and Strain Energy Values at Predetermined Number of Cycles for Multi-Cell Deck at 35\% of Ultimate Load

Table 4.8 Stiffness and Strain Energy Values of a Multi-Cell Deck for Test 2

Table 4.9 Energy Release Rate of Multi-Cell Deck for Different Percentage of Ultimate Strain

Table 4.10 Fatigue Coefficients for Multi-Cell Deck 


\section{CHAPTER 1}

\section{INTRODUCTION}

\subsection{General}

Approximately $30 \%$ of highway bridges in the United States are functionally obsolete or structurally deficient ${ }^{1}$. This indicates importance of developing alternate material for construction resulting in higher structural durability than conventional materials. The successful application of fiber reinforced polymer (FRP) composite materials in aerospace, marine and mechanical industries over the 50 years indicates its potential use in civil and military infrastructural systems. Consideration of FRPs in civil infrastructure applications are mainly due to FRP's superior characteristics such as high strength and stiffness to weight ratio, high resistance to fatigue and corrosion, rapid installation through modularizations, reduced maintenance costs and good dynamic characteristics when compared to conventional material designs.

Even though extensive research was done on FRPs, most of it was on carbon/aramid based composites. Carbon composites are not commonly used in civil infrastructural applications because of high initial cost. So glass fiber composites became an alternate to carbon/aramid composites because of their cost competitiveness in terms of weight per unit performance. For wider use in construction industry, FRPs need to be investigated extensively in the laboratory and through field applications. In addition, design specifications have to be determined as the composite materials are anisotropic and inhomogeneous and their failure could be combination of many factors such as fiber fracture, matrix cracking, matrix crazing, fiber buckling, fiber-matrix interface failure, delaminations, etc ${ }^{2}$. 
Mechanical properties such as strength and stiffness of FRPs under tension, bending, compression, shear, fatigue and dynamic loads have to be characterized for safe and efficient designs. The present study focuses on fatigue response of FRP materials both at coupon and component levels.

In this study internal strain energy model developed by GangaRao and Natarajan (2003) was used to predict the fatigue life of glass fiber reinforced polymer composites. The internal strain energy measure was used as a damage metric because of its sensitivity resulting from squaring of strain or curvature terms. The model was successfully applied to unidirectional (1D), bidirectional (2D) fabrics. Unidirectional composites consist of rovings in one direction while bidirectional fabrics consist of fibers in two directions $\left(0^{0} / 90^{0}, 45^{\circ} /-45^{0}\right.$, etc. $)$. The application of strain energy model is extended to single cell deck as well as 4 inch deep multi-cell bridge deck modules.

\subsection{Objectives}

The main objective of this research is to predict fatigue life of FRP composite components at coupon and component level. To accomplish the above objective, following tasks were carried out:

- Perform tension-tension fatigue on FRP coupons having unidirectional (1D) and multidirectional (2D) fibers/fabrics.

- Compare theoretical fatigue life of $1 \mathrm{D}$ and 2D composites using experimental data.

- Validate the experimental life of coupon with theoretical fatigue model developed by GangaRao and Natarajan (2003). 
- Perform bending fatigue on FRP components single cell deck and multi-cell deck.

- Validate experimental fatigue life of single cell deck with theoretical model.

\subsection{Scope}

Chapter 2 discusses damage in composite materials, fatigue life prediction models for composite materials, fatigue damage in composite materials at coupon level and component level.

Chapter 3 consists of the experimental testing and evaluation of various fiber architecture (1D, 2D) of glass fiber-vinyl ester composite plates that were tested under tension-tension fatigue, bending fatigue. In addition fatigue life prediction of composite plates by internal strain energy model is discussed.

Chapter 4 presents the testing and evaluation of single cell deck, 4 inch deep multi-cell deck subjected to fatigue loading. Chapter 5 presents conclusions and recommendations for future work. 


\section{CHAPTER 2}

\section{LITERATURE REVIEW}

\subsection{Introduction}

Many researchers introduced several models to represent the damage in composite materials. This chapter presents the literature review of composite materials which is divided into four categories namely

1) General discussion on Fatigue damage in composite materials

2) Fatigue life prediction models

3) Fatigue life prediction of composite materials at coupon level

4) Fatigue life prediction of composite materials at component level

\subsection{Fatigue Damage in Composite Materials ${ }^{1}$}

The damage process in composite materials consists of three stages which is as shown in Figure 2.1. Stage 1 occurs during the first $10-15 \%$ of life where the damage rate is very rapid. Stage 2 occurs during the next $70-80 \%$ of fatigue life during which the damage continue to grow with time but at a slower rate than Stage 1. Stage 3 corresponds to $10-15 \%$ where continued cyclic loading accelerates due to severe damage caused during the Stage 2.

The major damage mode in Stage 1 is matrix cracking. During the Stage 1, the crack number increases (matrix crack) until cracks in each ply attain saturation spacing. This state of damage is called Characteristic Damage State which is achieved near the end of Stage 1. The crack spacing in a given ply is a function of material properties and the constraints imposed on the ply by the surrounding plies. The fiber failure initiates in 
adjacent plies in regions of stress concentration created by primary cracks. In most of the cases, two thirds of the total number of fibers that fail before fracture, fail in the first onethird of life. The primary cracks initiate small secondary

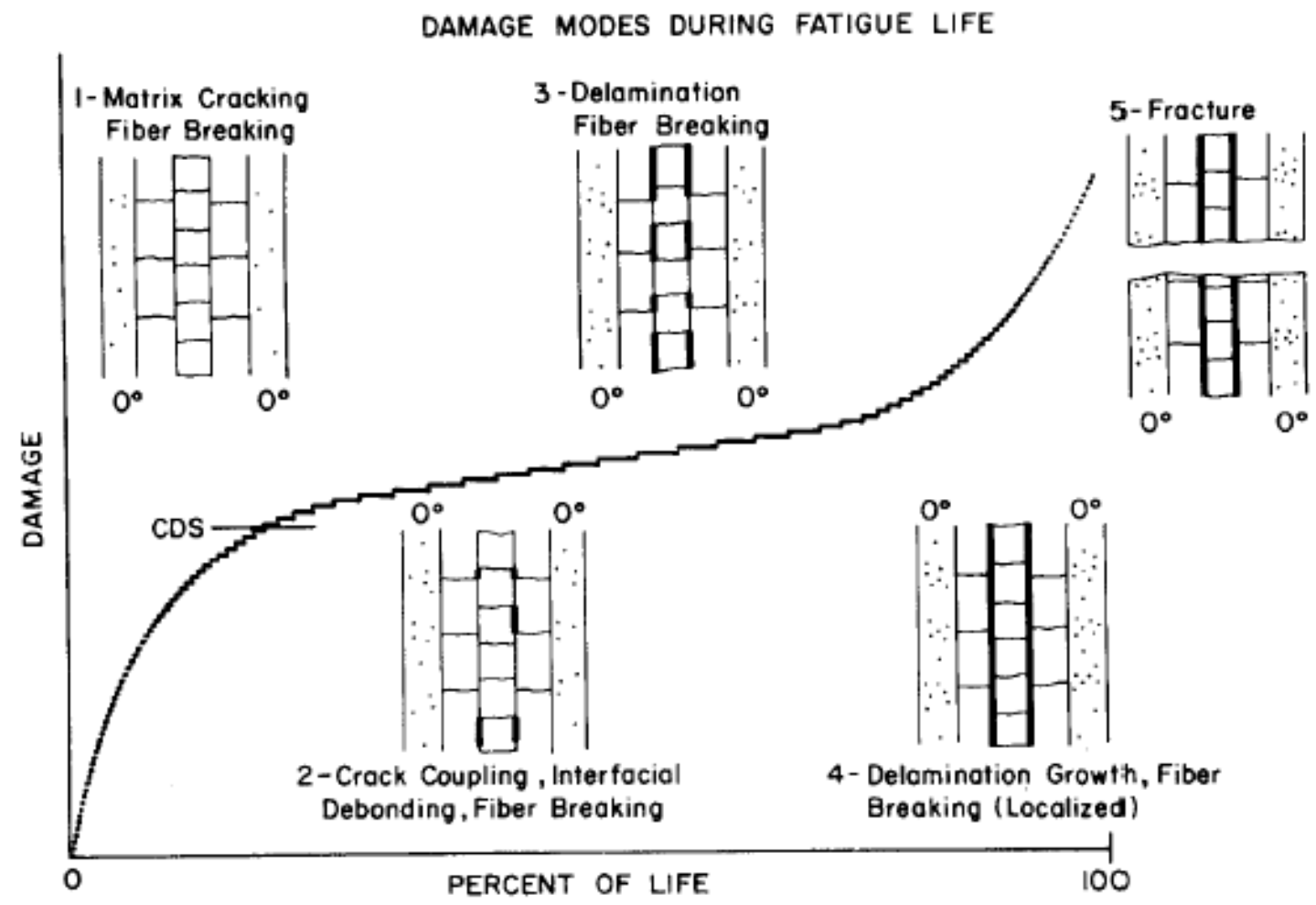

Figure 2.1 Fatigue Damage Development of a Composite Laminate ${ }^{1}$

cracks which are generally perpendicular to the primary cracks. This is followed by the delamination of a laminate which is caused by a mixed mode growth of interlaminar cracks which are due to strong interlaminar stresses in regions where primary and secondary cracks cross. In compression loading the out-of-plane displacement of plies also influences the delamination growth.

In the second stage the damage increases rapidly due to the increase in the rate of progression of all damage modes in a rapidly decreasing volume culminating in a critical local state of stress which initiates fracture of component. 
Stage 3 is characterized by an increase in the damage rate caused by damage localization and delamination growth. Under cyclic tensile loads, laminate fracture is coincident with the catastrophic fracture of a major load bearing plies. Under cyclic compressive loads, failure occurs when the laminate stiffness degrades to such an extent that the laminate cannot support the applied loads. Laminates subjected to both tensile and compressive cyclic loads may exhibit either tensile or compressive fracture modes, depending on the response of competing damage modes to the magnitudes of the loads and the material system.

\subsection{Fatigue Life Prediction Models}

Based on constant amplitude fatigue the theories available for predicting fatigue life can be divided into four categories:

1) Fatigue life models

2) Phenomenological models

2.1) Residual stiffness models

2.2) Residual strength models

3) Progressive damage models

\subsubsection{Fatigue Life Models}

These models are based on S-N curves or Goodman-type diagrams. They predict number of cycles to failure without taking into account damage accumulation and at which fatigue failure occurs under fixed load conditions. 
Hashin and Rotem ${ }^{3}$ proposed first fatigue failure criteria and developed a fiberfailure mode and a matrix-failure mode, expressed as $\sigma_{A}=\sigma_{A}^{u},\left(\frac{\sigma_{T}}{\sigma_{T}^{u}}\right)^{2}+\left(\frac{\tau}{\tau^{u}}\right)^{2}=1$, where $\sigma_{A}$ and $\sigma_{T}$ are the stresses along the fibers and transverse to the fibers, $\tau$ is the shear stress and $\sigma_{A}^{u}, \sigma_{T}^{u}$ and $\tau^{u}$ are the ultimate tensile, ultimate transverse tensile and ultimate shear stress respectively. The criteria was expressed in three S-N curves which were determined experimentally on testing off-axis unidirectional specimens under uniaxial load as the ultimate strengths are function of fatigue stress level, stress ratio and number of cycles. This criteria is valid only for laminates with unidirectional piles which exhibit two failure modes during fatigue.

Reifsnider and $\mathrm{Gao}^{4}$ proposed a failure criteria which is similar to Hashin and Rotem, the only difference is that they considered average stresses $\left\langle\sigma_{i j}^{m}\right\rangle$ and $\left\langle\sigma_{i j}^{f}\right\rangle$ in matrix and fibers. Their criterion is based on average stress formulation of composite materials derived from Mori-Tanaka method (a method to calculate the average stress fields in homogeneities and their surrounding matrix). The failure functions for the two failure mechanisms are $\left\langle\sigma_{11}^{f}\right\rangle=X^{f},\left(\frac{\sigma_{22}^{m}}{X^{m}}\right)^{2}+\left(\frac{\sigma_{12}^{m}}{S^{m}}\right)^{2}=1$ where $X^{f}, X^{m}$ are fatigue failure functions under tensile loading for fiber and unreinforced matrix materials and $S^{m}$ is the fatigue failure function of the unreinforced matrix under shear loading. The failure functions depend on the stress ratio $R$, the number of cycles $N$, the frequency $f$, S-N curves which are determined experimentally. 
Harris $^{5}$, proposed normalized constant-life model expressed as $a=f .(1-m)^{u} .(c+m)^{v}$ where $f, u, v$ are linear functions of ' $\log \left(N_{f}\right)$ ' ( $f$ often kept constant), $\sigma_{t}$ is the tensile strength, $a=\frac{\sigma_{a l t}}{\sigma_{t}}$ is the normalized alternating stress component, $m=\frac{\sigma_{m}}{\sigma_{t}}$ is the normalized mean stress component, $c=\frac{\sigma_{c}}{\sigma_{t}}$ is the compressed compression strength. Beheshty and Harris, Beheshty successfully applied this model to impact-damaged laminates. Beheshty observed from these experiments that the parameter $f$ depends on normalized compression strength $c$ and suggested an inverse power-law relationship between $f$ and $c$, are functions of fatigue life $N_{f}$.

Philippidis and Vassilopoulos ${ }^{6}$ proposed a multiaxial fatigue criteria similar to Tsai-Wu quadratic failure criteria for static loading and expressed as $F_{i j} \sigma_{i} \sigma_{j}+F_{i} \sigma_{i}-1 \leq 0 ; i, j=1,2,6$ where $F_{i j}$ and $F_{i}$ are functions of number of cycles $N$, the stress ratio $R$ and the frequency of loading $v$. The tensor components $F_{i j}$ and $F_{i}$ are calculated using the $\mathrm{S}-\mathrm{N}$ curves which were determined assuming $X_{t}=X_{c}$ and $Y_{t}=Y_{c}$, where $X_{t}, X_{c}, Y_{t}, Y_{c}$ are static failure stresses of the material. They have used laminate properties to predict laminate behaviour instead of lamina properties as the S-N curves for the laminate account for various damage types occurring in different types of composite materials. Their criteria predicted acceptable fatigue failure under multiaxial loading but for each laminate stacking sequence new series of experiments should be conducted. 


\subsubsection{Phenomenological Models}

These models consist of Residual stiffness models, Residual strength models which are based on the deterioration of the stiffness or strength of the composite specimen in terms of macroscopically observable properties.

\subsubsection{Residual Stiffness Models}

These models take into account the degradation of the elastic properties during fatigue loading. Stiffness is more adequate parameter than strength when full-scale structural components are considered as it is a nondestructive parameter ${ }^{2}$.

The fatigue modulus concept was introduced by Hwang and $\operatorname{Han}^{7}$ and is defined as slope of applied stress and resultant strain at a specific cycle. According to this study fatigue modulus degradation rate is a power function of the number of fatigue cycles. $\frac{d F}{d N}=-A c n^{c-1}$ where $A$ and $c$ are material constants.

Hwang and $\operatorname{Han}^{7}$ have proposed three cumulative damage models based on fatigue modulus $\mathrm{F}(\mathrm{n})$ and the resultant strain. Of all the three cumulative damage models third one showed good agreement with experimental results. According to third model failure occurs when $D=\sum_{i=1}^{m} \Delta D_{i}=1$ where $\Delta D_{i}$ is the amount of damage accumulation during fatigue at stress level $r_{i}$ and $m$ is the number of load sequences until final failure.

Sidoroff and Subagio $^{8}$ proposed a model for the damage growth rate and expressed as $\frac{d D}{d N}=\frac{A \cdot(\Delta \varepsilon)^{c}}{(1-D)^{b}}$ in Tension, $\frac{d D}{d N}=0$ in Compression where the variable $D=1-\frac{E}{E_{0}} ; A, b, c$ are material constants calculated from experiments and $\Delta \in$ is the 
applied strain amplitude. The model of Sidoroff and Subagio was implemented by many researchers in terms of stress amplitude instead of strain amplitude. Van Paepegem and Degrieck implemented the model of Sidoroff and Subagio and developed a finite element code.

A residual stiffness model was proposed by Whitworth ${ }^{9}$ for Graphite/epoxy composites which is presented below.

$$
\left(\frac{E\left(N^{*}\right)}{E(0)}\right)^{a}=1-H .\left(1-\frac{S}{R(0)}\right)^{a} N^{*}
$$

where $N^{*}=n / N$, ratio of applied cycles to the fatigue cycles $\mathrm{N}, \mathrm{S}$ is the applied stress level, $R(0)$ is the static strength, $E(0)$ is the initial modulus and a and $H$ are parameters independent of applied stress level. Whitworth (1990) used this model to propose cumulative damage model which was defined as $D=\left(\frac{H \cdot(1-\bar{S})^{a}}{1-\bar{S}^{a}}\right) \cdot \frac{n}{N}$ where $\bar{S}=\frac{S}{R(0)}$ is the normalized applied stress range, $\mathrm{D}$ is the damage function, a and $\mathrm{H}$ are the parameters. This model was also applied to find fatigue life of specimens subjected to variable amplitude loading. Whitworth ${ }^{9}$ proposed degradation law model

$\frac{d E^{*}(n)}{d n}=\frac{-a}{(n+1)\left[E^{*}(n)\right]^{m-1}}$ where $E^{*}(n)=\frac{E(n)}{E(N)}$ is the ratio of residual stiffness to failure stiffness, $\mathrm{n}$ is the number of loading cycles, a and $\mathrm{m}$ are the parameters which depend on the applied stress, loading frequency, etc.

Brondsted et $a{ }^{10}$ proposed a model for Glass fiber-reinforced composites based on experiments conducted on wind turbine materials subjected to constant amplitude loading, variable amplitude block loading and stochastic spectrum loading. They have 
used four-layer 90:10 fabric with a chopped strand mat on both sides. The stiffness

reduction can be calculated as $\frac{d\left(\frac{E}{E_{1}}\right)}{d N}=-K \cdot\left(\frac{\sigma}{E_{0}}\right)^{n}$ where $E$ is the cyclic modulus after $N$ cycles, $E_{1}$ is the initial cyclic modulus, $E_{0}$ is the static modulus, $\sigma$ is the maximum stress, $K$ is a constant.

\subsubsection{Residual Strength Models}

Sudden death model and wearout model are two types of residual strength models. The sudden death model is applied to high strength unidirectional composites which are subjected to high level state of stress (low-cycle fatigue) where the residual strength is a function of number of cycles. The residual strength is constant initially and decreases when the number of cycles to failure is being reached. Wearout model is the one in which composite specimens are subjected to lower level state of stress, where strength degrades more gradually. These models are based on strength-life equal rank assumption, which means the strongest specimen has either the longest fatigue life or the highest residual strength at runout which was experimentally proved, by Hahn and $\mathrm{Kim}^{40}$. Halpin et $\mathrm{al}^{11}$ proposed a wearout model assuming the residual strength $R(n)$ is a monotonically decreasing function of the number of cycles $n$, expressed as $\frac{d R(n)}{d n}=-\frac{A(\sigma)}{m[R(n)]^{m-1}}$ where $A(\sigma)$ is a function of the maximum cyclic stress $\sigma, m$ is a constant.

Daniel and Charewicz ${ }^{12}$ proposed a model based on normalized change in residual strength by studying damage accumulation in cross-ply graphite/epoxy laminates under 
cyclic tensile loading, expressed as $\left[\frac{1-f_{r}}{1-s}\right]=g\left(\frac{n}{N}\right)$ where $f_{r}=\frac{F_{r}}{F_{0}}$ is the normalized strength, $s=\frac{\sigma_{a}}{F_{0}}$ is the normalized applied cyclic stress, $N$ is the number of cycles to failure at stress $\sigma_{a}$ and $g(n / N)$ is a function of the normalized number of cycles. This model relies on residual strength curve, also they assumed fatigue damage is a function of residual strength only such that the specimen cycled at a stress $\sigma_{1}$ for $n_{1}$ cycles has the same damage as a specimen cycled at stress $\sigma_{2}$ for $n_{2}$ cycles if they have same residual strength $F_{r}$ after their respective cycles $n_{1}$ and $n_{2}$. Based of this assumption equal damage curves were determined in $(\sigma, n)$ plane and then residual life predictions were determined.

Whitworth $^{13}$ proposed a model which can be written as $S_{R}^{v}=S_{U}^{v}-\frac{n}{N}\left(S_{U}^{v}-S^{v}\right)$ where $S_{R}$ is the residual strength, $v$ is a parameter, $S$ is the applied stress level, $S_{U}$ is the ultimate strength, $N$ is the fatigue life.

Yao and Himmel ${ }^{14}$ proposed separate models for tension fatigue and compression fatigue which are expressed as follows.

Tension fatigue: $R(i)=R(0)-[R(0)-S] \frac{\sin (\beta x) \cos (\beta-\alpha)}{\sin \beta \cos (\beta x-\alpha)}$, where $R(i)$ is the residual strength at the I-th loading cycle, $R(0)$ is the static strength, $S$ is the stress loading level, $x=i / N_{f}, \alpha$ and $\beta$ are parameters that are determined experimentally. 
Compression fatigue: $R(i)=R(0)-[R(0)-S]\left(\frac{i}{N_{f}}\right)^{v}$, where $v$ is a strength degradation parameter which depends on stress ratio and the peak stress. The cumulative damage was assessed based on assumption that the damage state can be treated equivalently if the residual strengths are equal.

\subsubsection{Progressive Damage Models}

These models are divided into two classes namely, the damage models which predict the damage growth as such (e.g. number of transverse matrix cracks per unit length, size of delamination area), the models which correlate the damage growth with the residual mechanical properties (stiffness/strength).

Bergmann and Prinz ${ }^{15}$ and Prinz proposed delamination growth model represnted as $\frac{d A_{i}}{d N}=\hat{c} \cdot f\left(G_{i t}\right)^{n}$ where $A_{i}$ is the delamination area, $G_{i t}$ is the maximum amplitude of the energy release rate, $\hat{c}$ and $\mathrm{n}$ are values obtained from experiments. They have conducted fatigue experiments on graphite /epoxy specimens of stacking order $\left[0_{2},+45,0_{2},-45,0,90\right]_{S}$ with a central hole and unidirectional specimens of stacking order $\left[0_{n}, 0_{m}\right]_{S}$ with $2 \mathrm{~m}$ severed central plies $\left[0_{m}\right]_{S}$. It was observed that a lateral crack occurred in the area of artificial separations from which two partial delaminations developed at each of the interface of the separated and continuous plies.

Feng et $a l^{16}$ developed fatigue damage growth model for carbon fiber-reinforced specimens due to matrix cracking. Based on experimental results he conclude mode I crack growth can be described by modified Paris law $\frac{d A}{d N}=D G_{\max }^{n}$ where A is the 
damage area due to matrix cracking, $\mathrm{N}$ is the number of fatigue cycles, $G_{\max }$ is the maximum strain energy release rate in a fatigue cycle, $\mathrm{D}$ and $\mathrm{n}$ are material constants. The value of $G_{\max }$ was evaluated by finite element analysis, to simulate damage growth the finite element analysis was done many times which allows to define mathematical relationship between A and $G_{\max }$. The damage area was predicted for a notched I-beam subjected to four-point bending fatigue due to matrix cracking and for a notched coupon subjected to tensile fatigue loading.

Talreja $^{17,18}$ proposed a continuum damage model, where internal damage variables are characterized by vectorial/tensorial quantities. He considered both intralaminar damage (matrix cracking) and interlaminar damage (delamination). He also assumed the damage modes present in the laminate given by aasociate damage vector do not mutually interact. Neglecting these interactions, one damage mode at a time was accounted and their effects are superimposed. Based on damage mode he defined damage sensor $D_{i j}$ as $D_{i j}=\frac{1}{V} \sum\left[\int_{\substack{S \\ S}}^{n} a n_{i} n_{j} d S\right.$ where $\mathrm{V}$ is the representative volume element, $\mathrm{S}$ is the crack surface area, a is the normal component of the vector of surface activity, $n_{i}$ and $n_{j}$ are the crack surface normals, $\mathrm{n}$ is the number of entities of the given damage mode.

\subsection{Fatigue Life Prediction of Composite Materials at Coupon Level}

Y. Setiadi et. al $^{19}$ studied the fatigue resistance of E-Glass fabric with polyurethane, isophthalic polyester based polymers. The experiments were conducted and strain energy dissipation rate (energy loss per cycle) was calculated for $50 \%$ of the 
ultimate tensile strength. From the test results it was found that polyurethane based FRP has better fatigue resistance than polyester because it resisted the development of matrix cracks. It was also found that polyurethane bonds well with glass fiber than polyester. The polyurethane based FRP had higher energy dissipation rate than polyester based FRP due to its better fatigue resistance.

Ho Sung Kim and Jianping Zhang ${ }^{20}$ proposed a fatigue modulus reduction model to predict life of E-glass/vinyl ester composites. The tension-tension fatigue tests were conducted on unnotched unidirectional composites with frequency $1.5 \mathrm{hz}, \mathrm{S}-\mathrm{N}$ curve is obtained from which life of the composite is predicted using the equation $N=\frac{1}{\sigma_{u}} \int_{\sigma_{\max }}^{\sigma_{u}} \frac{1}{f\left(\sigma_{\max }\right)} d \sigma_{\max }$ for stress ratio $=0$, where $N$ is the fatigue life in cycles, $\sigma_{u}$ is the ultimate stress, $\sigma_{\max }$ fatigue stress at the $n$th cycle. They have drawn S-N curves and discussed fatigue mechanisms at different stress ranges based on stiffness reduction/fatigue modulus and quantitative damage. They have conducted experiments on Knytex A130A (Unidirectional E-glass fabric) and Derakane 441-400 Epoxy Vinyl Ester to compare results with the model developed based on stiffness reduction and fatigue modulus. They have evaluated damage rate and found that it obeys power law. The lifetime predictions obtained from model were in good agreement with experimental results.

Cornelia E. Demers ${ }^{21}$ presented tension-tension fatigue data for E-glass FRP composites considering no environmental effects. The experiments were conducted for $\mathrm{R}$ $\left(\frac{\sigma_{\text {min. }}}{\sigma_{\text {max. }}}\right)$ ratios $0.05,0.1,0.5,0.9$ and frequencies $1,3,5 \mathrm{hz}$. The experiments supported lower bound confidence level which can be used to estimate fatigue life of E-glass FRP 
composites in tension-tension axial fatigue with test frequency $5 \mathrm{hz}$ or less. From the experiments it was found that the fatigue life of E-glass/vinylester increased with increase in $\mathrm{R}$ ratio. A lower bound $95 \%$ confidence level was introduced regardless of varying test parameters, given by the equation $S_{\max } / S_{u l t}=-.078 \log N+.790$, which was used to find fatigue life less than or equal to one million cycles.

Z. Khan et. $\mathrm{al}^{22}$ proposed an analytical model based on stiffness degradation for estimating fatigue life of fiber reinforced plastics and applied to woven carbon fiber/polyester resin. The model was applied to 3 different fiber architecture plies namely unidirectional $(0)_{8},(0,0,+45,-45)_{\mathrm{s}},(+45,-45,0,0)_{\mathrm{s}}$. The model was used to establish a relation between damage rate $d D / d N$ and the stress range $\Delta \sigma$ which is different for different fiber architecture coupons and is as follows. $d D / d N=2 * 10^{-46}(\Delta \sigma)^{16.057}$ for $(0,0,45,-45)_{\mathrm{s}} ; d D / d N=8^{*} 10^{-71}(\Delta \sigma)^{25.979}$ for $(45,-45,0,0)_{\mathrm{s}}$. Due to the failure of the specimens near the tab ends for $(0)_{8}$ coupons they couldn't establish a relationship between $d D / d N$ and $\Delta \sigma$. The experimental values obtained for $(0,0,45,-45)_{\mathrm{s}}$,

$(45,-45,0,0)_{\mathrm{s}}$ coupons were found to be with in a factor of 3 when compared to predicted values.

J. N. Yang et $\mathrm{al}^{23}$ developed a statistical stiffness degradation model for graphite/epoxy laminates subjected to fatigue loading. Two analytical methods one based on linear regression analysis, other based on Bayesian approach which can be used to predict stiffness degradation of a composite material subjected to cyclic loading was presented. When a stiffness reduction data was available for a particular specimen up to a certain number of load cycles, linear regression analysis was used to predict stiffness degradation of that specimen at the subsequent number of load cycles. When a base-line 
data and measured data are available for a specimen the Bayesian approach was used to predict the subsequent stiffness degradation of that specimen. The experimental results of graphite/epoxy $(90 /+45 /-45 / 0)_{\mathrm{s}}$ laminates were compared with the predicted results obtained from analytical methods, which were in the reasonable range.

Z. Fawaz and F. Ellyin ${ }^{24}$ proposed a multiaxial fatigue failure model considering various parameters like multiaxiality ratios, fiber orientation, stress ratio. The model predicted fatigue failure based on the establishment of a reference stress versus life line and determination of two simple functions which considers static strength along the $\mathrm{x}$ direction under the actual loading parameters, static strength along the $\mathrm{x}$-direction under reference loading parameters, stress range applied to obtain the reference line. The model was validated with a variety of FRM's under uniaxial and biaxial stresses. The model was found to correlate stress vs life behavior for different FRM's such as graphiteepoxy, glass-epoxy, boron-aluminum. The model correlated well with the test results on unidirectional and bidirectional materials, also on different specimen configurations like uniaxial, cruciform and tubular specimens.

A. Poursartip et $\mathrm{al}^{25}$ derived a general differential formulation for damage accumulation in composite laminates. The damage growth rate was found to be a power function of the stress amplitude, mean stress and is independent of damage when cycling at constant stress amplitude. The specimen failure occurred when the damage reached critical level which depends on the maximum stress level reached during the loading level. It was found that the stiffness at the end of fatigue failure (E) is 0.65 times the stiffness $\left(\mathrm{E}_{\mathrm{o}}\right)$ at the start of fatigue test assuming the damage is a mixture of delamination, 
matrix cracking and damage is linear. The model was successfully tested on quasiisotropic carbon fiber composite laminate

[CFC XAS/914(45/90/-45/0) $]$ ] with epoxy resin.

T. Kevin O'Brien, Kenneth L. Reifsnider ${ }^{26}$ made an attempt to introduce secant modulus criteria for composite materials and find the fatigue damage evaluation through stiffness measurements. Stiffness reduction was measured for unnotched $(+/-45)_{\text {s }}$, $(0 / 90)_{s},(0 / 90 /+45 /-45)_{s}$ boron/epoxy laminates. The fatigue damage was uniformly distributed throughout the coupons in $(+/-45)_{\mathrm{s}}$ due to matrix crazing, fatigue damage in $(0 / 90)_{\mathrm{s}}$ laminates was localized consisting of transverse tracks along the specimen length and fatigue damage in $(0 / 90 /+45 /-45)_{\mathrm{s}}$ laminates occurred due to both localized ply cracking and uniform matrix crazing. The secant modulus criteria was found to be not applicable as the damage growth and stiffness loss at were load-history dependent.

Jitendra S. Tate and Ajit D. Kelkar ${ }^{27}$ studied the fatigue behavior of VARTM manufactured biaxial braided composites . The material used was biaxial carbon (AS4) braided sleevings with derakane vinyl ester resin (braid angle $\sim 25^{\circ}$ ). The stiffness degradation was recorded for the first 400 cycles or till failure. The endurance limit was found to be $45 \%$ of ultimate tensile strength, fatigue failure diagram of braided composites was found to resemble woven composites.

\subsection{Fatigue Response in Composite Materials at Component Level}

Natarajan ${ }^{28}$ conducted bending fatigue tests on two glass fiber reinforced composite decks, one with polyester resin the other being vinyl ester resin. The pultruded FRP decks were designed by Constructed Facilities Center and manufactured by Bedford 
Reinforced Plastics Inc. The decks were fatigued with frequency of $2 \mathrm{~Hz}$ and a load range of 2-50 kips. The polyester deck failed after 230,000 cycles due to punching shear because of lack of enough fibers in the transverse direction. For this the vinyl ester deck was reinforced with $100 \mathrm{oz} / \mathrm{yd}^{2}$ of fibers in the transverse direction. There was no damage or cracking observed in the vinyl ester deck even after 2 million cycles.

Deepthi Punyamurthula ${ }^{29}$ tested two low profile E-glass FRP composite decks with vinyl ester resin under 3 point bending. Each deck was fabricated by bonding four modules together at the Bedford reinforced plastics Inc. One of the deck modules were connected using rivets the other being bonded using plyogrip. The glued deck failed prematurely after 495, 000 cycles due to improper seating of patch load plate. The riveted deck showed no damage even after 1.5 million cycles. The bending rigidity degradation was $9 \%$ for riveted deck and $4.6 \%$ for glued deck.

$\mathrm{K}$. chandrashekhara et $\mathrm{al}^{30}$ tested $30 \mathrm{ft}$ long by $2 \mathrm{ft}$ wide pultruded FRP bridge deck under four point bending fatigue. A load range of 0.5-11 kips, frequency of $4 \mathrm{~Hz}$ was used for testing the composite deck under fatigue. The degradation in stiffness was noted by performing quasi-static tests periodically after some cycles. The test was conducted until 2 million cycles are reached and it was found that there was no change in stiffness. The deck was to taken to failure after fatigue test and there was no loss in strength of composite deck.

Stephenson $\mathrm{L}$ et $\mathrm{al}^{31}$ conducted fatigue tests on pultruded deck and VARTM deck, pultruded deck being 36" wide and VARTM deck being 45" wide. The pultruded deck was tested under a load range of 2-35 kips and VARTM deck was tested under a load range of 2-50 kips considering the difference in the width of the two decks. A patch load 
of $10 " * 20$ " to simulate AASHTO HS20-44 truck wheel was used at the center of each deck. Stiffness degradation was noted by performing static tests at every 500, 000 cycles. The results showed that there was $6 \%$ stiffness loss in the pultruded deck and 5\% stiffness loss in the VARTM deck.

Banerjee $\mathrm{R}$ et $\mathrm{a}^{32}$ conducted three point bending fatigue test on sandwich core FRP bridge deck, applying load range which was calculated using HS25-44 design truck. A patch load of $10 " * 20$ " was applied to simulate the truck wheel load. The bridge deck was tested under fatigue loading with a maximum load of 19.5 kips. There was $15 \%$ stiffness loss in the first 100, 000 cycles and remained unchanged even after 300, 000 cycles at which the test was stopped so as to install deck where there is less traffic.

Soon-Chul Kwon et $\mathrm{al}^{33}$ conducted fatigue tests on three glass FRP composite bridge deck prototypes, glass FRP-concrete hybrid bridge deck prototype, conventional reinforced concrete bridge deck system under two temperature conditions $-22^{0} \mathrm{~F}\left(-22^{0} \mathrm{C}\right)$ and $150^{\circ} \mathrm{F}\left(50^{\circ} \mathrm{C}\right)$. Of the three FRP decks one was manufactured by pultrusion process, other by VARTM process, another by hand lay-up process. The design loads were applied at two points simultaneously using specially designed servo-controlled hydraulic actuators. The load-deflection and load-strain data were noted at predetermined fatigue life cycles using LVDT's, strain gages mounted at respective places. The load was applied so as to simulate AASHTO HS20-44 truck wheel load. The fatigue stress ratio was 0.077 and the frequency used for fatigue test was $3.5 \mathrm{~Hz}$. Quasi-static tests were performed at 0 cycles, 2 million cycles, 10 million cycles to determine the change in stiffness at two different temperature conditions. It was found the stiffness degraded progressively with the number of cycles for each deck under two extreme temperatures. 
The FRP composite bridge decks performed well under extreme temperature applications compared to other bridge decks. The FRP bridge decks were affected more stiffness degradation due to temperature changes than to ten million cumulative load cycles.

Hota $\mathrm{G}$ et $\mathrm{al}^{34}$ tested a pultruded FRP bridge deck under three point bending in the laboratory simulating the wheel loads of HS20-44 design truck. A patch load of 20"*10" was used to simulate the wheel load with the deck span of 108 ". The deck was fatigued for 2 million cycles, quasi-static tests were performed every 500, 000 cycles to note the deflection, strain values. After running for 2 million cycles the deck was taken to failure to find the failure load of the deck. It was found that the ultimate load of the deck degraded by $4 \%$, central deflection increased by $10 \%$ than the initial values obtained before the start of fatigue test. 


\section{CHAPTER 3}

\section{FATIGUE TEST ON GFRP COMPOSITE COUPONS UNDER FATIGUE LOADING}

\subsection{Introduction}

Fatigue response of composite materials is different from metals. Metals exhibit cracking in different planes and different directions, while composites exhibit one or a combination of failure modes including fiber breakage, delamination, matrix cracking, interface debonding and void growth ${ }^{35}$. The parameters which influence the fatigue performance of composites are fiber type, matrix type, type of reinforcement structure, laminate stacking sequence, environmental conditions, loading conditions and boundary conditions $^{36}$. There are various models available to determine fatigue response of composites which are presented in the literature review. This chapter consists of application of a model proposed by Natarajan and GangaRao ${ }^{28}$ based on the internal strain energy dissipation per fatigue cycle which is important in assessing fatigue life of a composite, in addition to evaluating stiffness and failure strain/stress.

\subsection{Internal Strain Energy Curve ${ }^{37}$}

The internal strain energy follows a linear stress versus strain relation in a composite material if the specimen is loaded within its elastic state and then brought to its original state. Most of the strain energy ( $\sim 95 \%)$ stored in a composite is expended once the failure (crack growth) starts in the material under fatigue loading. 
The internal strain energy curve consists of three stages, as shown in Figure 3.1. The strain energy dissipation is a function of applied strain, number of cycles to failure, fiber architecture.

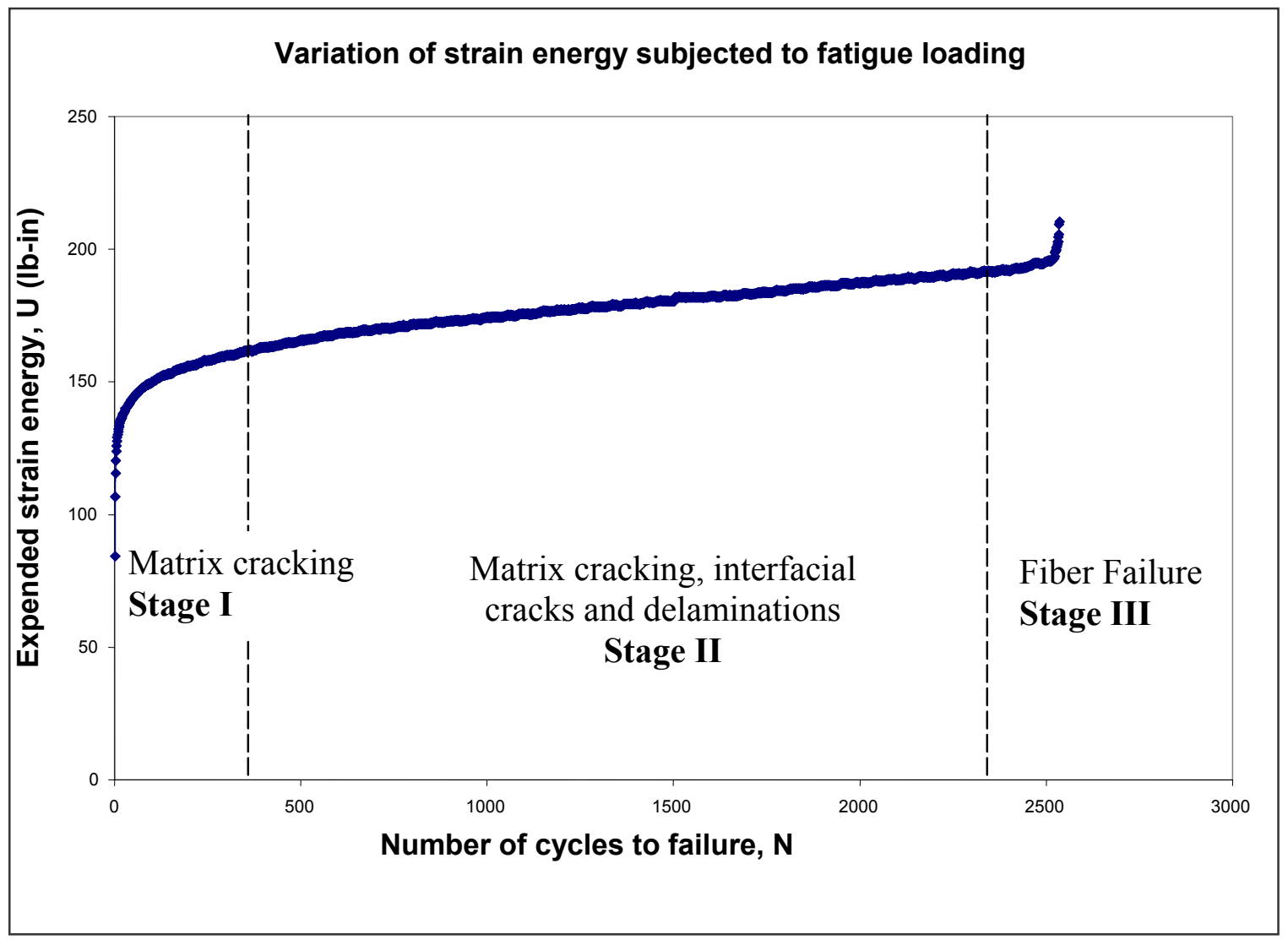

Figure 3.1 Strain Energy Curve for a GFRP Composite Specimen

In the first stage there is sharp increase in strain energy due to matrix cracking, initiated by the presence of micro voids formed due to process variations in terms of temperature variation, cure rate, fabric wet-out, fabric kinks and many other parameters. Stage I corresponds to $10-15 \%$ of the total life of a composite specimen. In stage II, the energy loss is linear which is attributed to matrix cracking, delamination, interfacial debonding between fiber and matrix of the material. Stage II corresponds typically to 
$75-80 \%$ of the total fatigue life. In stage III, failure of all fibers occurs rapidly leading to a catastrophic failure of a test specimen. Stage III corresponds to about $10 \%$ of total life of specimen. Since most of the fatigue damage occurs in the second stage, the strain energy dissipation per cycle (strain energy release rate defined as strain energy loss per cycle) in that stage is computed and used for finding the fatigue life of the specimen.

\subsection{Experimental Procedure}

\subsubsection{Static Test}

\subsubsection{Description of the Material}

The test coupons were cut from unidirectional, bidirectional stitched glass fiber reinforced vinyl ester composite plates. The unidirectional and bidirectional composite plates were manufactured by pultrusion process. The properties and fiber architecture of the plates used for testing are presented in Table 3.1 and Figure 3.2.

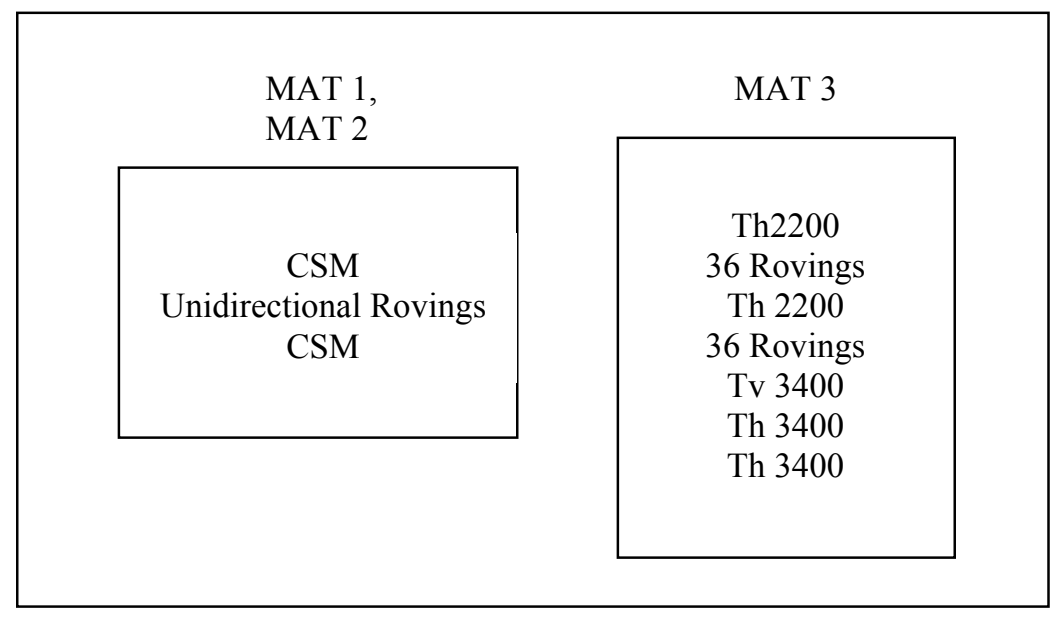

Figure 3.2 Fiber Architecture of the Materials Studied

\section{Note:}

Th-2200 - 90/45/-45 
Th-3400 - 90/45/-45

Tv-3400 - 0/45/-45

\subsubsection{Static Test Results}

The static properties of all materials used for study are presented in Table 3.1.

Table 3.1 Properties of Materials Studied

\begin{tabular}{|c|c|c|c|}
\hline Material ID & MAT 1 & MAT 2 & MAT 3 \\
\hline Fiber/Resin & $\begin{array}{c}\text { Glass/Vinyl } \\
\text { ester }\end{array}$ & $\begin{array}{c}\text { Glass/Vinyl } \\
\text { ester }\end{array}$ & $\begin{array}{c}\text { Glass/Vinyl } \\
\text { ester }\end{array}$ \\
\hline Fiber Direction & Unidirectional & Unidirectional & $\begin{array}{c}\text { 2D woven } \\
\text { fabrics }\end{array}$ \\
\hline $\begin{array}{c}\text { Fiber Volume } \\
\text { Fraction }\end{array}$ & 0.45 & 0.45 & 0.30 \\
\hline Width (inches) & 1 & 0.5 & 0.5 \\
\hline $\begin{array}{c}\text { Plate Thickness } \\
\text { (inches) }\end{array}$ & 0.125 & 0.25 & 0.25 \\
\hline $\begin{array}{c}\text { Ultimate Load } \\
\text { (lb) }\end{array}$ & 7500 & 8000 & 5800 \\
\hline $\begin{array}{c}\text { Longitudinal } \\
\text { Modulus (psi) }\end{array}$ & $3.63^{*}$ & $3.48^{*}$ & 2.7 \\
\hline $\begin{array}{c}\text { Failure Strain } \\
(\mu \text { strains) }\end{array}$ & $20954^{*}$ & $18831^{*}$ & 19089 \\
\hline $\begin{array}{c}\text { Ultimate } \\
\text { Strength (ksi) }\end{array}$ & 60 & 64 & 46.4 \\
\hline $\begin{array}{c}\text { Manufacturing } \\
\text { Process }\end{array}$ & Pultrusion & Pultrusion & Pultrusion \\
\hline
\end{tabular}

* Error in calibration

\subsubsection{Test Specimen Preparation}

The test coupons were prepared according to ASTM D3039. All the test coupons tested were rectangular and cut along the cell direction. The dimensions of the specimens tested are shown in Figure 3.3. The dimensions of the test coupons used for static and fatigue tests are $10 " * 1$ " for the plates less than $1 / 4$ " thick, 10 "* $1 / 2$ " for the plates of $1 / 4$ " 
thick. Based on ASTM D3039, steel tabs were used on either ends of specimen for better gripping with the metal wedge grips of the Instron machine. The tab dimensions were $3 " * 1$ " for coupons that are $10 " * 1$ " and $3 " * 1 / 2$ " for coupons that are $10 " * 1 / 2$ " and were tapered at the ends using $45^{\circ}$ angle. The thickness of the tabs used were 0.125 " for all the coupons tested irrespective of their thickness since the metal wedge grips of Instron machine can hold a maximum of $1 / 2$ " thickness coupons including tabs. The tabs were bonded to coupons using plyogrip, clamped using c-clamps for about $12 \mathrm{hrs}$ to ensure proper curing of the adhesive used for clamping. The tabs, coupons were grinded before bonding together to ensure proper adhesion between the two materials.

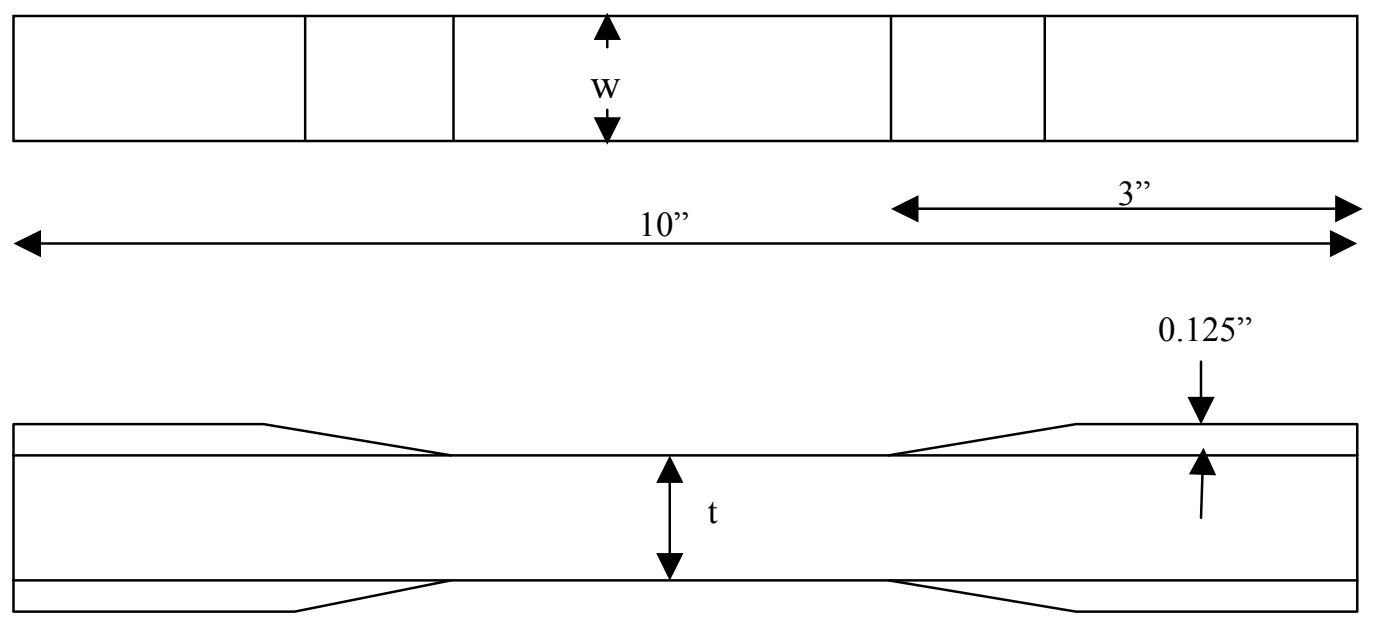

Figure 3.3 Static and Fatigue Test Specimen Configuration

\subsubsection{Testing Equipment}


The mechanical equipment used for static and fatigue tests was Instron 8501 series two-column load frame machine is shown in Figure 3.4. This machine consisted of in built load cell and LVDT. The control panel of the Instron machine is connected to a computer which consists of the software to run the test. The software consisted of waveform editor and waveform runner. The extensometer was used for measuring strain as shown in Figure 3.5. The waveform editor consists of options to give parameters to do the test, to provide data storage file name where the entire test data would be stored, test description file where the description of the test conducted can be described. The waveform runner was used to start the test after providing the test parameters in the waveform editor.

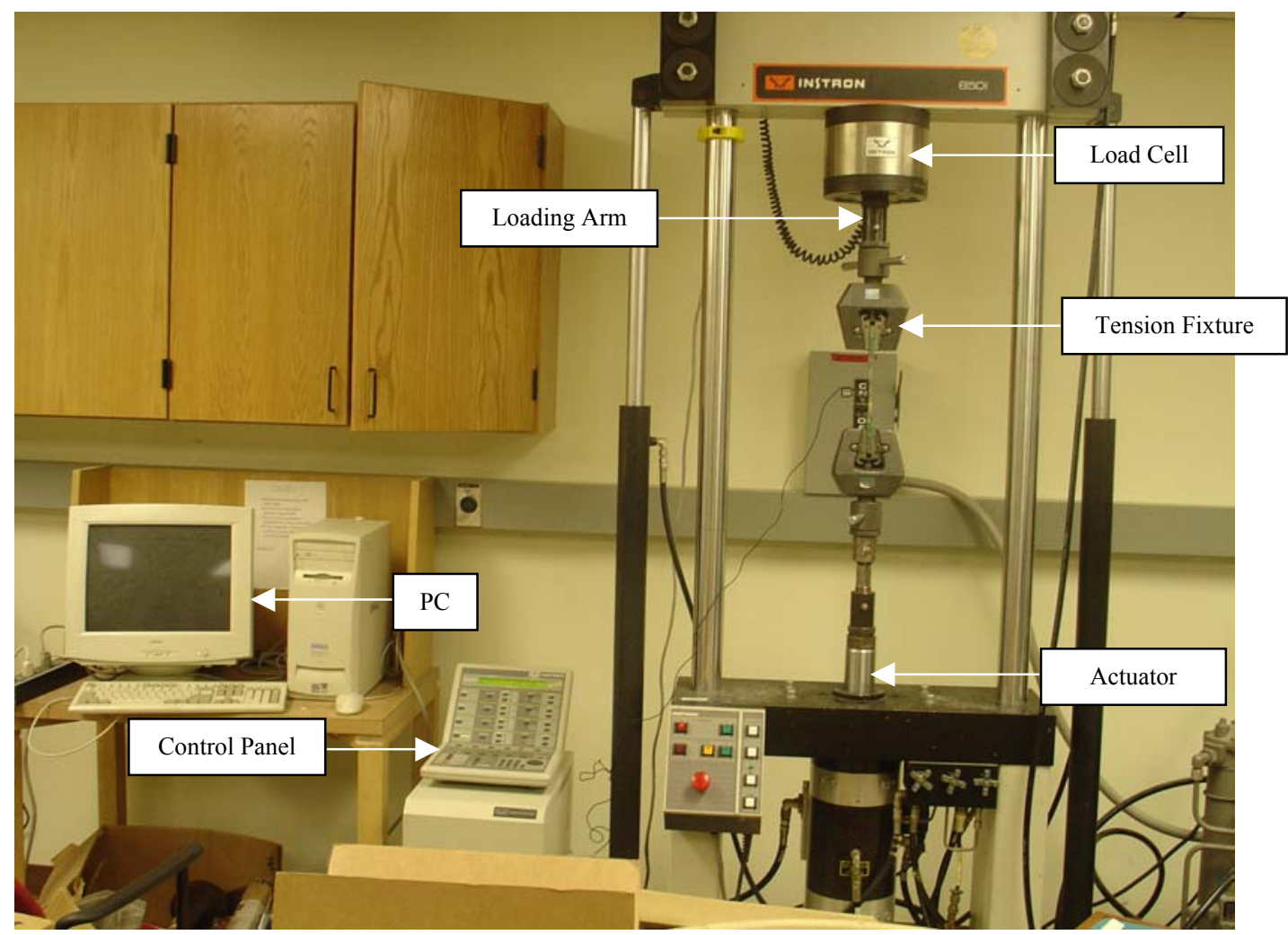

Figure 3.4 Instron 8501 Machine 


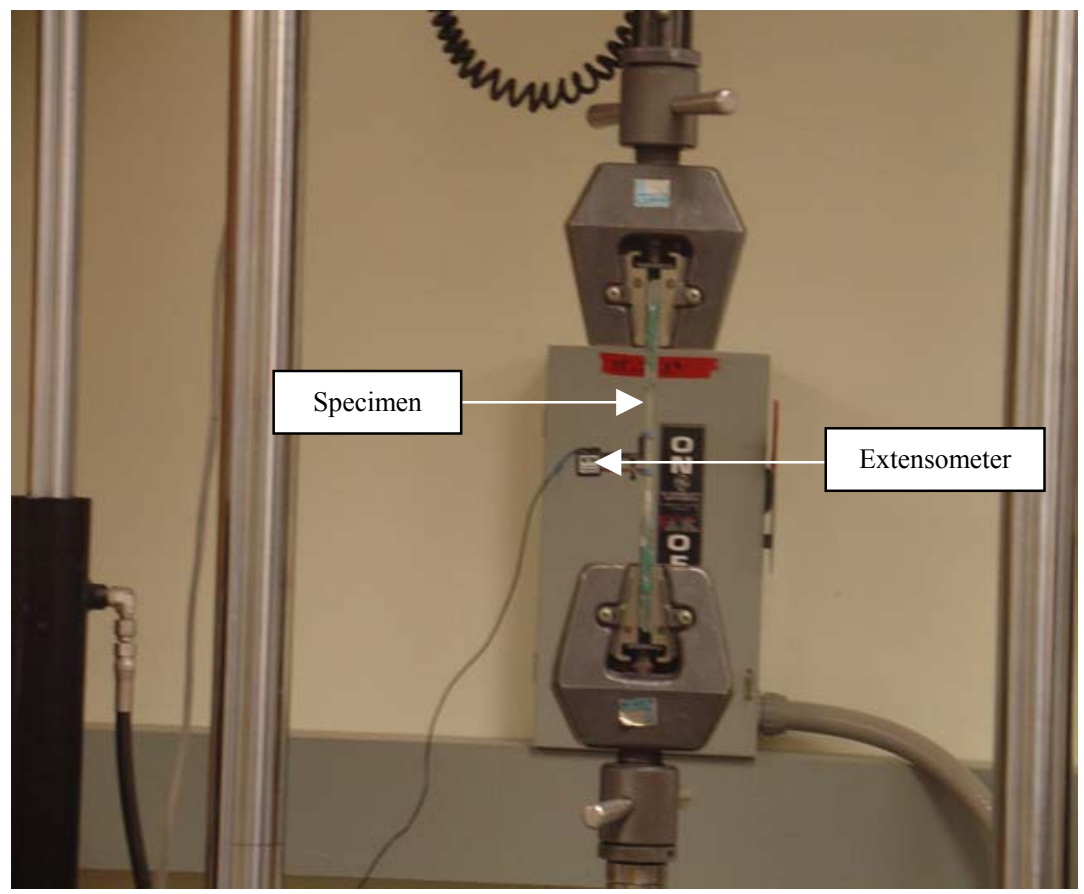

Figure 3.5 Extensometer Connected to Specimen

\subsubsection{Test Procedure}

The static test was conducted on all coupons according to ASTM D3039. A minimum of three tests were conducted to find out static properties of each material. The load and strain was noted using inbuilt load cell in the Instron machine and extensometer respectively. The tensile stiffness and strength was determined using the following equations,

$$
\text { Tensile stiffness } \mathrm{E}=\frac{\mathrm{P}}{\varepsilon^{*} \mathrm{~A}}
$$

where $\frac{\mathrm{P}}{\varepsilon}$ is the slope of the load-strain graph, A is the cross-sectional area of the coupon tested.

$$
\text { Tensile Strength }=\frac{\mathrm{P}}{\mathrm{A}}
$$


where $\mathrm{P}$ is the ultimate load, A is the cross-sectional area of the coupon tested.

The tensile stiffness and strength were calculated to observe their degradation during the fatigue test and to find out strain energy loss in each cycle.

\subsubsection{Tension-Tension Fatigue Test}

\subsubsection{Test Procedure}

The test coupons used for fatigue test were of the same dimensions as used for static test and cut from the same batch used for static test. The testing equipment used for fatigue test was same as static test. The tension-tension fatigue test was conducted according to ASTM D3479. During fatigue testing, the load was first taken to mean load $[(\max$. load $+\min$. load $) / 2]$ through static loading and then the constant amplitude sine waveform (in each cycle specimen was fatigued from minimum load to maximum load and then maximum to minimum) was applied as shown in Figure 3.6. A minimum load as $200 \mathrm{lbs}$ was chosen so as to avoid compression in the test specimen during the tensiontension fatigue test. The parameters (mode, shape, end point, rate) for static test are given in block 1 (shown in Figure 3.7) and block 2 (shown in Figure 3.8) that consists of fatigue parameters such as mode, shape, cycles, amplitude, frequency. After giving parameters for block 1 and block 2 in waveform editor the test was started using waveform runner which reads the waveform editor program. Each block has its own data storage file where the data is stored. Block 2 has the option of collecting the data at peak/trough points for every cycle during the fatigue test. The frequency for fatigue test was selected as $4 \mathrm{~Hz}$ since the composite material gets heated due to adiabatic heating at 
higher frequencies. The fatigue tests were conducted at various strain ratios ranging from $30 \%-70 \%$ of FRP coupon's ultimate load.

The Instron 8501 machine has built-in load cell and LVDT which measures the load and deflection, stored in the data storage files of each block. The fatigue tensile stiffness $\left(E_{n}\right)$ and internal strain energy loss for each cycle $\left(U_{n}\right)$ at a given cycle is calculated using the equations

$$
\begin{gathered}
E_{n}=\left(\frac{P_{n} l}{A \delta_{n}}\right) \\
U_{n}=\left(\frac{P_{n} \delta_{n}}{2}\right)
\end{gathered}
$$

where $E_{n}$ is the fatigue tensile stiffness at nth cycle, $U_{n}$ is the internal strain energy at $n$th cycle, $P_{n}$ is the load at nth cycle, $l$ is the gage length of the specimen, $A$ is the cross-sectional area of the specimen, $\delta_{n}$ is the deflection at $n$th cycle. 


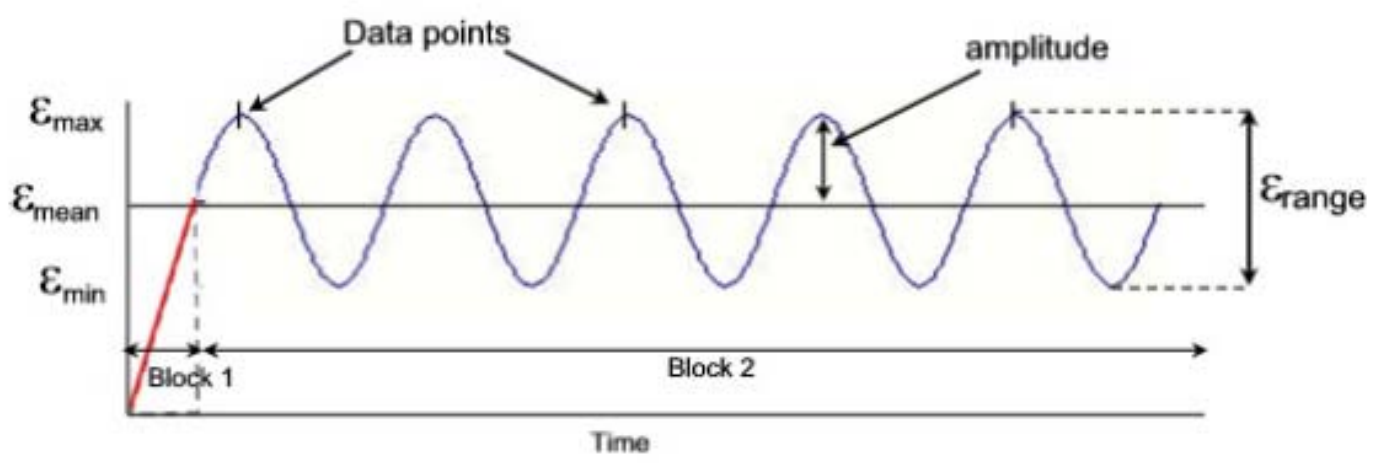

Figure 3.6 Sine Waveform and Data Measurements

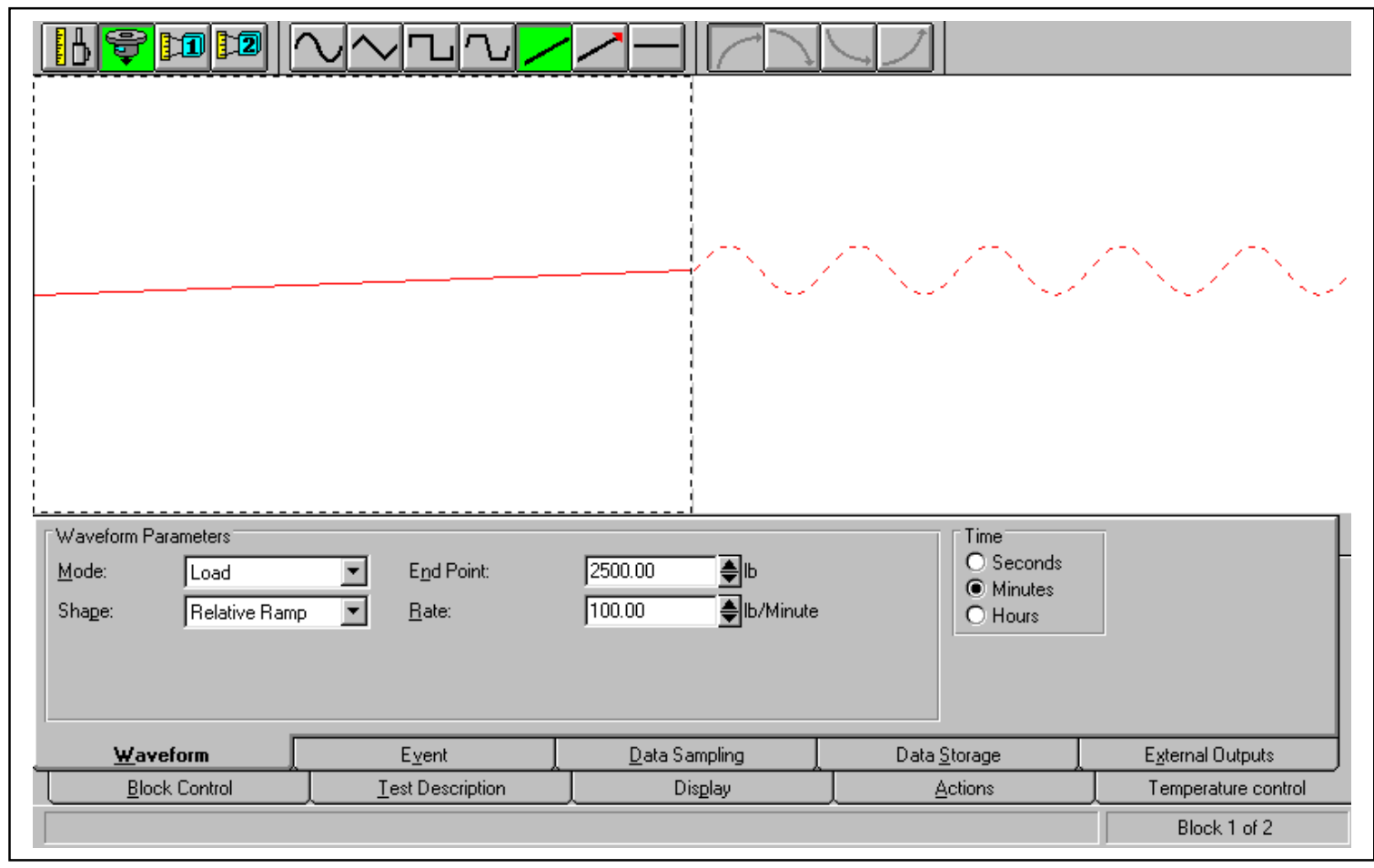

Figure 3.7 Waveform Editor (Block 1) 


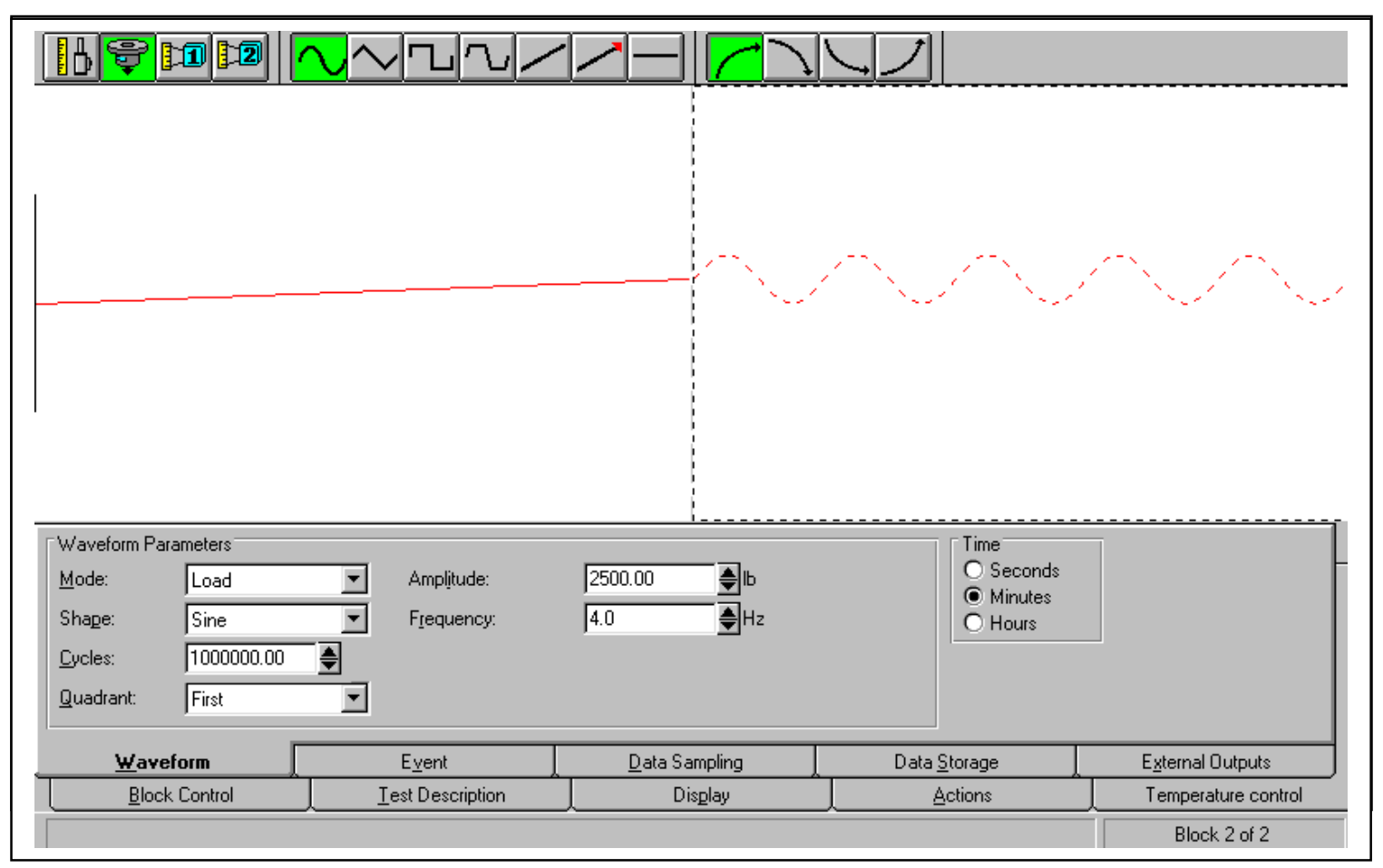

Figure 3.8 Waveform Editor (Block 2)

\subsubsection{Steps to Determine Strain Energy Release Rate and Fatigue Coefficients from Experimental Data}

1) All the specimens were tested at strain ratios $\left(\frac{\varepsilon_{\max }}{\varepsilon_{u l t .}}\right)$ ranging from $30-70 \%$ to determine the number of cycles to failure under Tension-Tension and Bending fatigue (Natarajan et al. ${ }^{28}$ ). The lower bound load in a fatigue experiment was assumed to be $2.5-3.45 \%$ of ultimate load.

2) Strain energy (U) and stiffness (E) computed from experimental data for each cycle (see Figure 3.6) were calculated by substituting the load vs deflection data in Equations (1) and (2).

3) Strain energy curve was drawn between strain energy (U) and number of cycles $(N)$ to determine the strain energy release rate (strain energy loss per cycle). The linear portion 
in strain energy curve (from $10-15 \%$ of total fatigue life to $\mathrm{N} / \mathrm{N}_{\mathrm{f}}=90 \%$ ) is considered to find the slope of $\mathrm{U}$ vs $\mathrm{N}$ which is the strain energy release for that particular test specimen.

4) Strain energy release rate, $\Delta U$ versus normalized strain, $\left(\frac{\varepsilon_{\max }}{\varepsilon_{u l t .}}\right)$ is shown (see Figure 3.18) and the power law, $\Delta U=a\left(\frac{\varepsilon_{\text {max }}}{\varepsilon_{u l t .}}\right)^{b}$ fit is used here in to determine 'a' and 'b' which are considered as fatigue coefficients.

\subsubsection{Tension-Tension Fatigue Test Results}

The tests were performed on unidirectional, multidirectional, $3 \mathrm{~d}$ stitched fabrics for various strain ratios ranging from $30 \%-70 \%$. The fatigue cycles to failure for each material under different strain ratios are shown in Table 3.2. From Table 3.2 we can observe that with the increase in the strain ratio, the number of fatigue cycles to failure decreases for all the materials. The fatigue failure mode for each material is shown in Figure(s) 3.9, through 3.11 respectively. Figure 3.12 represents normalized strain vs logarithmic number of fatigue cycles to failure (S-N curve) for each material for different strain ratios. 

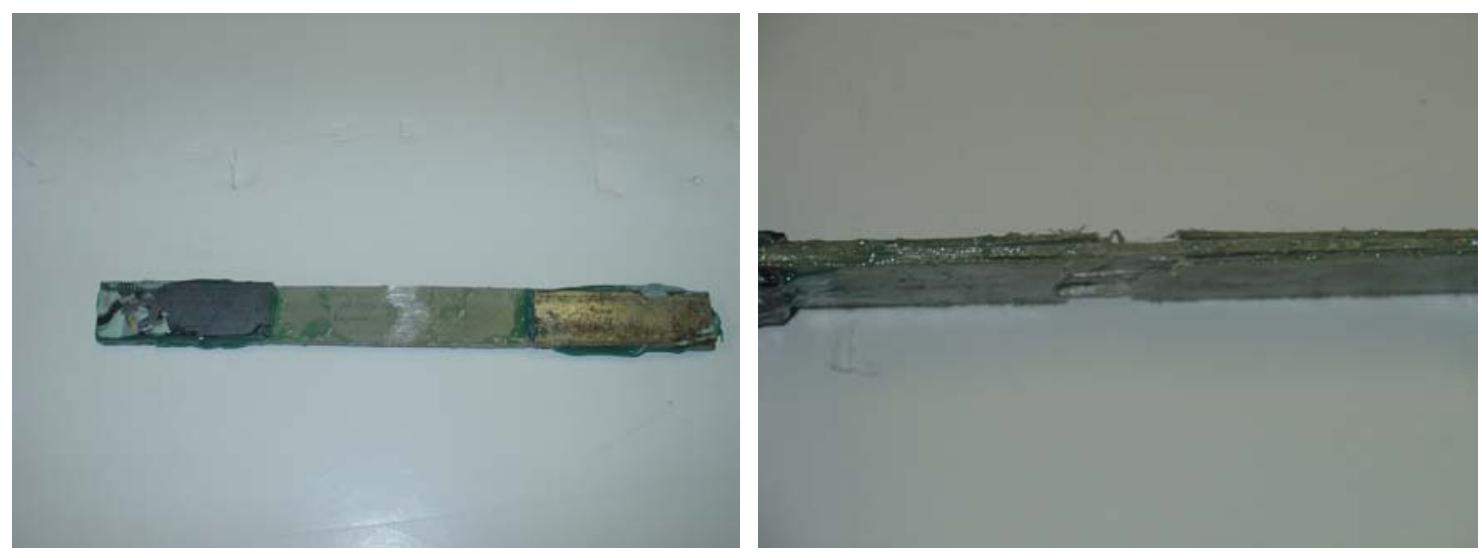

Figure 3.9 Tension-Tension Fatigue Failure Mode of MAT 1
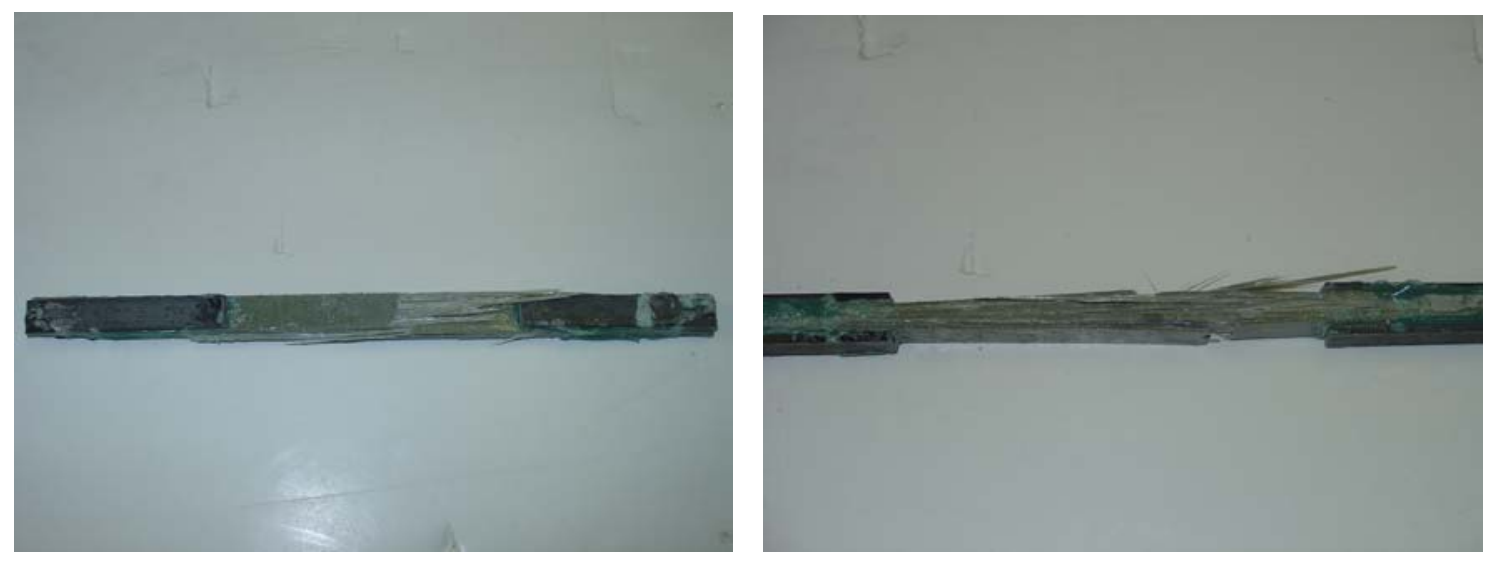

Figure 3.10 Tension-Tension Fatigue Failure Mode of MAT 2
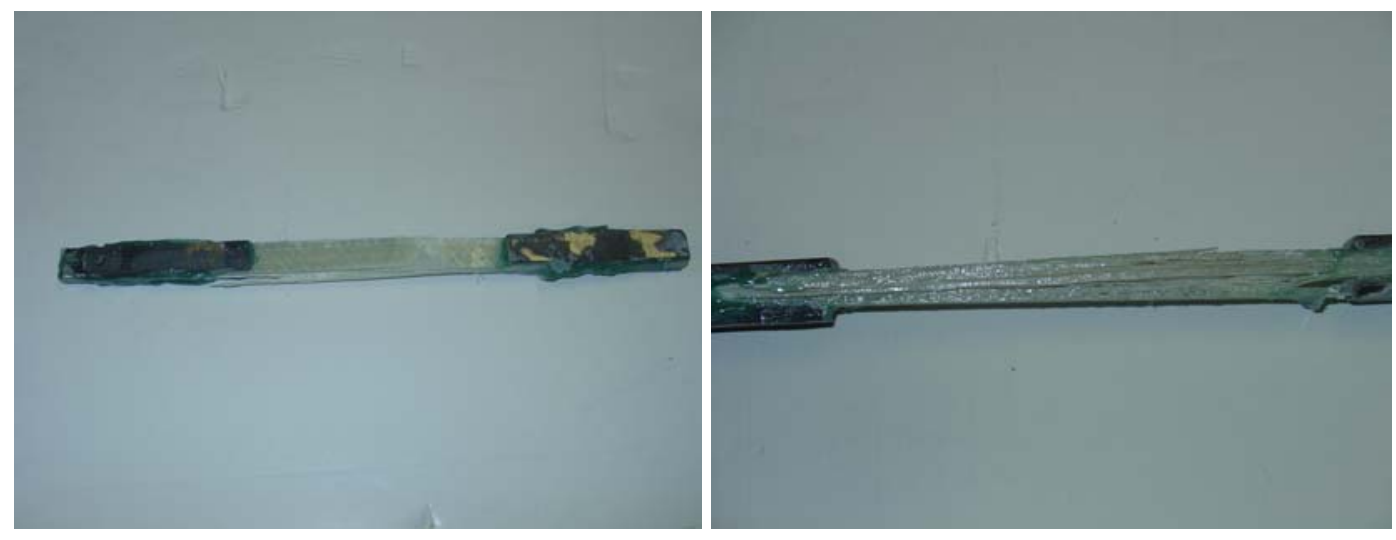

Figure 3.11 Tension-Tension Fatigue Failure Mode of MAT 3 


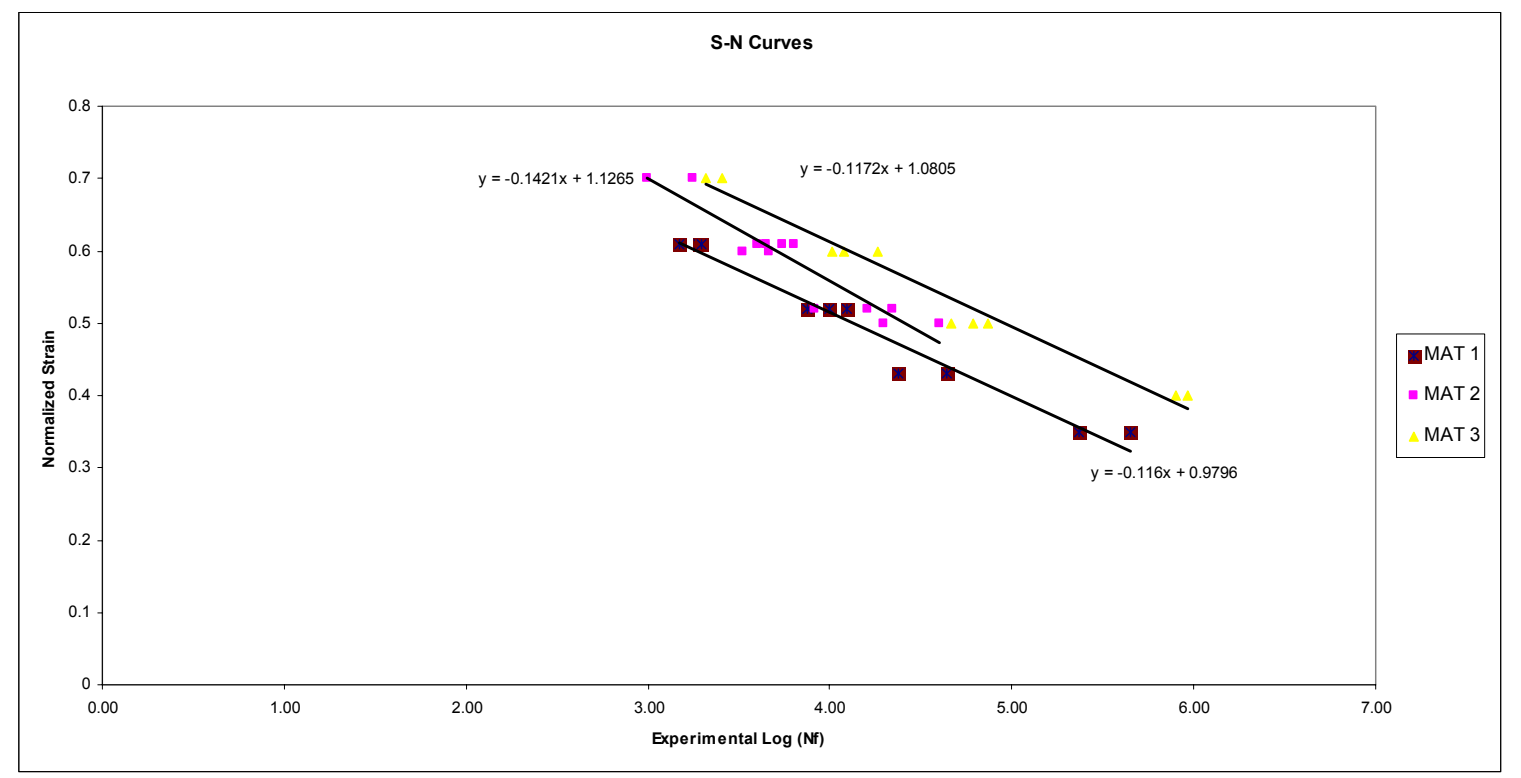

Figure 3.12 S-N Curves for MAT 1, MAT 2 and MAT 3

Table 3.2 Summary of Fatigue Test Results for MAT 1, MAT 2, MAT 3

\begin{tabular}{|c|c|c|c|c|}
\hline \multicolumn{5}{|c|}{ MAT 1} \\
\hline Specimen No. & $\begin{array}{c}\text { Specimen } \\
\text { Dimension }\end{array}$ & $\begin{array}{l}\text { Load Range } \\
\text { (lbs) }\end{array}$ & $\% \varepsilon_{u l t}$ & $\begin{array}{l}\text { Cycles to } \\
\text { Failure }\end{array}$ \\
\hline 1 & \multirow{10}{*}{$10 " * 1 " * 0.125 "$} & $200-2625$ & 35 & 451700 \\
\hline 2 & & $200-2625$ & 35 & 234760 \\
\hline 3 & & $200-3225$ & 43 & 43740 \\
\hline 4 & & $200-3225$ & 43 & 23950 \\
\hline 5 & & $200-3900$ & 52 & 9997 \\
\hline 6 & & $200-3900$ & 52 & 12495 \\
\hline 7 & & $200-3900$ & 52 & 7439 \\
\hline 8 & & $200-4575$ & 61 & 1883 \\
\hline 9 & & $200-4575$ & 61 & 1497 \\
\hline 10 & & $200-4575$ & 61 & 1961 \\
\hline \multicolumn{5}{|c|}{ MAT 2} \\
\hline Specimen No. & $\begin{array}{c}\text { Specimen } \\
\text { Dimension }\end{array}$ & $\begin{array}{l}\text { Load Range } \\
\text { (lbs) }\end{array}$ & $\% \varepsilon_{u l t}$ & $\begin{array}{c}\text { Cycles to } \\
\text { failure }\end{array}$ \\
\hline 1 & \multirow[t]{7}{*}{$10 " * 0.5 " * 0.25 "$} & $200-3200$ & 40 & 136610 \\
\hline 2 & & $200-4000$ & 50 & 39850 \\
\hline 3 & & $200-4000$ & 50 & 19844 \\
\hline 4 & & $200-4160$ & 52 & 22000 \\
\hline 5 & & $200-4160$ & 52 & 16236 \\
\hline 6 & & $200-4160$ & 52 & 8299 \\
\hline 7 & & $200-4800$ & 60 & 4670 \\
\hline
\end{tabular}




\begin{tabular}{|c|c|c|c|c|}
\hline 8 & & $200-4800$ & 60 & 3297 \\
\hline 9 & & $200-4880$ & 61 & 6380 \\
\hline 10 & & $200-4880$ & 61 & 4500 \\
\hline 11 & & $200-4880$ & 61 & 3982 \\
\hline 12 & & $200-4880$ & 61 & 5471 \\
\hline 13 & & $200-5600$ & 70 & 1759 \\
\hline 14 & & $200-5600$ & 70 & 983 \\
\hline \multicolumn{5}{|c|}{ MAT 3} \\
\hline Specimen No. & $\begin{array}{c}\text { Specimen } \\
\text { Dimension }\end{array}$ & $\begin{array}{l}\text { Load Range } \\
\text { (lbs) }\end{array}$ & $\% \varepsilon_{u l t}$ & $\begin{array}{l}\text { Cycles to } \\
\text { failure }\end{array}$ \\
\hline 1 & \multirow{11}{*}{$10 " * 0.5 " 0.25 "$} & $200-1740$ & 30 & 957957 \\
\hline 2 & & $200-2320$ & 40 & 805175 \\
\hline 3 & & $200-2320$ & 40 & 918858 \\
\hline 4 & & $200-2900$ & 50 & 46031 \\
\hline 5 & & $200-2900$ & 50 & 61650 \\
\hline 6 & & $200-2900$ & 50 & 73257 \\
\hline 7 & & $200-3480$ & 60 & 12021 \\
\hline 8 & & $200-3480$ & 60 & 18280 \\
\hline 9 & & $200-3480$ & 60 & 10350 \\
\hline 10 & & $200-4060$ & 70 & 2536 \\
\hline 11 & & $200-4060$ & 70 & 2069 \\
\hline
\end{tabular}

\subsubsection{Strain Energy Curves, Energy Release Rate and Determination of Fatigue Coefficients}

The load deflection data obtained from the tension-tension fatigue test were plotted as strain energy versus number of cycles for all test specimens. The expended strain energy by the material was calculated using Equation $U_{n}=\frac{P_{n}^{2} l}{2 A E}$. As it is evident from Figure 3.1 that during stages I and III together, about only $20 \%$ of life line was contributed and remaining $80 \%$ life line is contributed during stage II, separate energy curves were plotted for stage II alone and these curves were used to determine energy release rates for different strains. Further, in stage III fiber breakage was dominant factor and there was a sudden increase in strain energy within short interval of time causing 
abrupt fiber failure. The failure of the fibers drastically reduces the strength of the composite thus increasing the stress on the individual fibers leading to global failure ${ }^{37}$.

Strain energy release rate (strain energy loss per cycle), which is obtained by performing regression analysis from the slope of Stage II in the stain energy curve for all the test specimens is tabulated in Table 3.3. The strain energy including release rate curves for all test specimens of each material are shown in Figures 3.13. -3.15. Figures $3.13 \mathrm{a}, 3.14 \mathrm{a}$ and $3.15 \mathrm{a}$ represent the curves from the time of fatigue initiation to failure of the test specimen and Figures 3.13b, 3.14b and 3.15b represent curves of the expended energy per cycle corresponding to only Stage II.

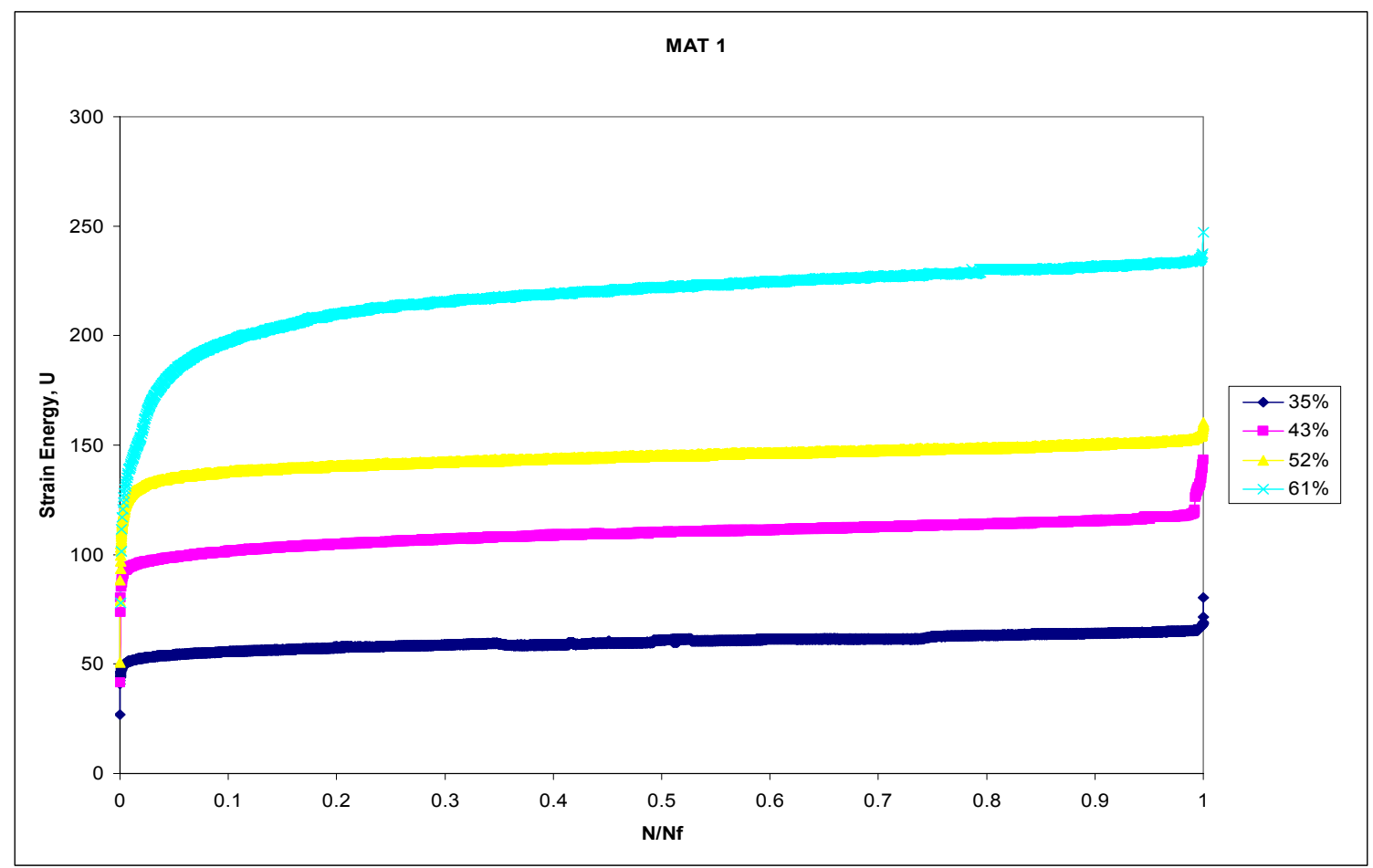

(a) 


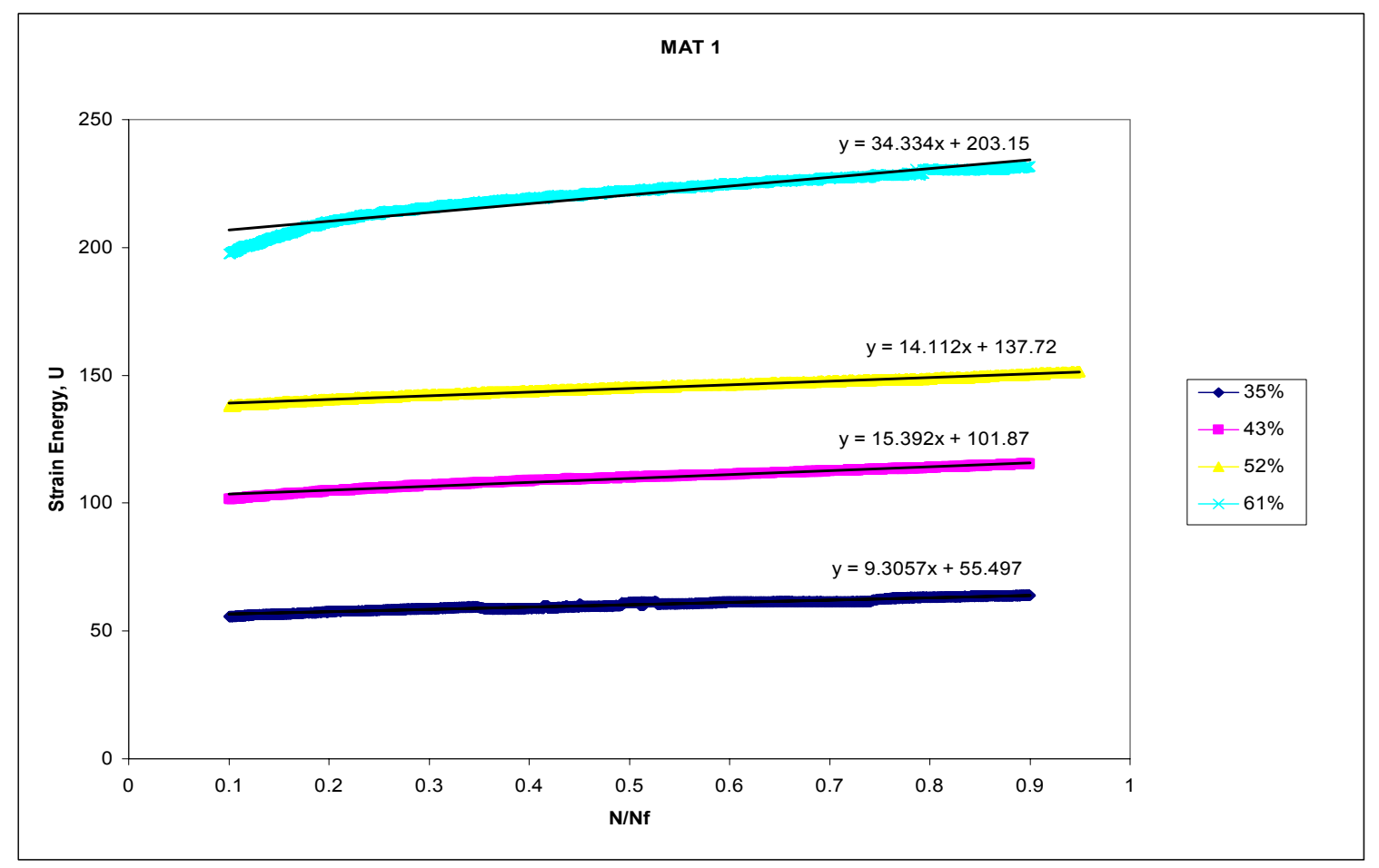

(b)

Figure 3.13 Strain Energy Curves for MAT 1

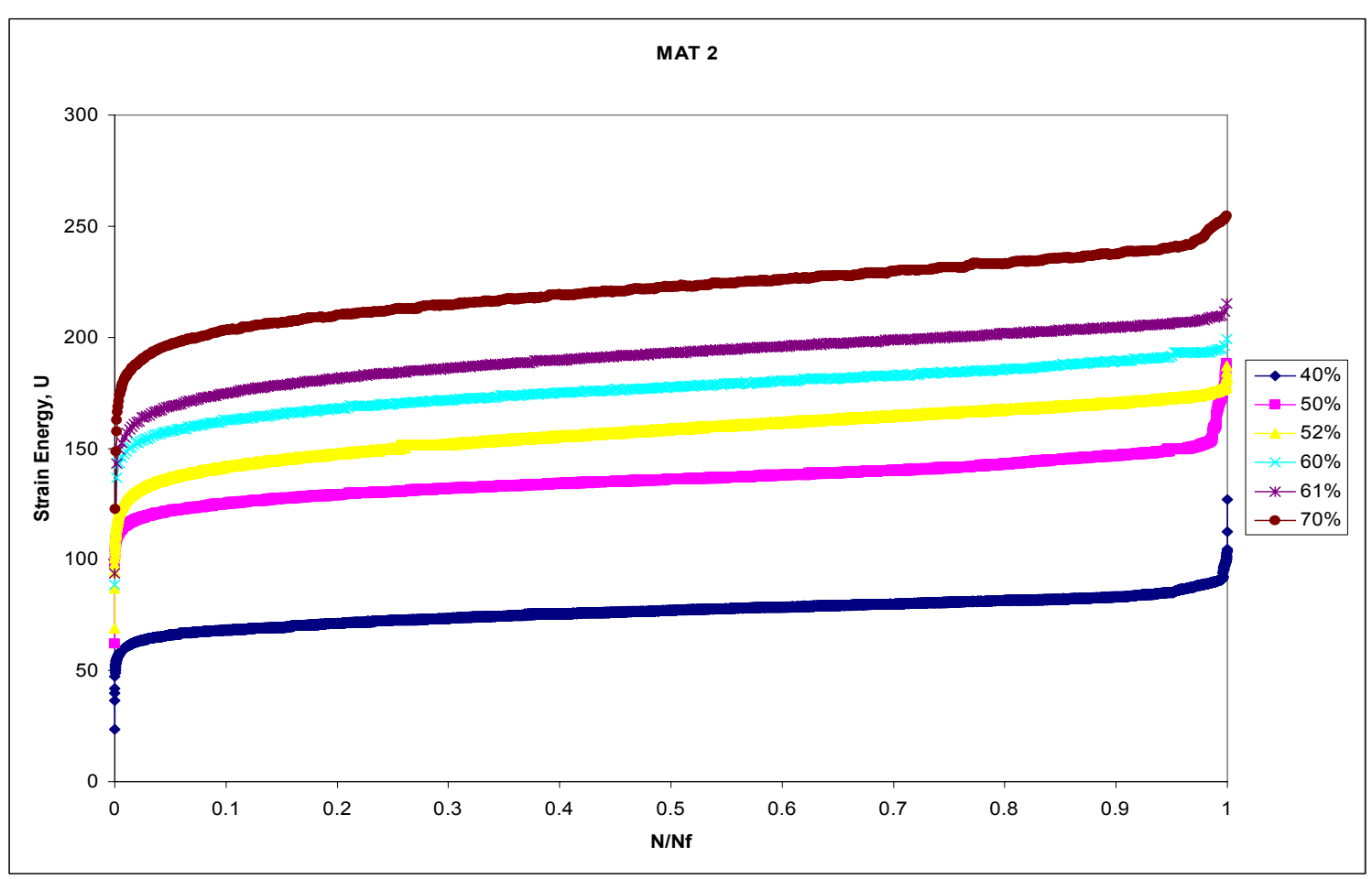

(a) 


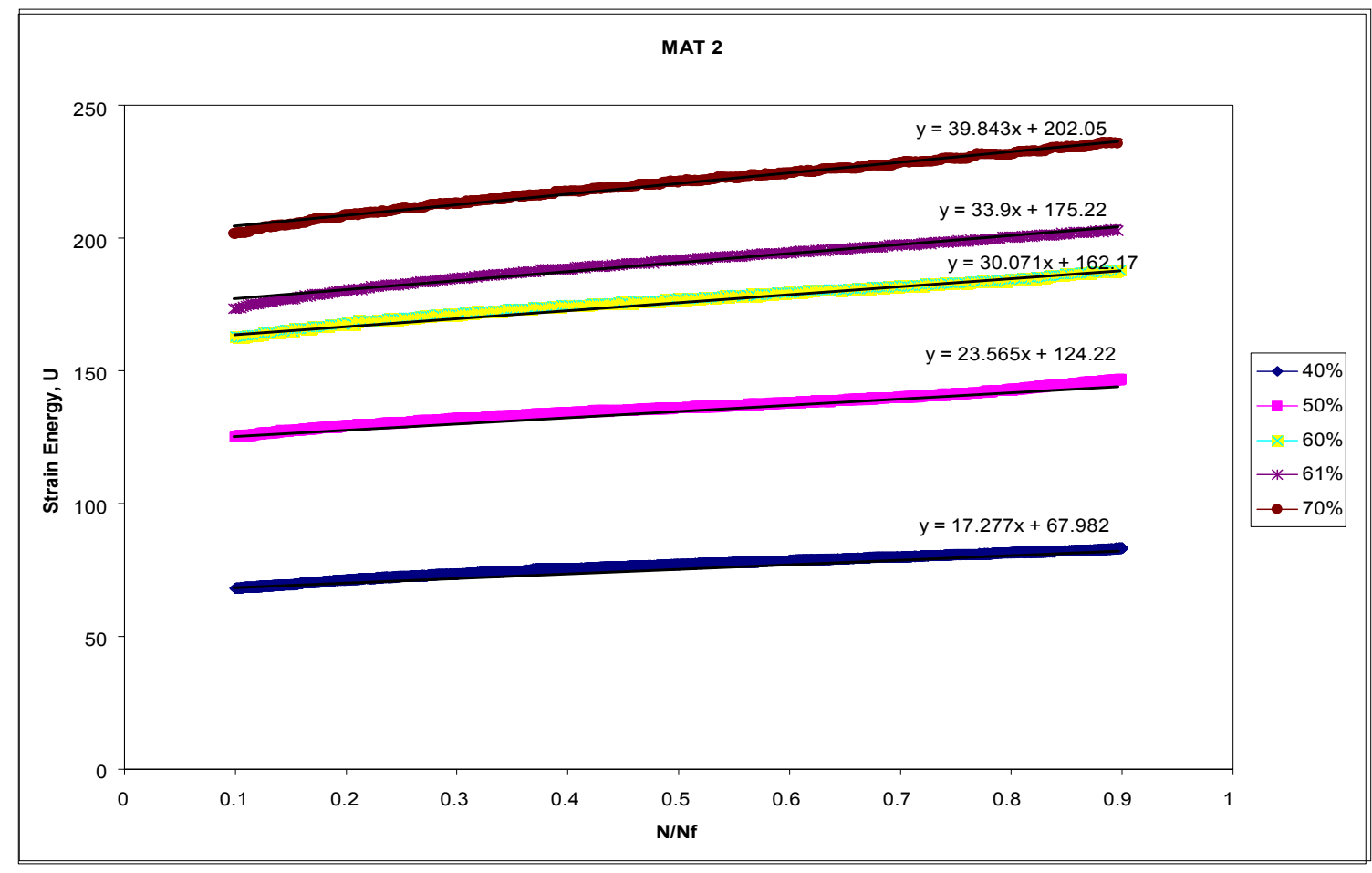

(b)

Figure 3.14 Strain Energy Curves for MAT 2

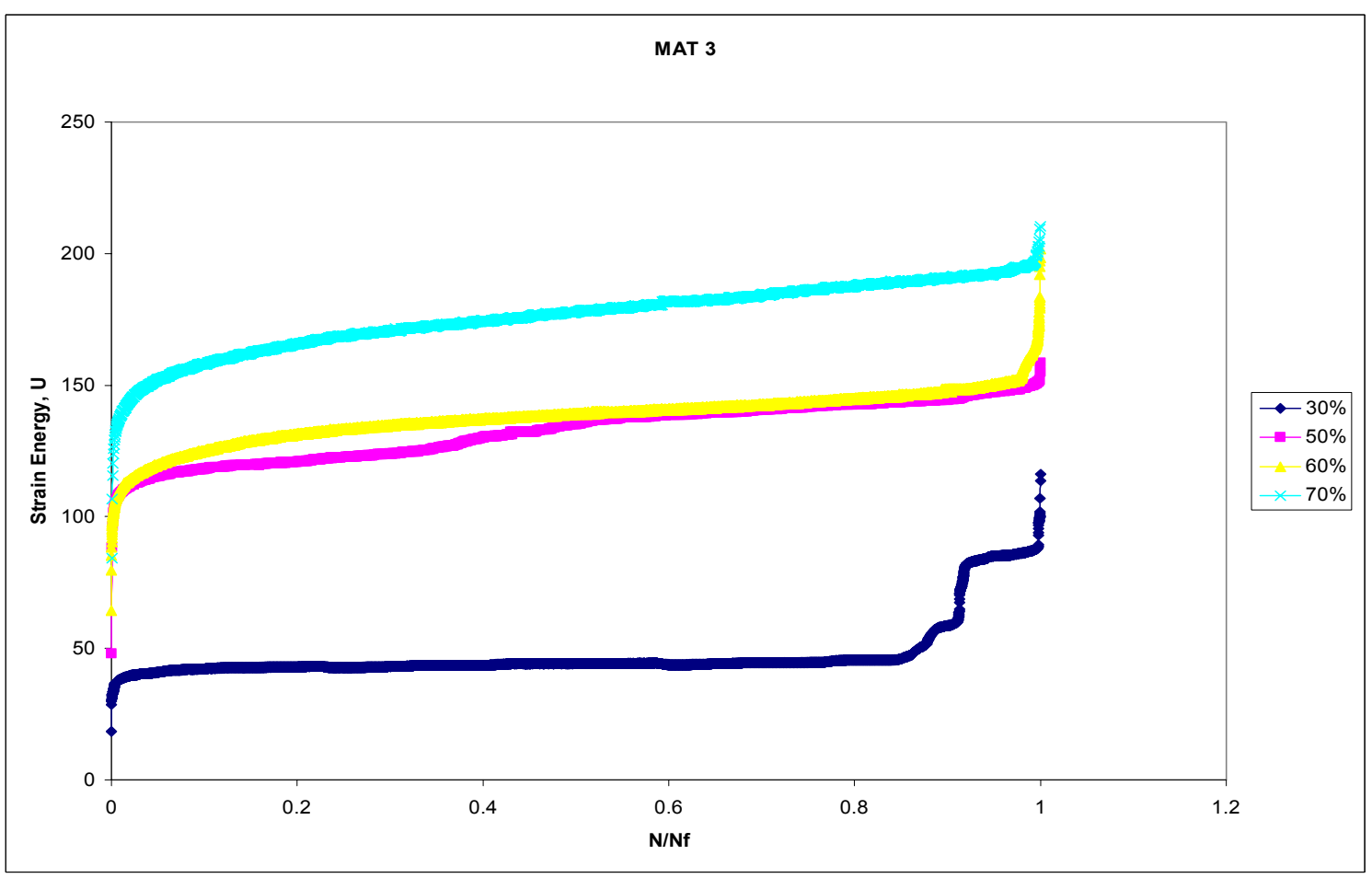

(a) 


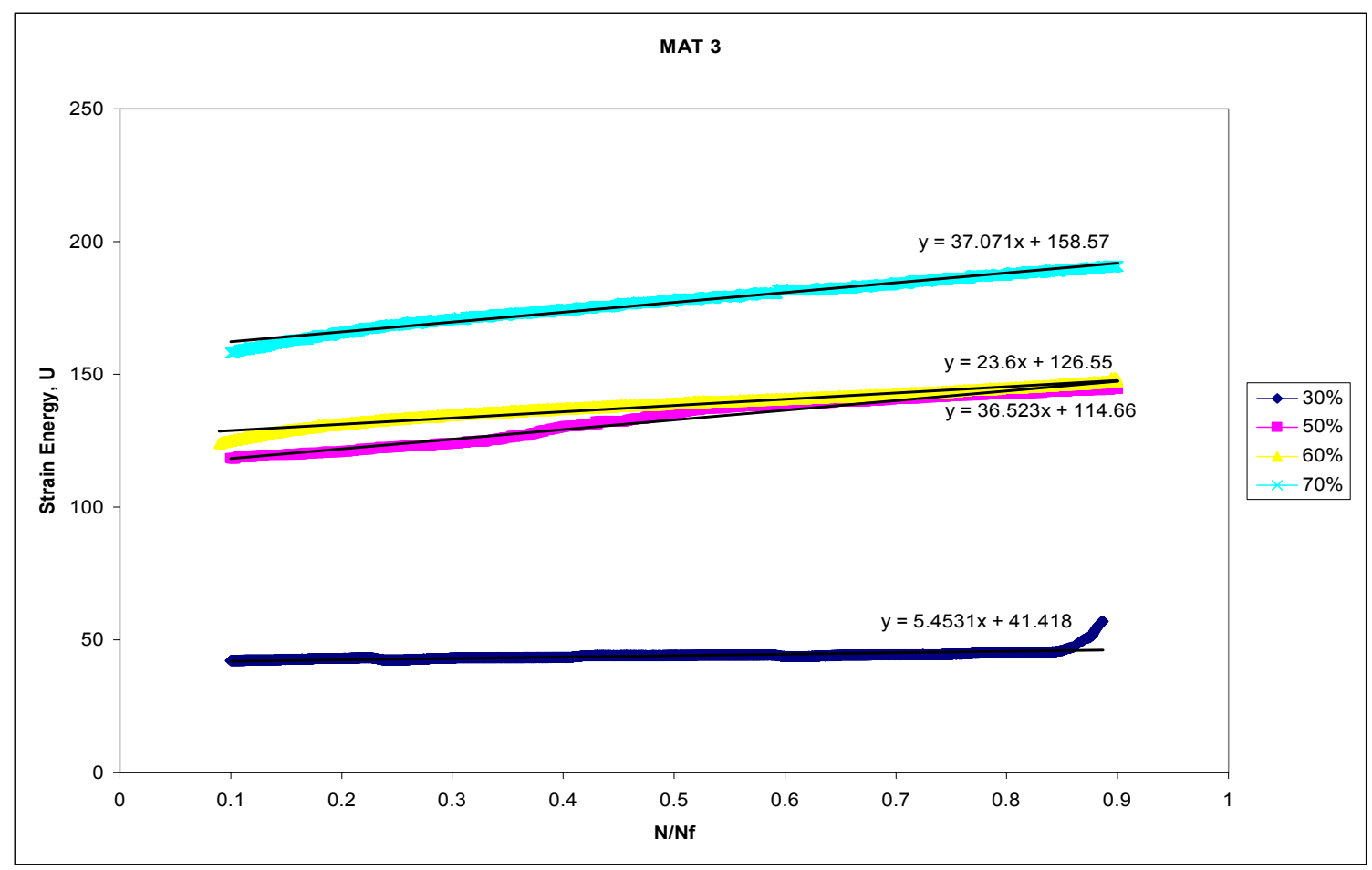

(b)

Figure 3.15 Strain Energy Curves for MAT 3

From Table 3.2 and 3.3 we can see that the slope of strain energy vs number of cycles to failure decreased with the increase in the percentage of strain applied on the glass fiber reinforced composites irrespective of the fiber architecture of the composite. This represents the damage developed decreased as the applied load decreased, also energy release rate (energy loss per cycle) was lower for low $\left(\frac{P_{\max }}{P_{u l t .}}\right)$ where $\mathrm{P}_{\max .}$ is the maximum applied load and $\mathrm{P}_{u l t}$ is the ultimate load of the composite coupon. 
Table 3.3 Summary of Strain Energy Results for MAT 1, MAT 2, MAT 3

\begin{tabular}{|c|c|c|c|c|c|}
\hline \multicolumn{6}{|c|}{ MAT 1} \\
\hline $\begin{array}{l}\text { Specimen } \\
\text { No. }\end{array}$ & $\% \varepsilon_{u l t}$ & $\begin{array}{c}\mathrm{U} \text { at } 0 \\
\text { cycles, } 1 \mathrm{~b}-\mathrm{in}\end{array}$ & $\begin{array}{c}\mathrm{U} \text { at } \\
\mathrm{N} / \mathrm{N}_{\mathrm{f}}=0.9 \\
\mathrm{lb}-\mathrm{in}\end{array}$ & $\begin{array}{l}\% \text { increase } \\
\text { in } U \text { from } \\
\text { cycle } 1 \text { to } \\
\mathrm{N} / \mathrm{N}_{\mathrm{f}}=0.9\end{array}$ & $\begin{array}{c}\text { Energy } \\
\text { Release Rate } \\
\text { (Slope of } \\
\text { U vs N), } \\
\text { lb-in }\end{array}$ \\
\hline 1 & 35 & 42 & 64 & 52 & 0.00002 \\
\hline 2 & 35 & 39 & 59 & 51 & 0.00002 \\
\hline 3 & 43 & 75 & 115 & 53 & 0.0003 \\
\hline 4 & 43 & 58 & 88 & 52 & 0.0003 \\
\hline 5 & 52 & 100 & 150 & 50 & 0.0014 \\
\hline 6 & 52 & 93 & 137 & 47 & 0.001 \\
\hline 7 & 52 & 94 & 139 & 48 & 0.0012 \\
\hline 8 & 61 & 135 & 206 & 53 & 0.0155 \\
\hline 9 & 61 & 133 & 200 & 50 & 0.0123 \\
\hline 10 & 61 & 155 & 231 & 49 & 0.0142 \\
\hline \multicolumn{6}{|c|}{ Avg. 50.5} \\
\hline \multicolumn{6}{|c|}{ MAT 2} \\
\hline $\begin{array}{c}\text { Specimen } \\
\text { No. }\end{array}$ & $\% \varepsilon_{u l t .}$ & $\begin{array}{c}\mathrm{U} \text { at } 0 \\
\text { cycles, } 1 \mathrm{~b} \text {-in }\end{array}$ & $\begin{array}{c}\mathrm{U} \text { at } \\
\mathrm{N} / \mathrm{N}_{\mathrm{f}}=0.9 \\
\mathrm{lb}-\mathrm{in}\end{array}$ & $\begin{array}{l}\% \text { increase } \\
\text { in } U \text { from } \\
\text { cycle } 1 \text { to } \\
\mathrm{N} / \mathrm{N}_{\mathrm{f}}=0.9\end{array}$ & $\begin{array}{c}\text { Energy } \\
\text { Release Rate } \\
\text { (Slope of } \\
\text { U vs N), } \\
\text { lb-in }\end{array}$ \\
\hline 1 & 40 & 55 & 83 & 51 & 0.00004 \\
\hline 2 & 50 & 98 & 147 & 50 & 0.0006 \\
\hline 3 & 50 & 95 & 143 & 50 & 0.0011 \\
\hline 4 & 52 & 100 & 146 & 46 & 0.001 \\
\hline 5 & 52 & 113 & 171 & 51 & 0.002 \\
\hline 6 & 52 & 108 & 159 & 47 & 0.003 \\
\hline 7 & 60 & 123 & 189 & 54 & 0.0064 \\
\hline 8 & 60 & 129 & 193 & 50 & 0.0086 \\
\hline 9 & 61 & 168 & 253 & 51 & 0.0082 \\
\hline 10 & 61 & 138 & 204 & 48 & 0.0072 \\
\hline 11 & 61 & 123 & 184 & 50 & 0.007 \\
\hline 12 & 61 & 146 & 215 & 47 & 0.0065 \\
\hline 13 & 70 & 158 & 237 & 50 & 0.0224 \\
\hline 14 & 70 & 171 & 250 & 46 & 0.0356 \\
\hline \multicolumn{6}{|c|}{ Avg. 49.36} \\
\hline \multicolumn{6}{|c|}{ MAT 3} \\
\hline $\begin{array}{c}\text { Specimen } \\
\text { No. }\end{array}$ & $\% \varepsilon_{u l t}$ & $\begin{array}{c}\mathrm{U} \text { at } 0 \\
\text { cycles, } 1 \mathrm{~b} \text {-in }\end{array}$ & $\begin{array}{c}\mathrm{U} \text { at } \\
\mathrm{N} / \mathrm{N}_{\mathrm{f}}=0.9 \\
\mathrm{lb}-\mathrm{in}\end{array}$ & $\begin{array}{l}\% \text { increase } \\
\text { in } U \text { from } \\
\text { cycle } 1 \text { to } \\
\mathrm{N} / \mathrm{N}_{\mathrm{f}}=0.9\end{array}$ & $\begin{array}{c}\text { Energy } \\
\text { Release Rate } \\
\text { (Slope of } \\
\text { U vs N), }\end{array}$ \\
\hline
\end{tabular}




\begin{tabular}{|c|c|c|c|c|c|}
\hline & & & & & lb-in \\
\hline 1 & 30 & 39 & 59 & 51 & 0.000004 \\
\hline 2 & 40 & 62 & 93 & 50 & 0.00002 \\
\hline 3 & 40 & 56 & 84 & 50 & 0.00001 \\
\hline 4 & 50 & 94 & 140 & 49 & 0.0009 \\
\hline 5 & 50 & 87 & 134 & 54 & 0.0004 \\
\hline 6 & 50 & 96 & 144 & 50 & 0.0005 \\
\hline 7 & 60 & 97 & 147 & 51 & 0.0019 \\
\hline 8 & 60 & 108 & 161 & 49 & 0.001 \\
\hline 9 & 60 & 102 & 151 & 48 & 0.0024 \\
\hline 10 & 70 & 126 & 191 & 51 & 0.014 \\
\hline 11 & 70 & 138 & 206 & 49 & 0.0194 \\
\hline
\end{tabular}

The synthesized data in Table 3.3 reveals that the percentage increase in strain energy loss from the $2-5 \%$ of total fatigue life to $\frac{N}{N_{f}}=0.9$ was found to be approximately $50 \%$ neglecting $0-2 \%$ of total fatigue life. Assuming $U_{0}$ is the strain energy at the $2-5 \%$ of total fatigue life, $U_{f}$ is the strain energy at $\frac{N}{N_{f}}=0.9$ it can be written as $U_{f}=1.5 U_{0}$.

The energy release rate $(\Delta U)$ vs normalized strain $\left(\frac{\varepsilon_{\max }}{\varepsilon_{u l t .}}\right)$ curves were plotted for each material as shown in Figure(s) 3.16, 3.17, 3.18. The data points were fit using power law, $\Delta U=a\left(\frac{\varepsilon_{\max }}{\varepsilon_{u l t .}}\right)^{b}$, where $\varepsilon_{\text {max. }}$ is the maximum applied strain of the material, $\varepsilon_{u l t .}$ is the ultimate tensile strength of the material, $a$ and $b$ are fatigue coefficients of the material. The fatigue coefficient ' $b$ ' represents the bond strength between fiber and matrix which depends on better durability/sizing of resin/fiber, better cure, brittle nature 
of resin, cut from a sample. The fatigue coefficients for each material are presented in Table 3.4. From Table 3.4, based on 'b' value it can be concluded that MAT 1 has better fatigue resistance than MAT 2 followed by MAT 3 as ' $b$ ' determines the bond strength between fibers/fabrics and matrix. The fatigue coefficient ' $b$ ' value varies from 10-13 which was observed in Natarajan ${ }^{37}$ thesis.

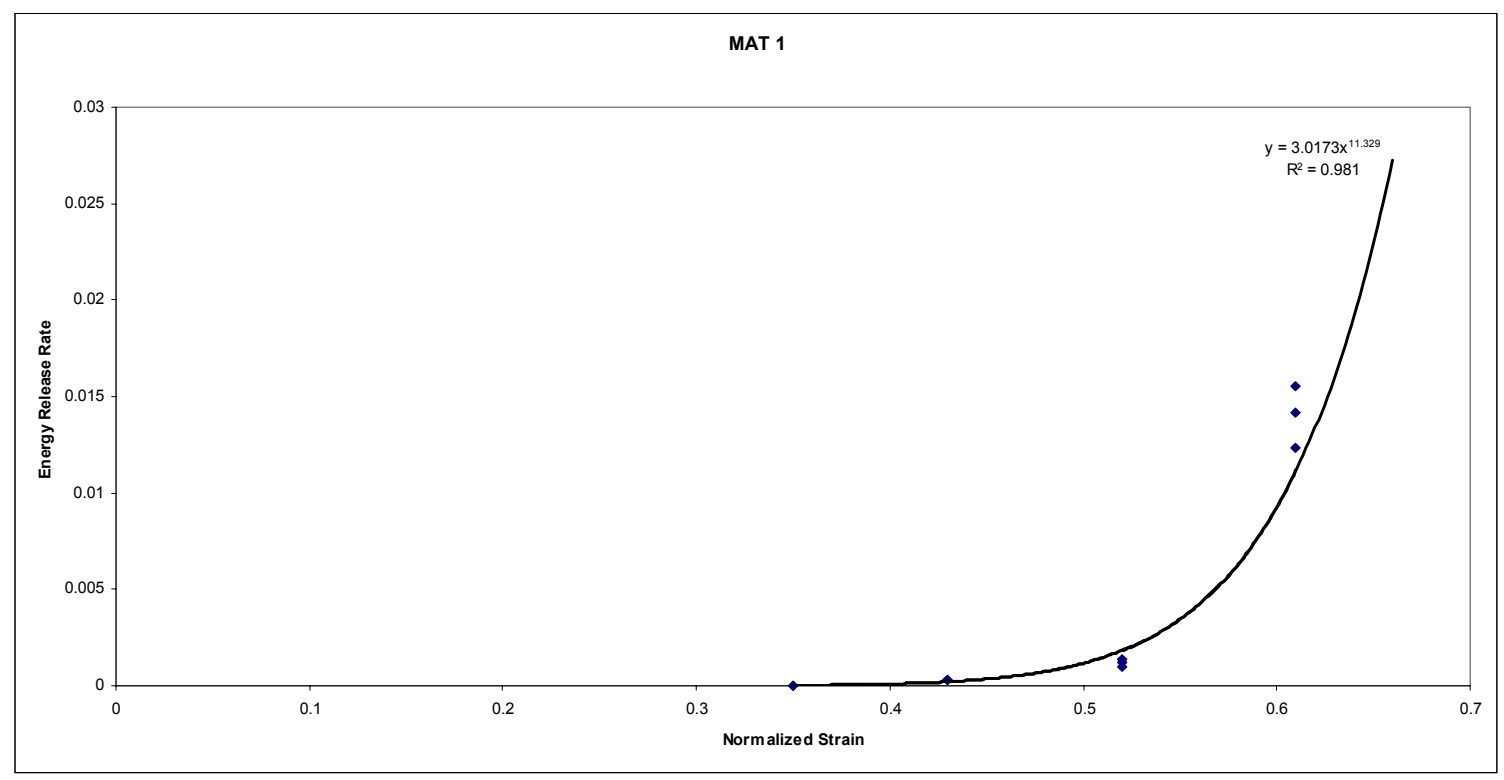

Figure 3.16 Variation of Strain Energy Release Rate with Normalized Strain for MAT 1 


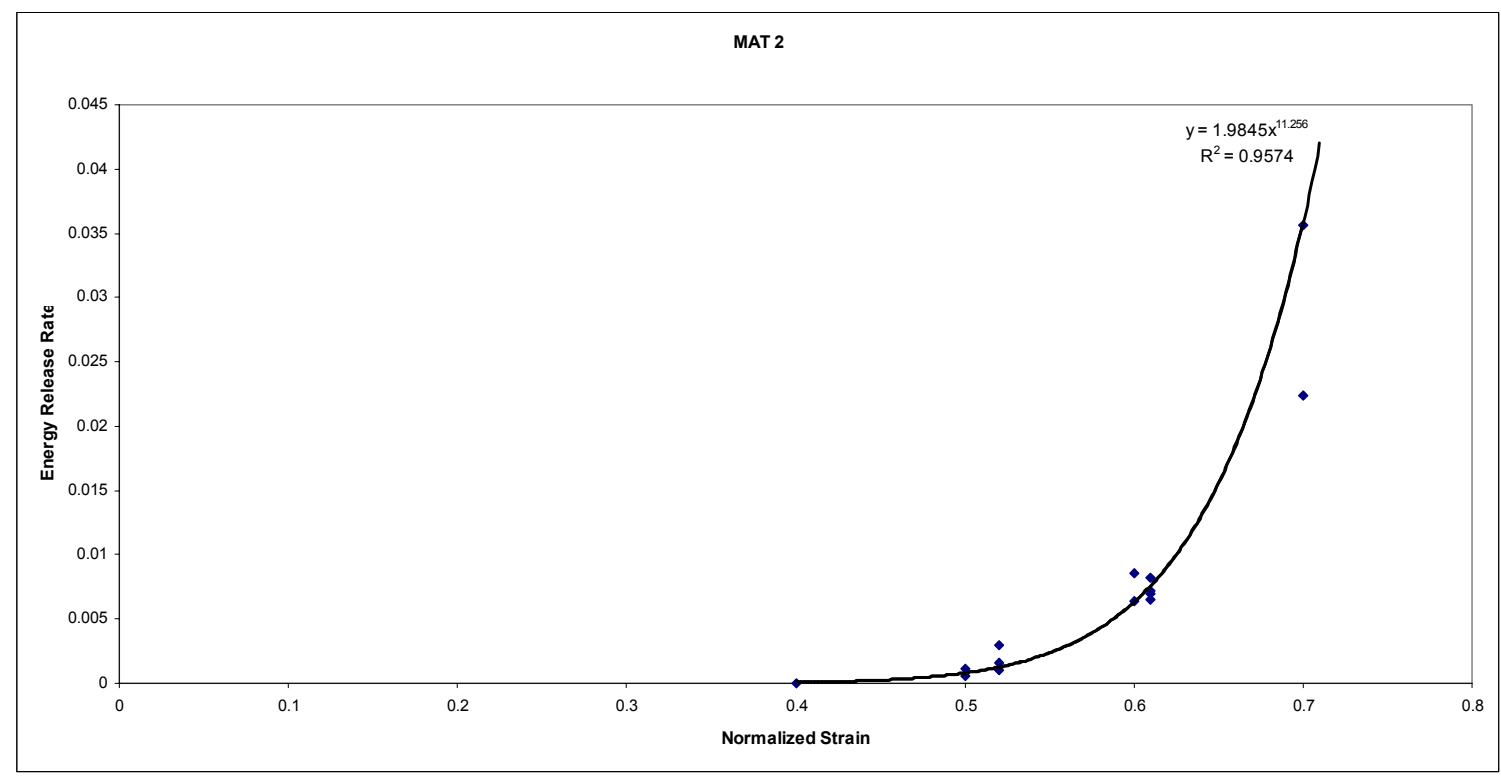

Figure 3.17 Variation of Strain Energy Release Rate with Normalized Strain for MAT 2

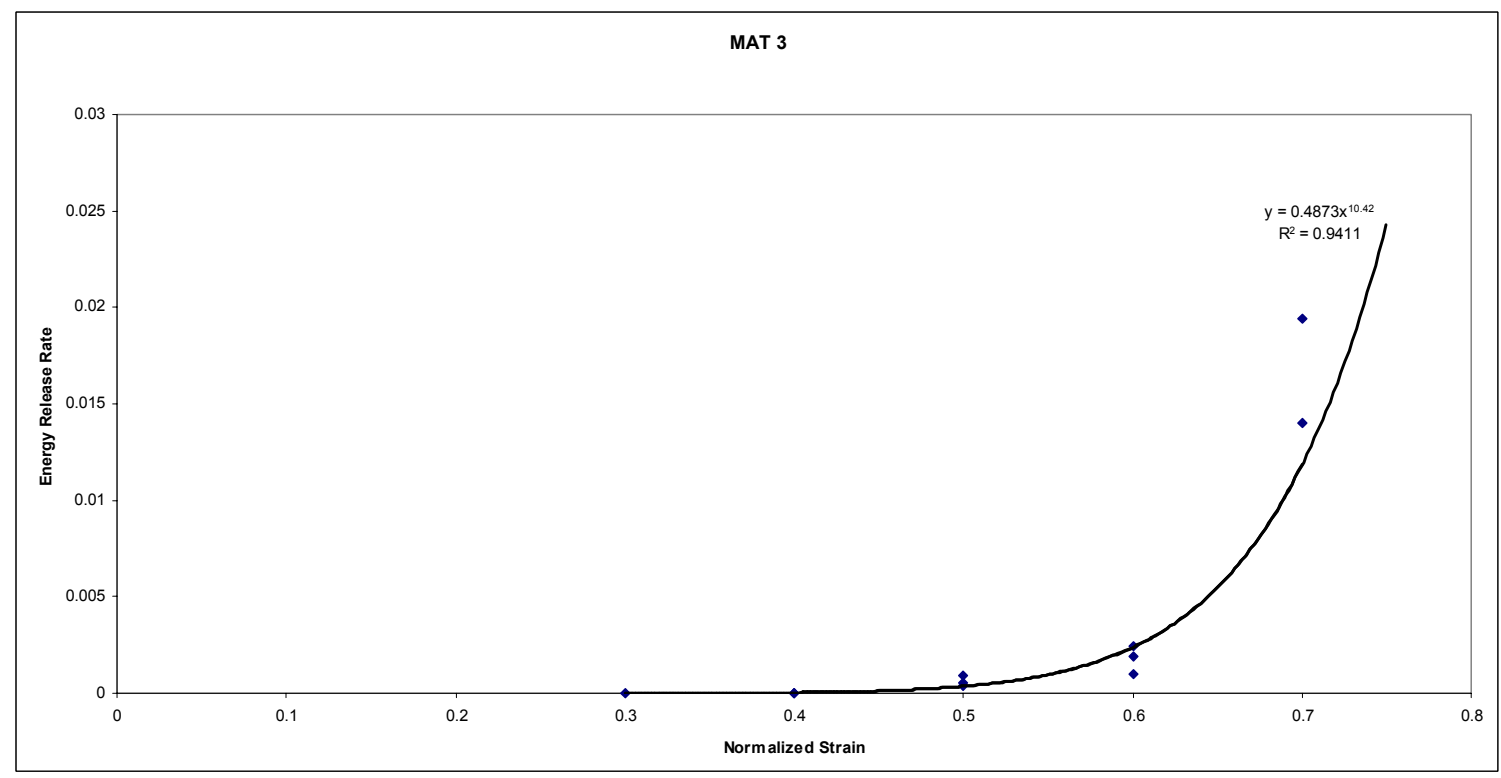

Figure 3.18 Variation of Strain Energy Release Rate with Normalized Strain for MAT 3 
Table 3.4 Fatigue Coefficients for MAT 1, MAT 2 and MAT 3

\begin{tabular}{|c|c|c|}
\hline \multirow{2}{*}{ Material } & \multicolumn{2}{|c|}{ Fatigue Coefficients } \\
\cline { 2 - 3 } & $\mathrm{a}$ & $\mathrm{b}$ \\
\hline MAT 1 & 3.0173 & 11.329 \\
\hline MAT 2 & 1.9845 & 11.256 \\
\hline MAT 3 & 0.4873 & 10.42 \\
\hline
\end{tabular}

\subsubsection{Comparision of MAT 1, MAT 2 and MAT 3 Based on Fatigue Coefficients:}

\subsection{MAT 1 VS MAT 2:}

MAT 1 and MAT 2 are unidirectional composites but of different thickness and width. It can be seen that fatigue resistance of MAT 1 is higher than MAT 2 since the value of ' $b$ ' is high. This is because the shear transfer capacity of specimen decreases with an increase in test specimen thickness. Also the control of void content and curing of the laminate become difficult with the increase of thickness.

\subsection{MAT 2 VS MAT 3:}

MAT 2 and MAT 3 are of the same thickness but of different fiber architecture. MAT 3 consisted of $0^{0}$ as well as $90^{\circ}, 45^{\circ}$ fibers which lower fatigue resistance of the material. The presence of $90^{\circ}, 45^{\circ}$ fibers increases the stress concentration at the points where $0^{0}, 90^{0}, 45^{\circ}$ fibers come in contact with each other which enhances the damage growth in the specimen and leads to quicker failure of 2D composite specimens than the unidirectional composite specimens. Also the poisson's effect causes compression in $90^{\circ}$ and $45^{\circ}$ when load is in $0^{0}$ direction. So the unidirectional material will have higher fatigue resistance than $2 \mathrm{D}$ which has $0^{\circ}, 90^{\circ}, 45^{\circ}$ fibers as constituents. 


\subsection{Application of Strain Energy Model for Fatigue Life Prediction of GFRP Material}

\subsubsection{Model Development}

The model was developed based on strain energy loss per fatigue cycle, considering the fatigue damage curve and the test results obtained during the fatigue tests. Also the fatigue coefficients ' $a$ ' and ' $b$ ' determined by experiments should be constant for glass/vinyl ester FRP subjected to tension-tension fatigue tests that were used to develop the model.

As can be seen from the strain energy curve stage II corresponds to maximum percentage of total fatigue life and since it was linear, the strain energy expended by the material at any cycle was taken as $U_{n}=U_{0}+D$ where $U_{0}$ is the strain energy of the material at the start of fatigue loading and $D$ is the damage function.

From the fatigue test procedure it can be seen that the coupon was taken to mean load before the actual fatigue test started. Strain energy $U_{0}$ can be written as

$$
U_{0}=\frac{P_{\max }^{2} l}{2 A E}
$$

where $P_{\text {mean }}$ is the mean load of the sine waveform, $l$ is the gage length of the coupon, $A$ is the cross-sectional area of the coupon, $E$ is the stiffness obtained during the static test.

The damage function depends on number of fatigue cycles to failure $(N)$, maximum applied strain $\left(\varepsilon_{\text {max. }}\right)$ assuming creep, environmental factors are constant.

$$
D=f\left(N, \varepsilon_{\text {max }}\right)
$$

Also the damage function was developed considering stage II is linear. The damage function can be modified to the form 


$$
D=(\Delta U) N
$$

where $\Delta U$ is the Energy Release Rate (energy loss per cycle) for a particular percentage of applied ultimate load. From the strain energy vs number of cycles to failure curves it can be seen that the energy release rate varies with percentage of applied strain irrespective of the material. So it can be written in the form

$$
\Delta U=a\left(\frac{\varepsilon_{\text {max. }}}{\varepsilon_{u l t .}}\right)^{b}
$$

formatting the trendline to power law where $\varepsilon_{\max }$ is the maximum applied strain, $\varepsilon_{u l t}$. is the ultimate static strain, 'a' and 'b' are fatigue constants. On substituting into it can be modified as

$$
U_{n}=U_{0}+\left(a\left(\frac{\varepsilon_{\text {max. }}}{\varepsilon_{\text {ult. }}}\right)\right)^{b} N
$$

Rearranging and substituting $N=N_{f}, U=U_{f}$ the fatigue life of the material can be computed as

$$
N_{f}=\frac{U_{f}-U_{0}}{a\left(\frac{\varepsilon_{\text {max. }}}{\varepsilon_{\text {ult. }}}\right)^{b}}
$$

where $U_{f}$ is the strain energy at the end of stage II, $N_{f}$ is the number of cycles to failure neglecting stage III which consists of fiber failure. Substituting $U_{f}=1.5 U_{0}$ Number of fatigue cycles to failure can be written as

$$
N_{f}=\frac{1.5 U_{0}-U_{0}}{a\left(\frac{\varepsilon_{\text {max. }}}{\varepsilon_{\text {ult. }}}\right)^{b}}=\frac{0.5 U_{0}}{a\left(\frac{\varepsilon_{\text {max. }}}{\varepsilon_{\text {ult. }}}\right)^{b}}
$$




\subsubsection{Application of Theoretical Model}

The mean strain energy $\left(U_{0}\right)$ for each percentage of strain applied was calculated using the equation (3). The predicted number of cycles to failure was calculated substituting $U_{0},\left(\frac{\varepsilon_{\text {max. }}}{\varepsilon_{\text {ult. }}}\right)$, a and b values in Equation (9) for all normalized strains of different fiber architecture plates which are found using experimental results and presented in Table 3.4. Normalized strain vs logarithmic number of cycles to failure $(\log (\mathrm{Nf}))$ plot was drawn for each fiber architecture plate and compared with the experimental fatigue lives. The experimental fatigue lives were found to be within $15 \%$ of predicted fatigue lives. The plots can be seen in Figure(s) 3.19 and 3.20.

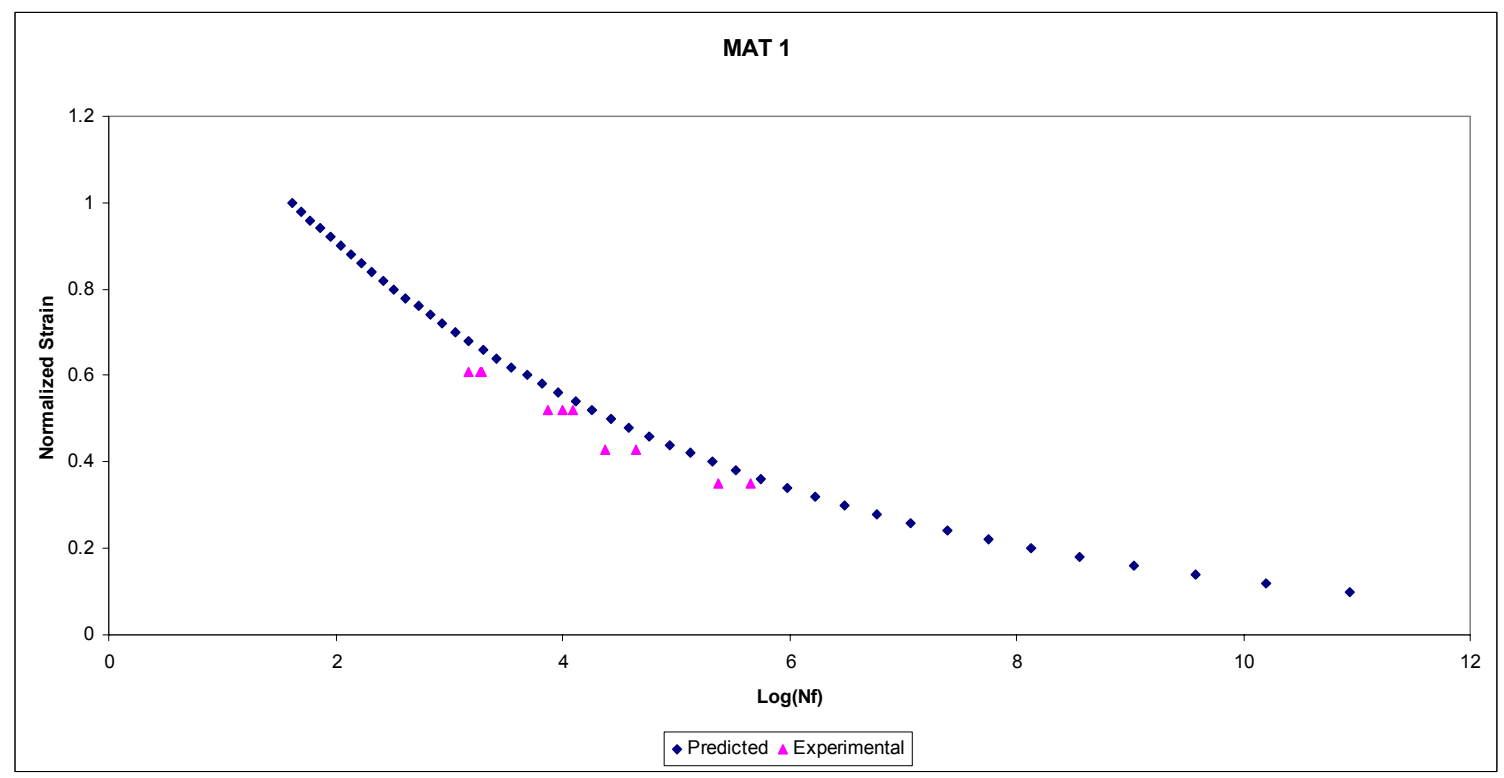

(a) 


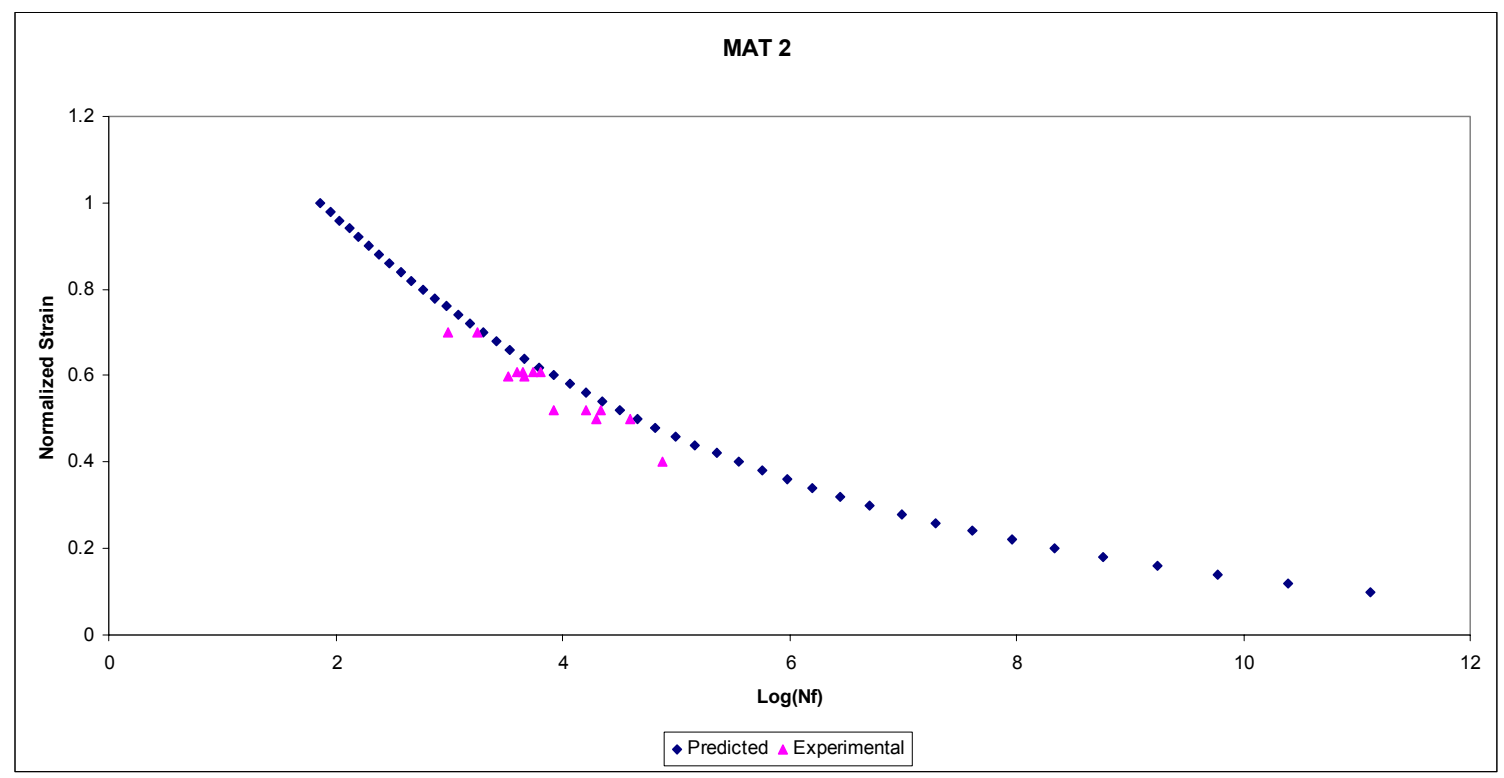

(b)

Figure 3.19 Comparision of Experimental and Predicted Fatigue Lives for MAT 1 and MAT 2

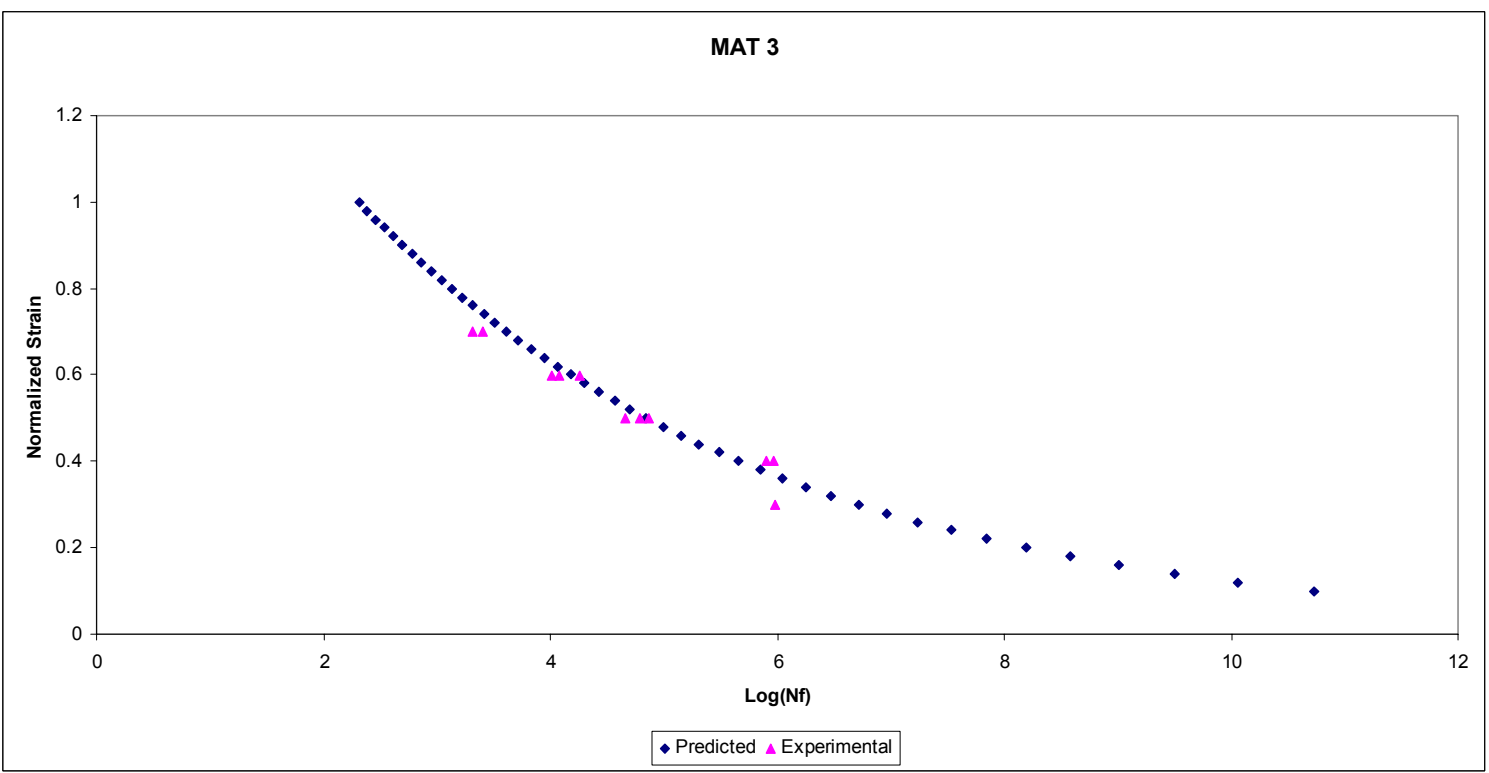

(a)

Figure 3.20 Comparision of Experimental and Predicted Fatigue Lives for MAT 3 


\subsection{Synonymy of Energy Release Rate Between Composites and Metals}

The energy release rate between composites and metals under fatigue loading is similar. In composites the strain energy release rate (due to crack formation and growth from fiber breakage, matrix cracking and debonding between fiber and matrix) can determine the remaining life of the material, especially, under fatigue where the progression of crack growth rate is gradual. The damage processes in composites have three stages as shown in Figure 3.1. In stage I, matrix cracking precedes fiber breakage, which typically is seen to occur only near the ultimate failure of the composites. In stage II the cracks (that occur in Stage I) may grow along the lines/plane of matrix cracking and leads to crack growth progression along the interface of fiber and the matrix, which blunts the crack and enhances the fracture resistance of the composites. In stage II, these interfacial cracks propagate toward the weak plane with stress concentrations and lead to fiber breakage.

Stage II, phenomenon the energy loss/cycle is very gradual due to blunting of cracks. Hence the loss of energy/cycle is much lower than the loss of energy/cycle in stage I where matrix cracking is dominated. This can be observed from Figure 3.13.

Since the energy release rate/cycle in stage II is gradual, and highly dependent on sizing of fiber, that is compatible with the matrix, we have consistently noted only gradual energy release rate/cycle (Figure 3.13). This observation is synominous to energy release rate/unit area in metallic structures which is a product of square of induced stress times the half the length of crack which is normalized with material stiffness. Like in 
metals in composite the energy release rate is not only gradual in stage II due to influence of sizing but also follows the power law. Hence strong co-relation of the proposed energy release rate/cycle is synominous with energy release rate/unit area which follows the power law.

\subsection{Conclusions}

Based on the test data of GFRP composite coupons made of unidirectional fibers, bidirectional fibers, the following conclusions are drawn:

1. Strain Energy Release Rate:

- $\quad$ The strain energy loss per cycle from $2-5 \%$ to $90 \%$ of the FRP composite's fatigue life was found to be approximately $50 \%$ of the strain energy induced at the mean fatigue load level (Table 3.3).

- The strain energy release rate was found to decrease with the decrease in the applied mean strain that was inducing fatigue (Table 3.3).

2. Fiber Volume Fraction:

- For all fatigue strain ranges fiber volume fraction increases the number of cycles to failure decreases. This is attributed to the interfacial bond failure between fibers and resin because resin thickness decreases as the fiber volume fraction increases. 


\section{Strain Range:}

- $\quad$ Number of cycles to failure decreases exponentially with the increase in strain range because the strain energy release rate increases exponentially with strain range in all the test specimens under this program.

4. Manufacturing:

- The fatigue coefficient ' $b$ ' was found to be with in the range of 10-13 for pultrusion process which is evident from earlier studies (Reference 37).

5. Fiber Architecture:

- The energy release rate is lower for unidirectional composites than for bidirectional composites because of overlapping of fibers leading to stress concentration.

6. Fatigue Coefficients:

- The fatigue coefficient ' $b$ ' depends on pliability of the FRP material or component which is a function of resin, shape, voids and other parameters. As can be seen from Table 3.4, 'b' is lower for bidirectional composites than for unidirectional composites.

- It was observed through the power law that the normalized fatigue coefficient, a/Uo (APPENDIX A), was found to decrease with an increase in the applied strain range. 


\section{CHAPTER 4}

\section{FATIGUE TEST ON SINGLE CELL DECK AND MULTI-CELL DECK UNDER FATIGUE LOADING}

\subsection{Introduction}

This chapter presents fatigue evaluation on single cell deck and multi-cell bridge deck which were designed by Constructed facilities Center and manufactured at Bedford Reinforced Plastics Inc. under bending. All the decks tested were manufactured using pultrusion process, made of glass fiber/vinyl ester resin. The strain energy model used in composite materials at coupon level was extended to bridge decks at component level. The single cell deck was tested with $30 \%, 50 \%, 70 \%$ of ultimate load and multi-cell bridge deck was tested with $30 \%$ of ultimate load until 2 million cycles then $50 \%$ was applied until 1 million cycles after which $70 \%$ of ultimate load was applied and tested till failure. Another test was conducted on multi-cell deck with $35 \%$ of its ultimate load.

\subsection{Fatigue Tests on Single Cell Deck}

\subsubsection{Description of the Deck}

The deck dimensions are as shown in Figure 4.1. The deck was cut from 4 inch 3 cell deck which was manufactured in Bedford Reinforced plastics Inc. by Pultrusion process. The deck was made of glass fiber/vinyl ester resin. The cross-section of the deck is as shown in Figure 4.1. The single cell deck used was $6 \mathrm{ft}$. long, 6.22" wide. 


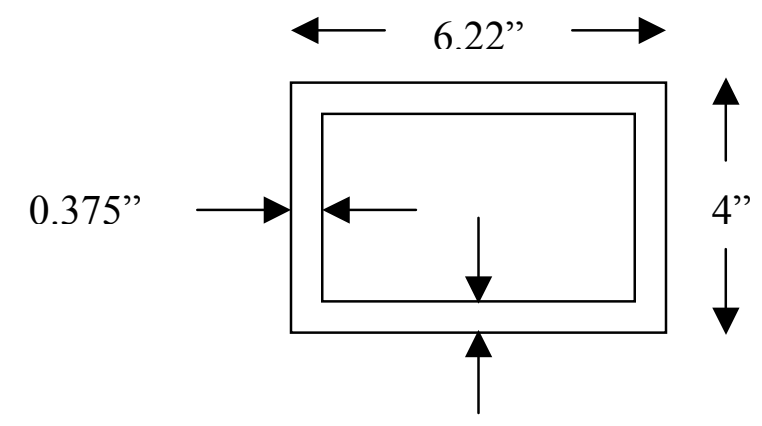

$0.43 "$

Figure 4.1 Cross-Section of the Single Cell Deck

\subsubsection{Testing Equipment}

The equipments used for fatigue test were MTS Hydraulic actuator, and MTS 407 controller, MTS Hydraulic pump. The test setup for the fatigue test is shown in Figure 4.2. The parameters required for static and fatigue test (maximum load, minimum load, set point, span, frequency, sine waveform) were controlled using MTS 407 controller. The MTS hydraulic actuator was used to apply load on the composite deck through hydraulic pump and 407 controller. The capacity of MTS Hydraulic actuator was 55 kips.

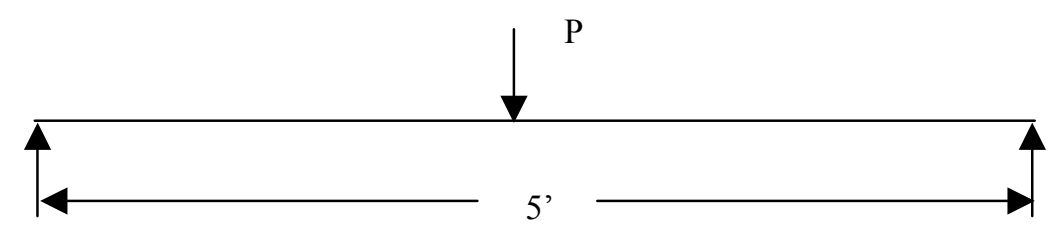

(a) 


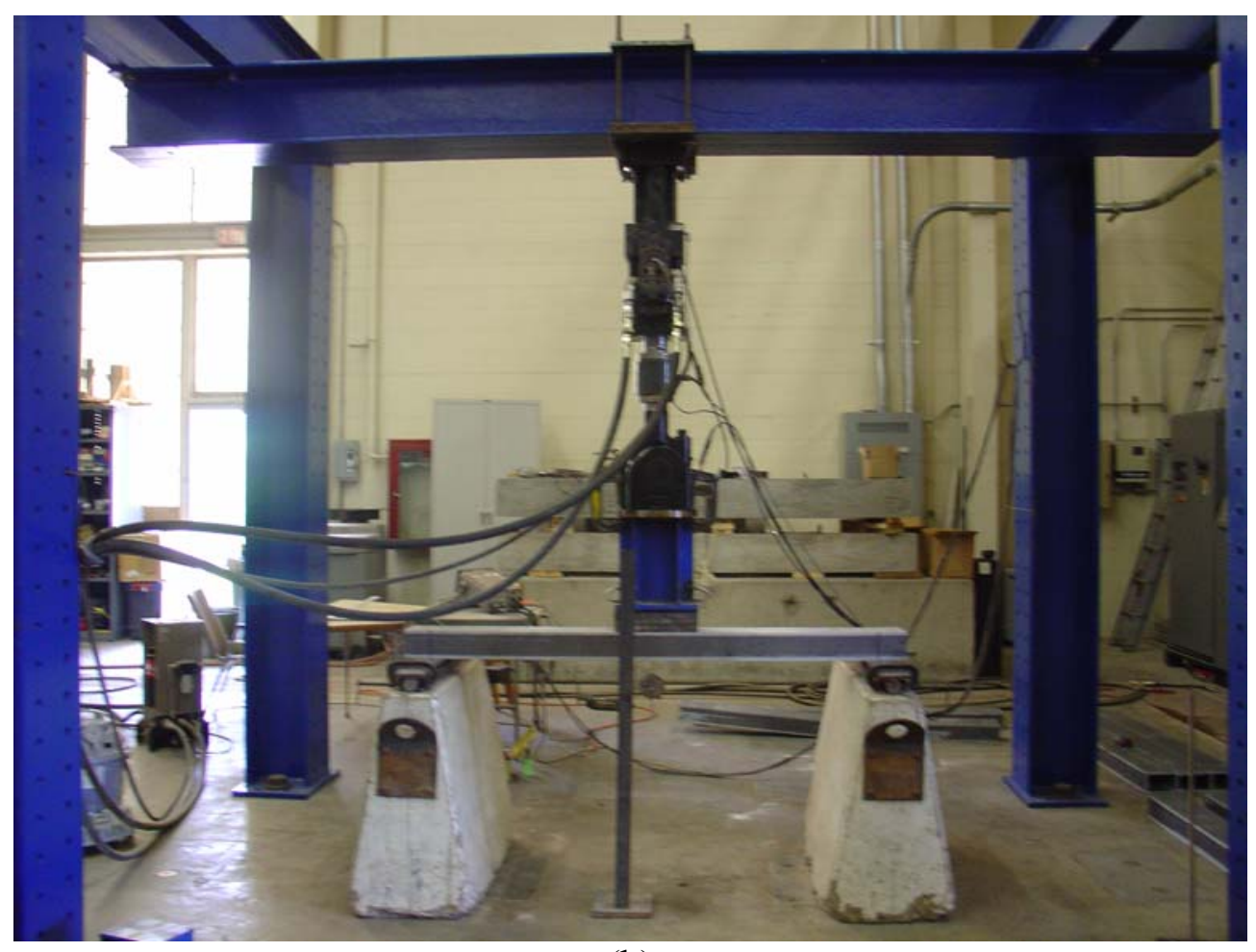

(b)

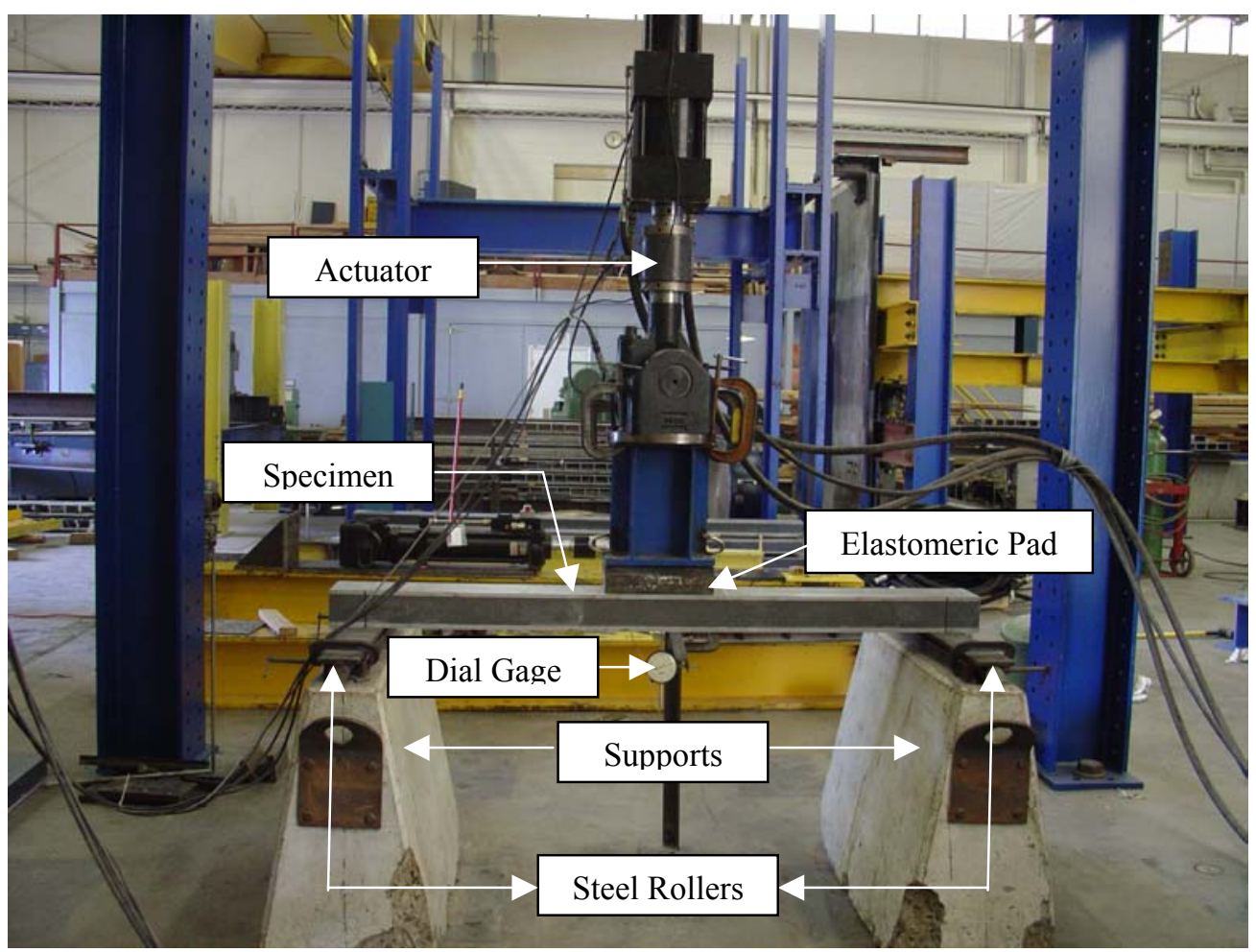

(c) 
Figure 4.2 Fatigue Test Set Up of Single Cell Deck

\subsubsection{Support Conditions:}

The deck was placed on two steel plates which are mounted on 2 supports with steel rollers sandwiched between them to simulate simply supported conditions and to provide firm base for the test setup. The center to center distance between the steel rollers was maintained as $5 \mathrm{ft}$ as shown in Figure 4.2.

\subsubsection{Loading Conditions:}

A patch load (12"*6”) was applied using steel plate on the deck through hydraulic actuator which has load cell attached to it to monitor the load applied on the deck. Elastomeric Pads were used between the actuator and deck to apply uniformly distributed load on the deck to be tested.

\subsubsection{Static Test:}

A patch load of $12 " * 6$ " was placed at the center of the deck to avoid direct contact of actuator with the specimen. The load was applied using MTS 407 controller and strain, deflection readings were noted at predetermined intervals using strain indicator and dial gage. A graph was drawn between load vs strain, load vs deflection using the load, strain, deflection data noted at regular intervals. The bending stiffness $(E)$ was calculated using the equation

$E=(p * l * c) /(4 * \varepsilon * I)$ based on deflection

$E=\left(p^{*} l^{\wedge} 3\right) /(48 * \delta * I)$ based on strain 
where $\left(\frac{P}{\delta}\right) \&\left(\frac{P}{\varepsilon}\right)$ are the slopes of load vs deflection $\&$ load vs strain curves, $l$ is the support span (60 inches), $I$ is the moment of inertia $\left(19.06 \mathrm{in}^{\wedge} 4\right), c$ is distance from the center of the deck to the outer end ( 2 inches). The moment of inertia is calculated using the equation $I=\left(\frac{b_{1} * d_{1}^{3}}{12}\right)-\left(\frac{b_{2} * d_{2}^{3}}{12}\right)$ where $b_{1}=6.22, d_{1}=4, b_{2}=5.47, d_{2}=3.14$; all are in inches.

Table 4.1 Static Test Results for Single Cell Deck

\begin{tabular}{|l|c|c|c|c|}
\hline & $\begin{array}{c}\text { Ultimate Load, } \\
\text { kips }\end{array}$ & $\begin{array}{c}\text { Ultimate } \\
\text { Stress, ksi }\end{array}$ & $\begin{array}{c}\text { EI*10 }^{8} \mathrm{lb}^{-\mathrm{in}^{2}} \\
(\text { Based on } \\
\text { Strain) }\end{array}$ & $\begin{array}{c}\mathrm{EI}^{*} 10^{8} \mathrm{lb}-\mathrm{in}^{2} \\
\text { (Based on } \\
\text { Deflection) }\end{array}$ \\
\hline $\begin{array}{l}\text { Single Cell } \\
\text { Deck }\end{array}$ & 21 & 33 & 0.71 & 0.73 \\
\hline
\end{tabular}

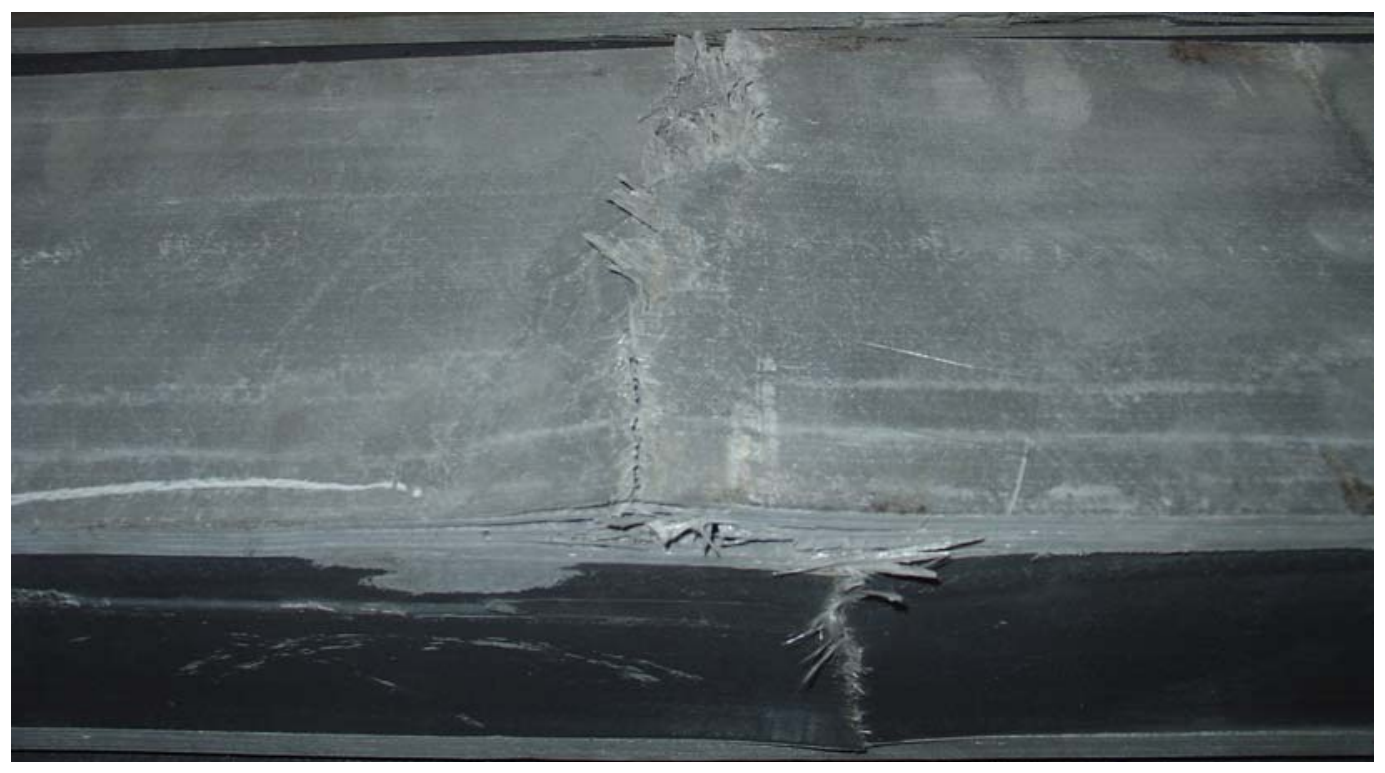

Figure 4.3 Static Failure Mode of Single Cell Deck under Bending 


\subsubsection{Fatigue Test}

The set up for fatigue test is same as static test. The parameters (set point, span, frequency) were given using MTS 407 controller. The set point is the mean load, span is the amplitude of the sine waveform. The percentage of ultimate loads applied during the fatigue tests were $30 \%, 50 \%, 70 \%$. The deck was tested under sinusoidal loading with frequency $1 \mathrm{HZ}$ and at a stress ratio of 0.1 . The static tests were conducted at predetermined number of cycles, deflection and strain readings were noted at the percentage of the load applied. The strain gages were fixed at the center on both top and bottom flanges and dial gage at the center of bottom flange. The stiffness and strain energy are calculated using the Equations

$$
\begin{aligned}
& E=\left(\frac{p^{*} l^{\wedge} 3}{48^{*} \delta^{*} I}\right) \\
& U=\left(\frac{p^{\wedge} 2^{*} l^{\wedge} 3}{96^{*} E^{*} I}\right)
\end{aligned}
$$

where $E$ is the stiffness, $U$ is the internal strain energy, $p$ is the load applied, $l$ is the span length (108 in.), $\delta$ is the deflection, and $I$ is the moment of inertia of the deck (19.06 in^4).

\subsubsection{Test Results and Discussion}

The crack started in the top flange of the deck on either sides from the center as shown in Figure 4.5(a) after certain number of cycles (approximately $10 \%$ of total number of cycles) depending on the percentage of the load applied. The crack progressed towards the supports on either sides from the center which also was a factor of applied percentage load. Then the layers of the top flange separated, crack progressed towards 
the bottom flange through the web as shown in Figure 4.5 (b). and failed due to delamination as shown clearly in Figure 4.5(c). There was buckling on one side due to more crack progression on that side than the other. The deck failed after 2620000 cycles for $30 \%$, after 1524 cycles for $50 \%$ and 208 cycles for $70 \%$ of application of load. Since all the single cell decks tested were cut from a multi-cell deck the deck failed prematurely with less number of cycles as cutting from multi-cell deck affects the bond strength between fiber and matrix.

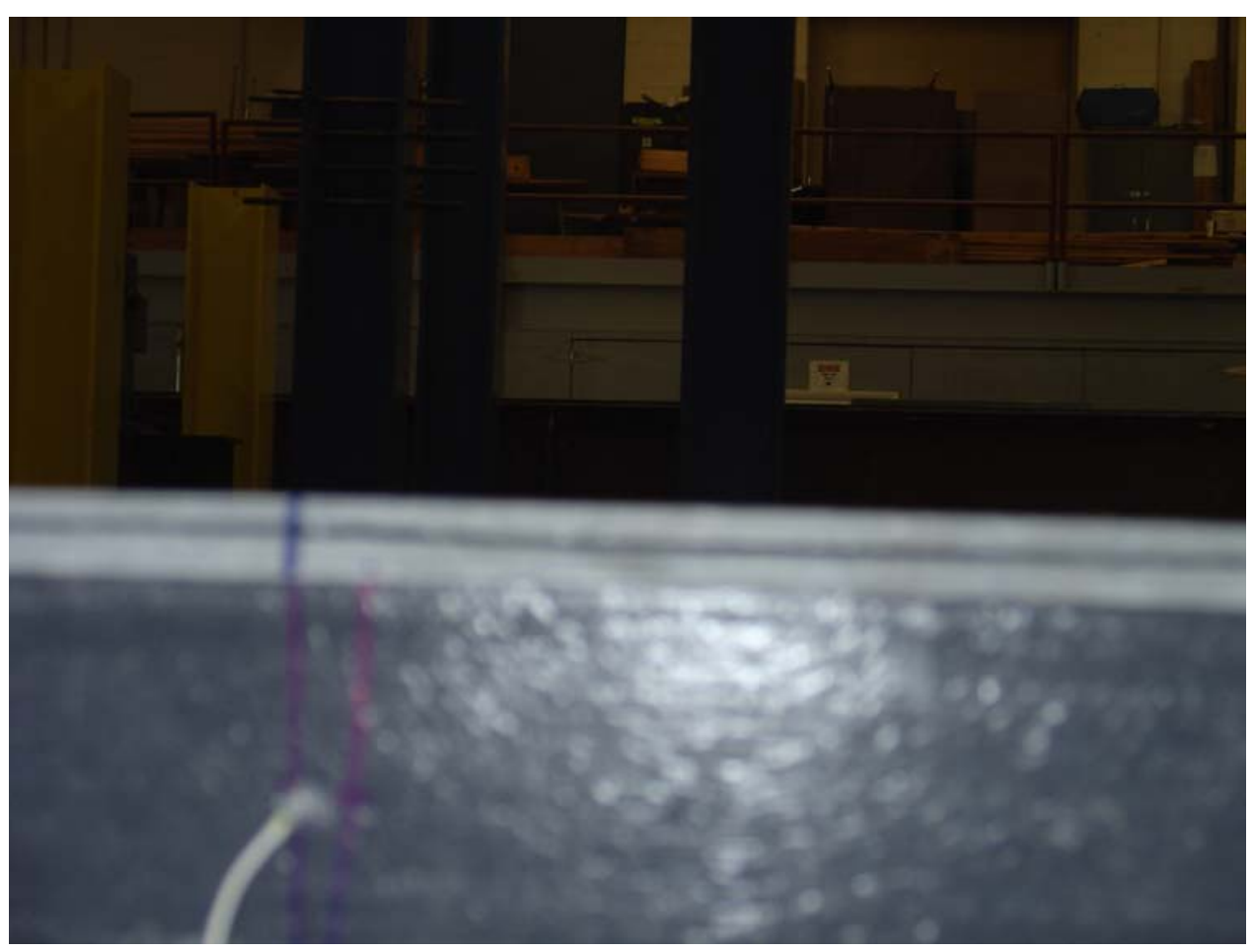

(a) 


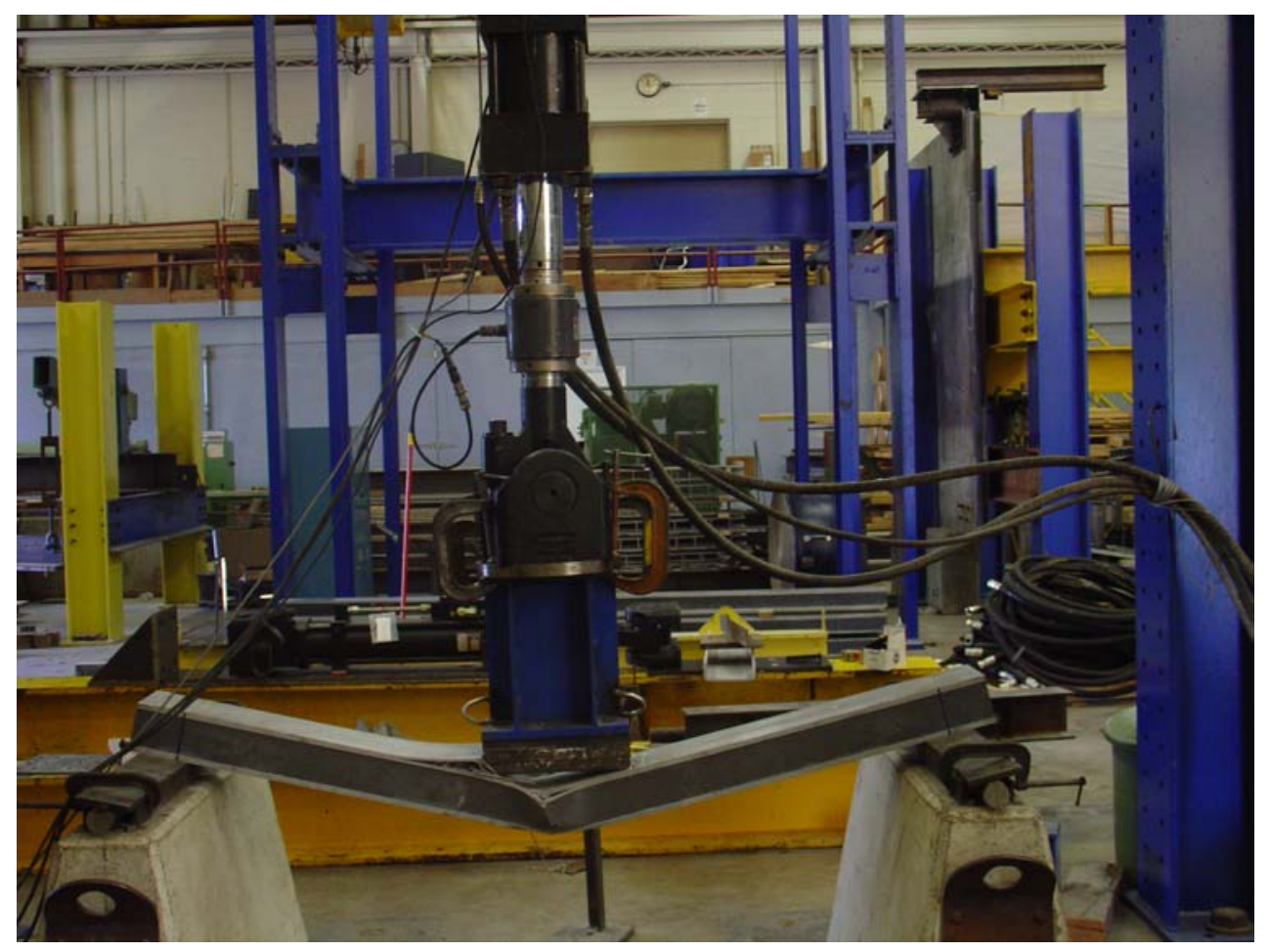

(b)

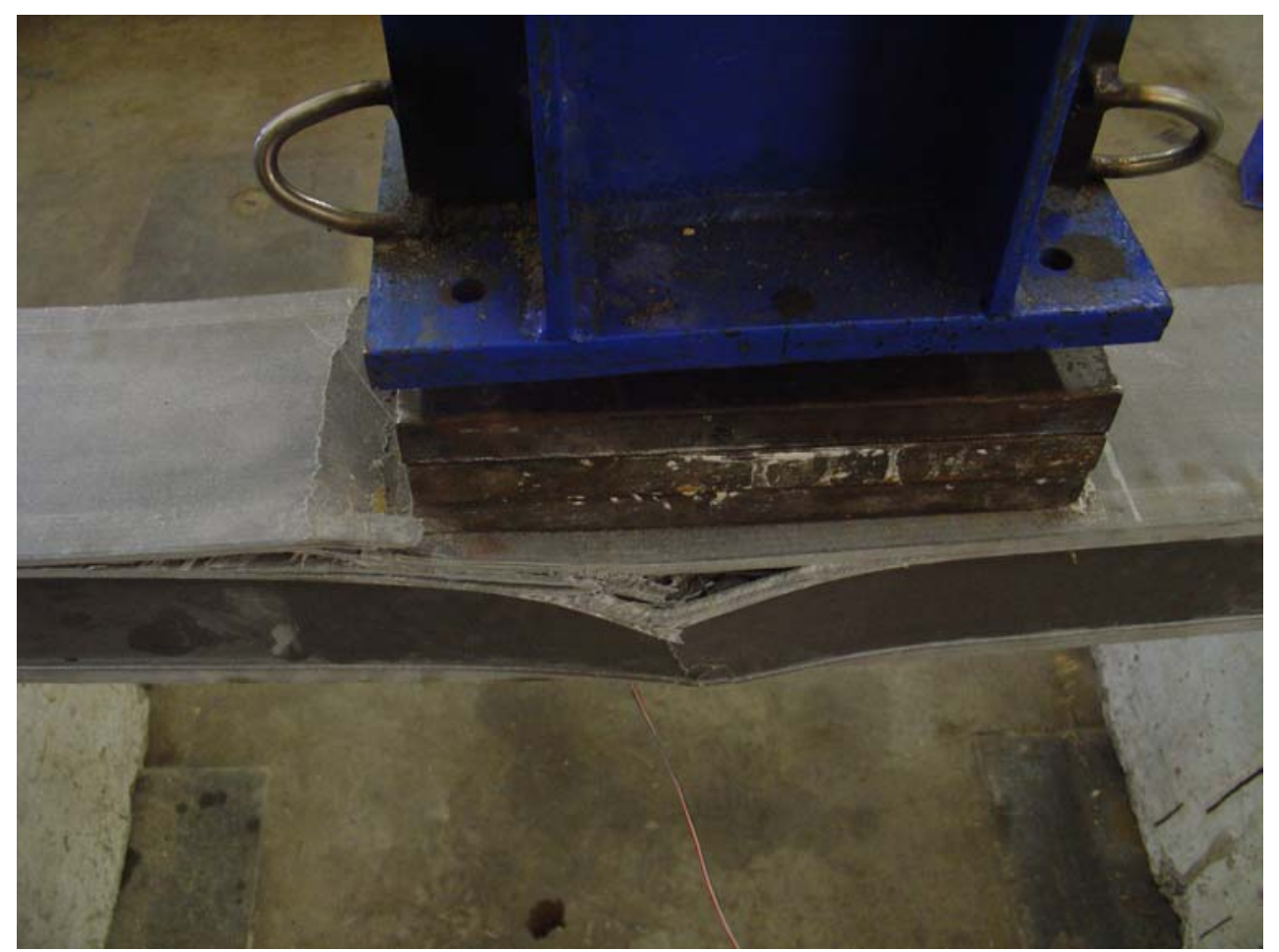

(c)

Figure 4.4 Fatigue Failure Mode of Single Cell Deck under Bending 


\subsubsection{Internal Strain Energy, Strain Energy Release Rate and Fatigue Coefficients}

The internal strain energy was calculated using the deflection, strain values noted at predetermined cycles. Before calculating Internal strain energy the bending stiffness ( $E$ ) was calculated using the equations (1) and (2), $p$ is the fatigue load applied, $\delta$ and $\varepsilon$ are deflection and strain at that fatigue load and predetermined cycles. The internal strain energy $(U)$ is calculated using the equation $U=\left(p^{\wedge} 2 * l^{\wedge} 3\right) /\left(96^{*} E^{*} I\right)$. The stiffness and internal strain energy values are presented in Table 4.2, 4.3 and 4.4. The strain energy vs normalized number of cycles plot for a single cell deck with strain ratios $30 \%$, $50 \%, 70 \%$ is presented in Figure 4.5. The slope of the strain energy vs number of cycles gives the energy release rate (energy loss per cycle). The energy release rate of the single cell deck for strain ratios $30 \%, 50 \%, 70 \%$ is presented in Table 4.5 . As can be seen from the Table 4.5 the energy release rate increases with the increase in the percentage of application of the strain which means strain energy loss per cycle is more under $70 \%$ of application of strain than $50 \%$ followed by $30 \%$. A graph is drawn between Energy release rate vs Normalized strain and fitted using the power law to find the fatigue coefficients ' $a$ ' and ' $b$ ' as shown in Figure 4.6. The fatigue coefficients for single cell deck are tabulated in Table 4.6. 
Table 4.2 Stiffness and Strain Energy Values at Predetermined Number of Cycles for Single Cell Deck at 30\% of Ultimate Load

\begin{tabular}{|c|c|c|}
\hline $\begin{array}{c}\text { Number of Cycles, } \\
\mathrm{N}\end{array}$ & $\begin{array}{c}\mathrm{E} * 10^{6} \text { (Based on } \\
\text { Deflection), } \mathrm{psi}\end{array}$ & $\begin{array}{c}\text { U (Based on Deflection), } \\
\text { lb-in }\end{array}$ \\
\hline 0 & 3.79 & 1236 \\
\hline 100000 & 3.75 & 1273 \\
\hline 300000 & 3.68 & 1297 \\
\hline 500000 & 3.61 & 1320 \\
\hline 800000 & 3.55 & 1359 \\
\hline 1200000 & 3.45 & 1404 \\
\hline 1600000 & 3.3 & 1456 \\
\hline 2000000 & 3.21 & \\
\hline
\end{tabular}

Table 4.3 Stiffness and Strain Energy Values at Predetermined Number of Cycles for Single Cell Deck at $50 \%$ of Ultimate Load

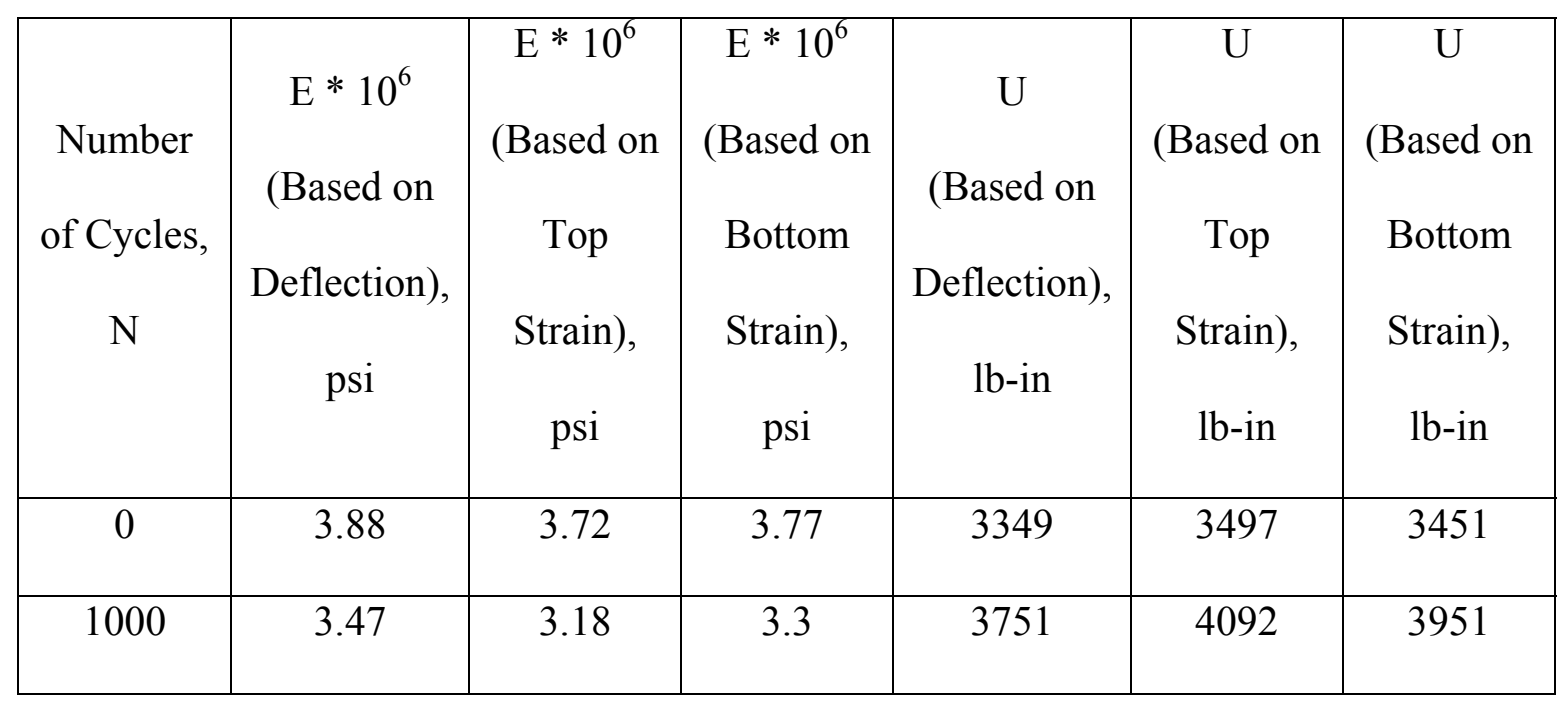


Table 4.4 Stiffness and Strain Energy Values at Predetermined Number of Cycles for Single Cell Deck at 70\% of Ultimate Load

\begin{tabular}{|c|c|c|c|c|c|c|}
\hline $\begin{array}{c}\text { Number } \\
\text { of Cycles, } \\
\text { N }\end{array}$ & $\begin{array}{c}\mathrm{E} * 10^{6} \\
\text { (Based on } \\
\text { Deflection), } \\
\text { psi }\end{array}$ & $\begin{array}{c}\mathrm{E}^{*} 10^{6} \\
\text { (Based on } \\
\text { Top } \\
\text { Strain), } \\
\text { psi }\end{array}$ & $\begin{array}{c}\mathrm{E}^{*} 10^{6} \\
\text { (Based on } \\
\text { Bottom } \\
\text { Strain), } \\
\text { psi }\end{array}$ & $\begin{array}{c}\mathrm{U} \\
\text { (Based on } \\
\text { Deflection), } \\
\text { lb-in }\end{array}$ & $\begin{array}{c}\text { U } \\
\text { (Based on } \\
\text { Top } \\
\text { Strain), } \\
\text { lb-in }\end{array}$ & $\begin{array}{c}\mathrm{U} \\
\text { (Based on } \\
\text { Bottom } \\
\text { Strain), } \\
\text { lb-in }\end{array}$ \\
\hline 0 & 3.82 & 3.69 & 3.75 & 6675 & 6910 & 6799 \\
\hline 150 & 3.34 & 3.05 & 3.2 & 7643 & 8361 & 7956 \\
\hline
\end{tabular}

Table 4.5 Energy Release Rate of Single Cell Deck for

Different Percentage of Ultimate Strain

\begin{tabular}{|c|c|c|}
\hline \% Ultimate Strain & Energy Release Rate & Energy Release Rate/a \\
\hline 0.3 & 0.0001 & 0.00000007 \\
\hline 0.5 & 0.402 & 0.00028 \\
\hline 0.7 & 6.4533 & 0.0045 \\
\hline
\end{tabular}




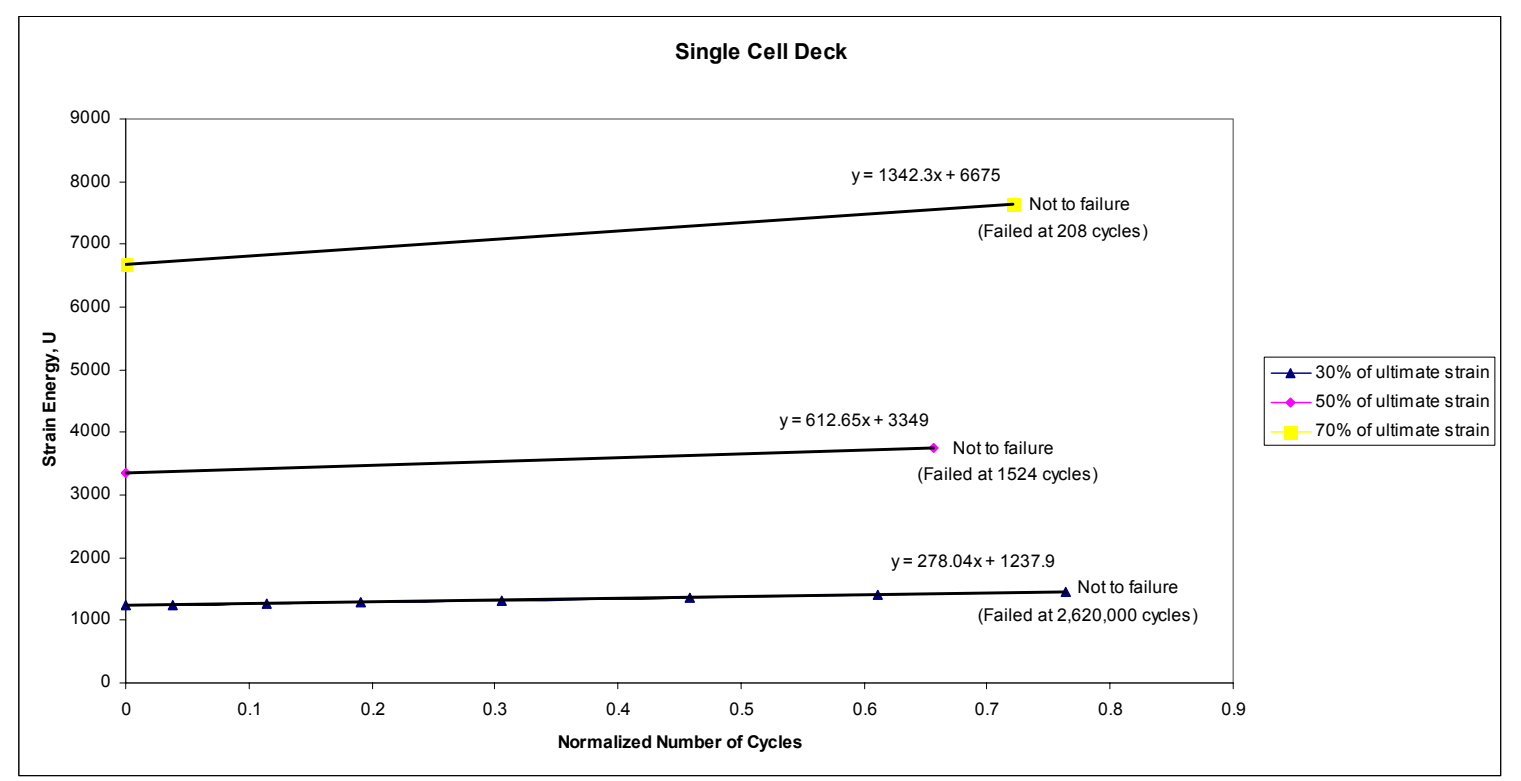

Figure 4.5 Strain Energy, U vs Normalized Number of Cycles, $\left(\mathrm{N} / \mathrm{N}_{\mathrm{f}}\right)$ for a Single Cell Deck

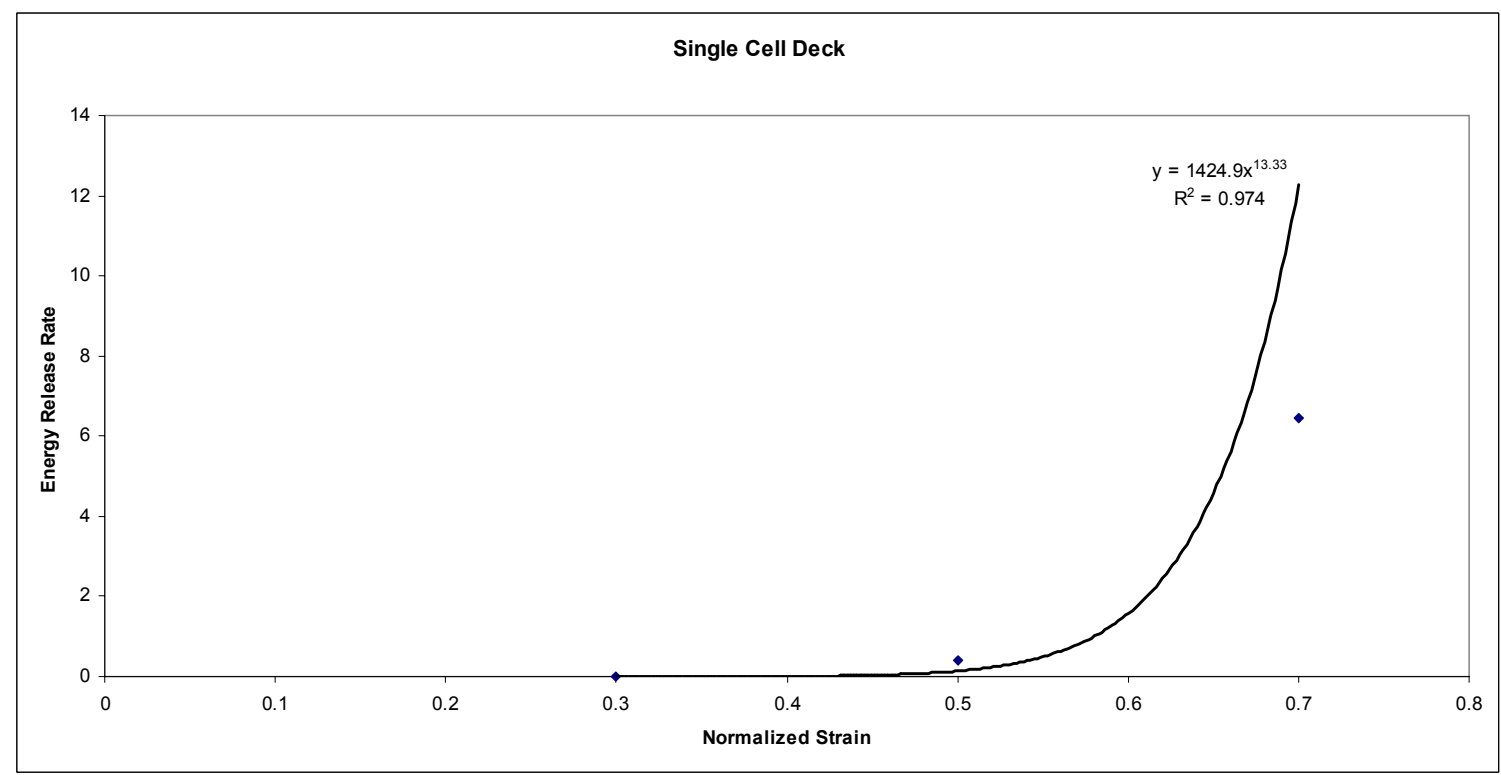

Figure 4.6 Variation of Strain Energy Release Rate with Normalized Strain for Single Cell Deck 
Table 4.6 Fatigue Coefficients for Single Cell Deck

\begin{tabular}{|l|c|c|}
\hline \multirow{2}{*}{ Single Cell Deck } & a & $\mathrm{b}$ \\
\cline { 2 - 3 } & 1424.9 & 13.33 \\
\hline
\end{tabular}

\subsubsection{Application of Strain Energy Model Developed for Single Cell Deck}

The strain energy model developed was applied to compare experimental fatigue life with the predicted fatigue life. The mean strain energy $\left(U_{0}\right)$ for each percentage of strain applied was calculated using the equation (5) where $p$ is the mean load applied. The predicted number of cycles to failure was calculated substituting $U_{0},\left(\frac{\varepsilon_{\max .}}{\varepsilon_{\text {ult. }}}\right)$, a and b values (Table 4.6) in Equation $N_{f}=\frac{0.5 U_{0}}{a\left(\frac{\varepsilon_{\max .}}{\varepsilon_{u l t .}}\right)^{b}}$ for all strain ratios. Normalized strain vs logarithmic number of cycles to failure $(\log (\mathrm{Nf}))$ plot was drawn for experimental and predicted data as shown Figure 4.7. 


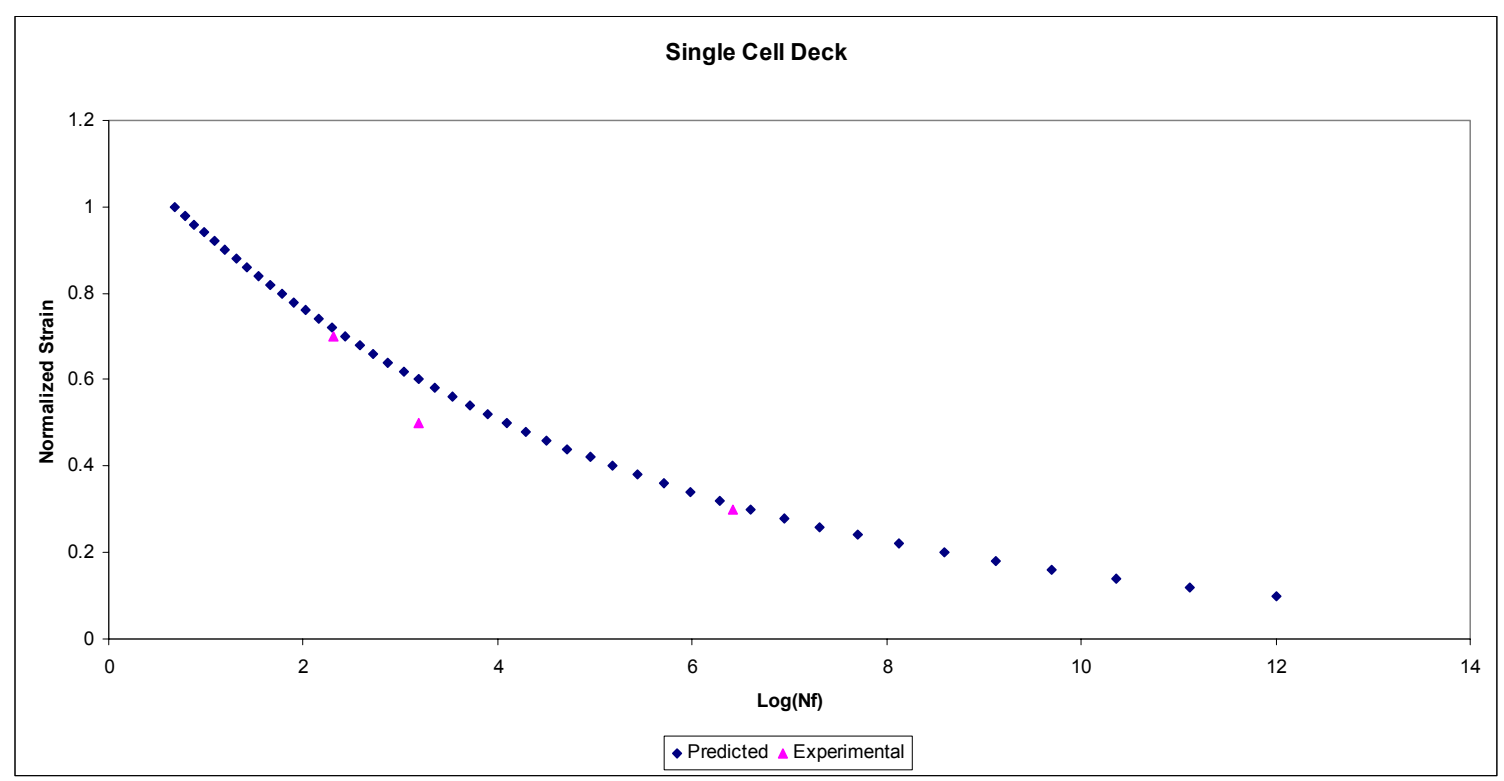

Figure 4.7 Comparision of Experimental and Predicted Fatigue Lives for Single Cell Deck

\subsection{Fatigue Test on 4" deep Multi-Cell FRP Bridge Deck}

\subsubsection{Cross-Section of the Deck}

The cross-section of the low-profile FRP bridge deck is shown in Figure 4.8 (a), (b). The deck is manufactured by Pultrusion process in Bedford Reinforced plastics Inc. The material used in the deck are Glass fiber, vinyl ester resin. The deck weighs about $10 \mathrm{lb} / \mathrm{ft}^{2}$ and has fiber volume fraction of approximately $50 \%$ and Moment of Inertia for 2' wide deck is $69.95 \mathrm{in}^{4}$. 


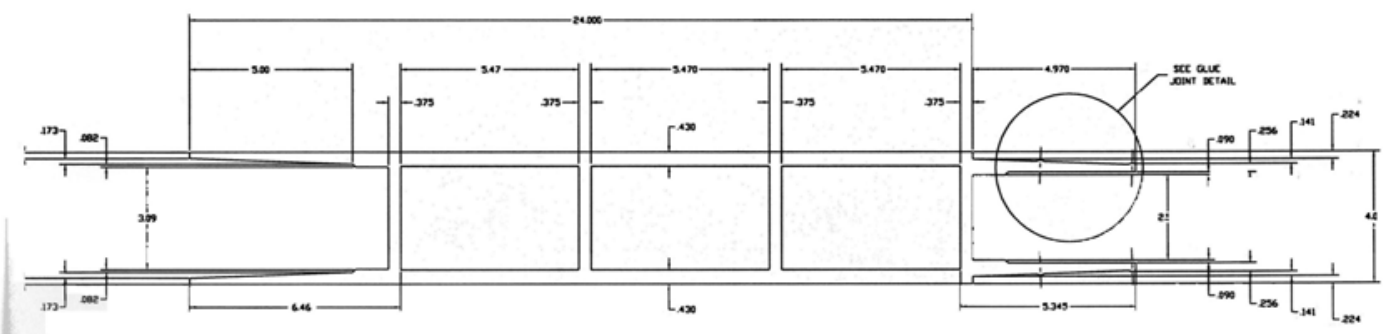

$\underline{\text { PRODECK }-4}$

(a)

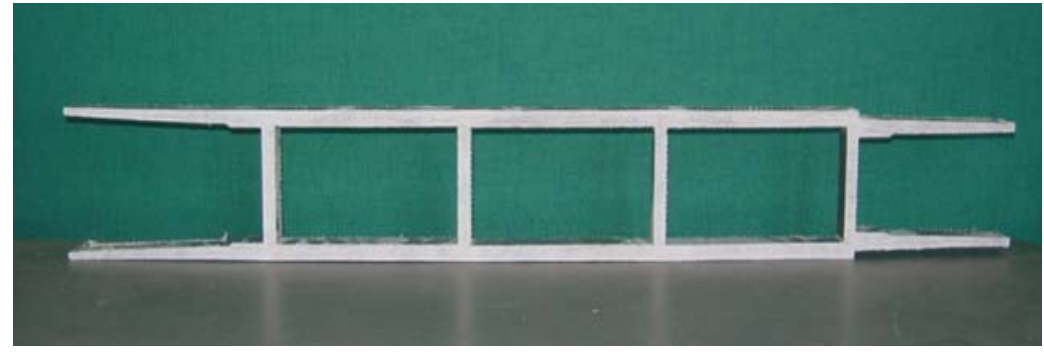

(b)

Figure 4.8 Cross-Section of Multi-Cell FRP Bridge Deck

\subsubsection{Static Test}

The test set up, procedure, equipment used for testing the deck was same as that of single cell deck. The support span used for testing the multi-cell deck is 9" and patch load is $20 " * 10 "$ to simulate AASHTO's HS25 load. The static test results were as per study conducted by Punyamurthula's ${ }^{29}$. The average ultimate static load, Bending Stiffness, Bending Rigidity were found to be $36.5 \mathrm{kips}, 3.83 * 10^{6} \mathrm{lb} / \mathrm{in}^{2}, 2.67 * 10^{8} \mathrm{lb}-\mathrm{in}^{2}$ respectively. 


\subsubsection{Fatigue Test}

The test procedure, stress ratio used for performing the fatigue test on multi-cell deck is same as single cell deck. The frequency used was $1 \mathrm{HZ}$ when the test was conducted at $30 \%$ of ultimate load and $0.5 \mathrm{HZ}$ at $50 \%$ and $70 \%$ of ultimate load. The frequency was changed at higher loads because of excessive vibration. Two decks were tested under fatigue with strain ratio $35 \%$ on one deck, $30 \%$ up to 2 million cycles then $50 \%$ to 1 million cycles and finally $70 \%$ to failure on the second deck. The strain and deflection values were noted at predetermined number of cycles to evaluate reduction in bending stiffness and to find out internal strain energy loss for each percentage of application of ultimate strain. The position of the dial gage and strain gages is same as for single cell deck. The test set up is as shown in Figure 4.9.

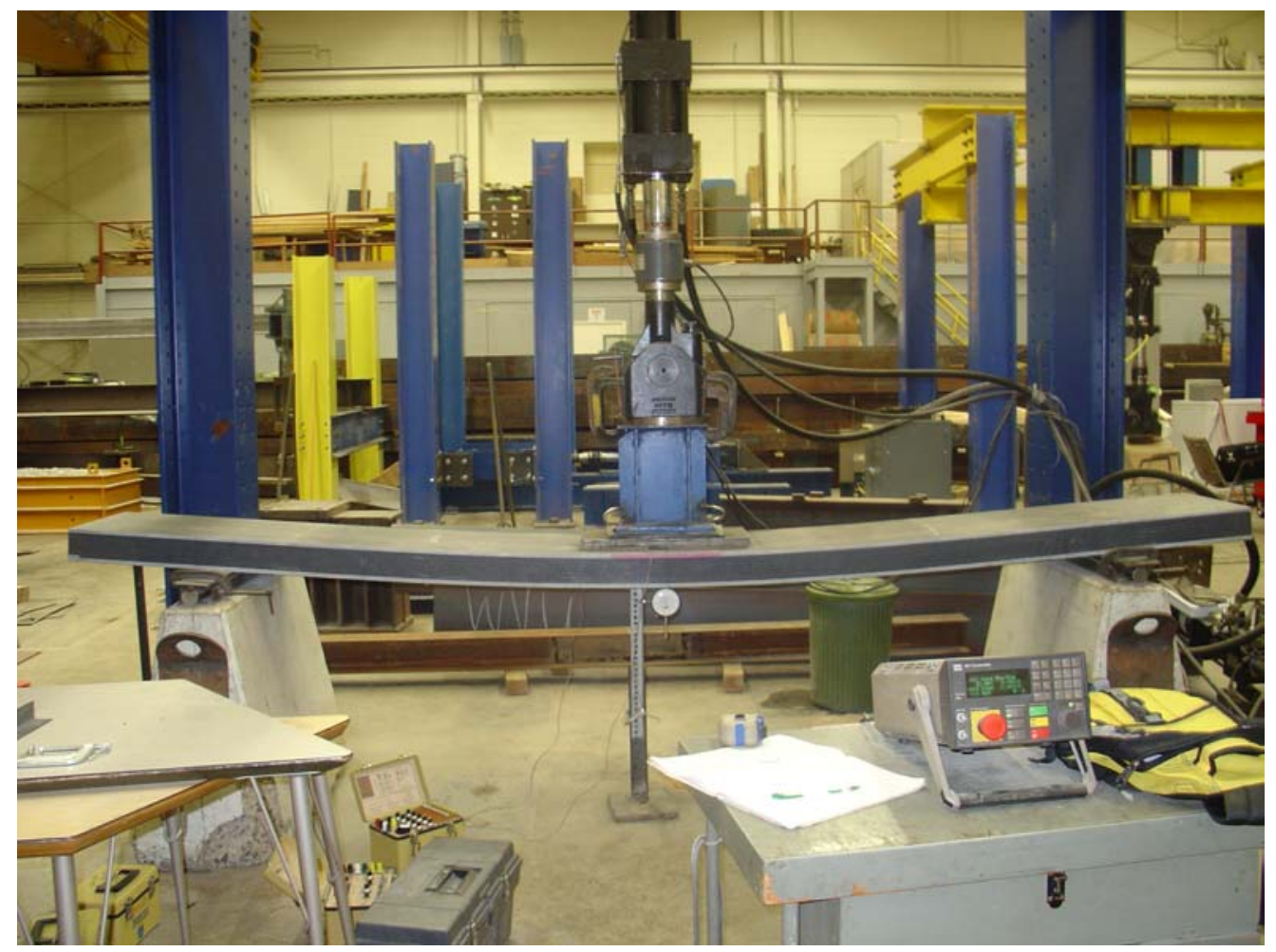

Figure 4.9 Fatigue Test Set Up of a Multi-Cell FRP Bridge Deck 


\subsubsection{Test Results and Discussion}

\subsubsection{Test 1}

In the Test 1 the percentage of ultimate load applied was $35 \%$ of 36.5 which is 12.775 kips. The test was continued for 2 million cycles after which it was stopped as there was only $3 \%$ increase in strain energy with no visible crack in the deck. The strain energy and stiffness values found at predetermined number of cycles are presented in Table 4.7.

Table 4.7 Stiffness and Strain Energy Values at Predetermined Number of Cycles for Multi-Cell Deck at $35 \%$ of Ultimate Load

\begin{tabular}{|c|c|c|c|c|c|c|}
\hline \multirow{2}{*}{ Number } & $\mathrm{E}^{*} 10^{6}$ & $\mathrm{E} * 10^{6}$ & $\mathrm{E}^{*} 10^{6}$ & $\mathrm{U}$ & $\mathrm{U}$ \\
of Cycles, & (Based on & (Based on & (Based on & & (Based on & (Based on \\
$\mathrm{N}$ & Deflection), & Top & Bottom & Top & Bottom \\
& psi & Strain), & Strain), & Deflection), & Strain), & Strain), \\
\hline 0 & 3.84 & 3.79 & 3.75 & 7973 & 8077 & 8164 \\
\hline 300000 & 3.81 & 3.78 & 3.73 & 8024 & 8105 & 8198 \\
\hline 600000 & 3.8 & 3.74 & 3.71 & 8052 & 8176 & 8231 \\
\hline 1000000 & 3.78 & 3.7 & 3.7 & 8104 & 8268 & 8274 \\
\hline 1300000 & 3.75 & 3.69 & 3.68 & 8156 & 8305 & 8316 \\
\hline 1600000 & 3.74 & 3.66 & 3.65 & 8188 & 8369 & 8387 \\
\hline 2000000 & 3.72 & 3.63 & 3.62 & 8227 & 8425 & 8466 \\
\hline
\end{tabular}




\subsubsection{Test 2}

The deck used for Test 2 had overhang on either side of the test specimen. Therefore only 3 cells were used to calculate moment of inertia $\left(53.18 \mathrm{in}^{4}\right)$. The ultimate load for Prodeck with overhang was found to be $36.5 \mathrm{kips}^{29}$, using this ultimate load and considering the linear relationship between load and moment of inertia the ultimate load of the deck with no overhang was calculated and found to be 27.75 kips. In the Test 2 the deck was fatigued to 2 million cycles with $30 \%$ of its ultimate load and then additional one million cycles with $50 \%$ of ultimate load was applied before increasing the load to $70 \%$ of ultimate load.

The crack started in the top flange on either side from the center of the test specimen and progressed towards the supports. The length of the crack was 4 in. on either side from the center of specimen for $30 \%$ of application of load until 2 million cycles. The crack progressed for about 20 in. on each side of the patch load and stopped progressing. As the fatigue testing was continued with $70 \%$ of its ultimate load, the crack progressed towards the supports and failed in top flange buckling, especially on one top side. The failure modes are shown in Figure 4.10. The internal strain energy and stiffness values are presented in Table 4.8. The strain gages failed before 2 million cycles so the values are calculated based on deflection readings. 


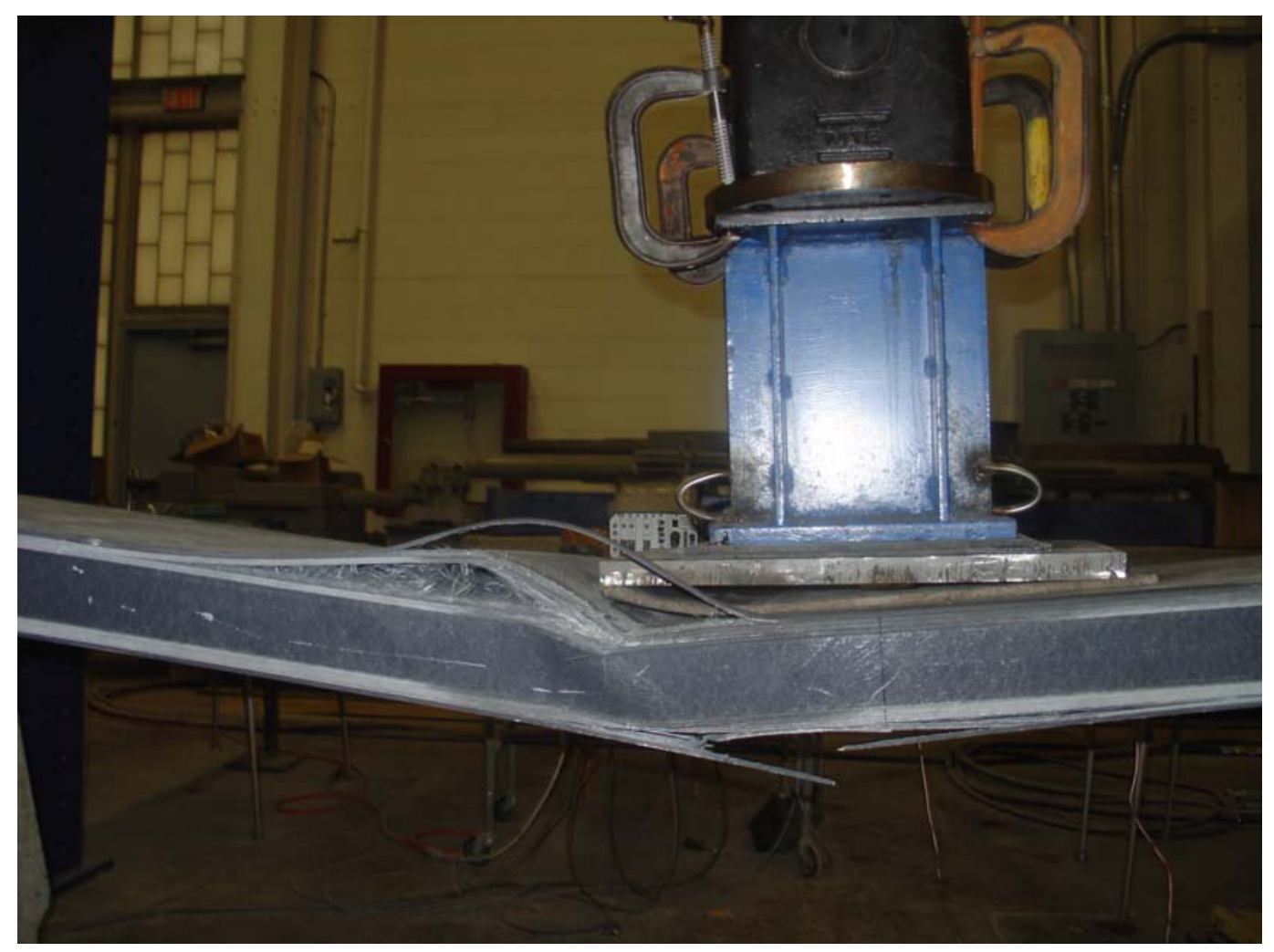

Figure 4.10 Fatigue Failure Mode of Deck for Test 2

Table 4.8 Strain Energy and Stiffness Values of Multi-Cell Deck for Test 2

(a)

\begin{tabular}{|c|c|c|}
\hline \multirow{2}{*}{ Number of Cycles, N } & $\mathrm{E}^{*} 10^{6}$ & $\mathrm{U}$ \\
& (Based on Deflection), psi & (Based on Deflection), lb-in \\
\hline 0 & 3.86 & 4425 \\
\hline 300000 & 3.83 & 4460 \\
\hline 600000 & 3.81 & 4486 \\
\hline 1000000 & 3.76 & 4548 \\
\hline 1500000 & 3.71 & 4606 \\
\hline 2000000 & 3.66 & 4663 \\
\hline
\end{tabular}


(b)

\begin{tabular}{|c|c|c|}
\hline $\begin{array}{c}\text { Number of Cycles, } \mathrm{N} \\
\text { (Based on Deflection), psi }\end{array}$ & $\begin{array}{c}\mathrm{U} \\
\text { (Based on Deflection), lb-in }\end{array}$ \\
\hline 0 & 3.05 & 15574 \\
\hline 200000 & 2.95 & 16102 \\
\hline 400000 & 2.87 & 16553 \\
\hline 600000 & 2.79 & 17023 \\
\hline 800000 & 2.74 & 17218 \\
\hline 1000000 & 2.67 & 17755 \\
\hline
\end{tabular}

(c)

\begin{tabular}{|c|c|c|}
\hline $\begin{array}{c}\text { Number of Cycles, } \mathrm{N} \\
\text { (Based on Deflection), psi }\end{array}$ & $\begin{array}{c}\mathrm{U} \\
\text { (Based on Deflection), lb-in }\end{array}$ \\
\hline 0 & 2.64 & 35267 \\
\hline 15000 & 2.56 & 36339 \\
\hline 30000 & 2.48 & 37542 \\
\hline 45000 & 2.36 & 39458 \\
\hline 60000 & 2.2 & 42320 \\
\hline
\end{tabular}




\subsubsection{Strain Energy Release Rate and Fatigue Coefficients for a Multi-Cell Deck}

The strain energy release rate and fatigue coefficients are found by plotting a graph between strain energy vs number of cycles and energy release rate vs normalized strain as shown in Figure(s) 4.11, 4.12 and 4.13 using the deflection values noted at predetermined cycles.

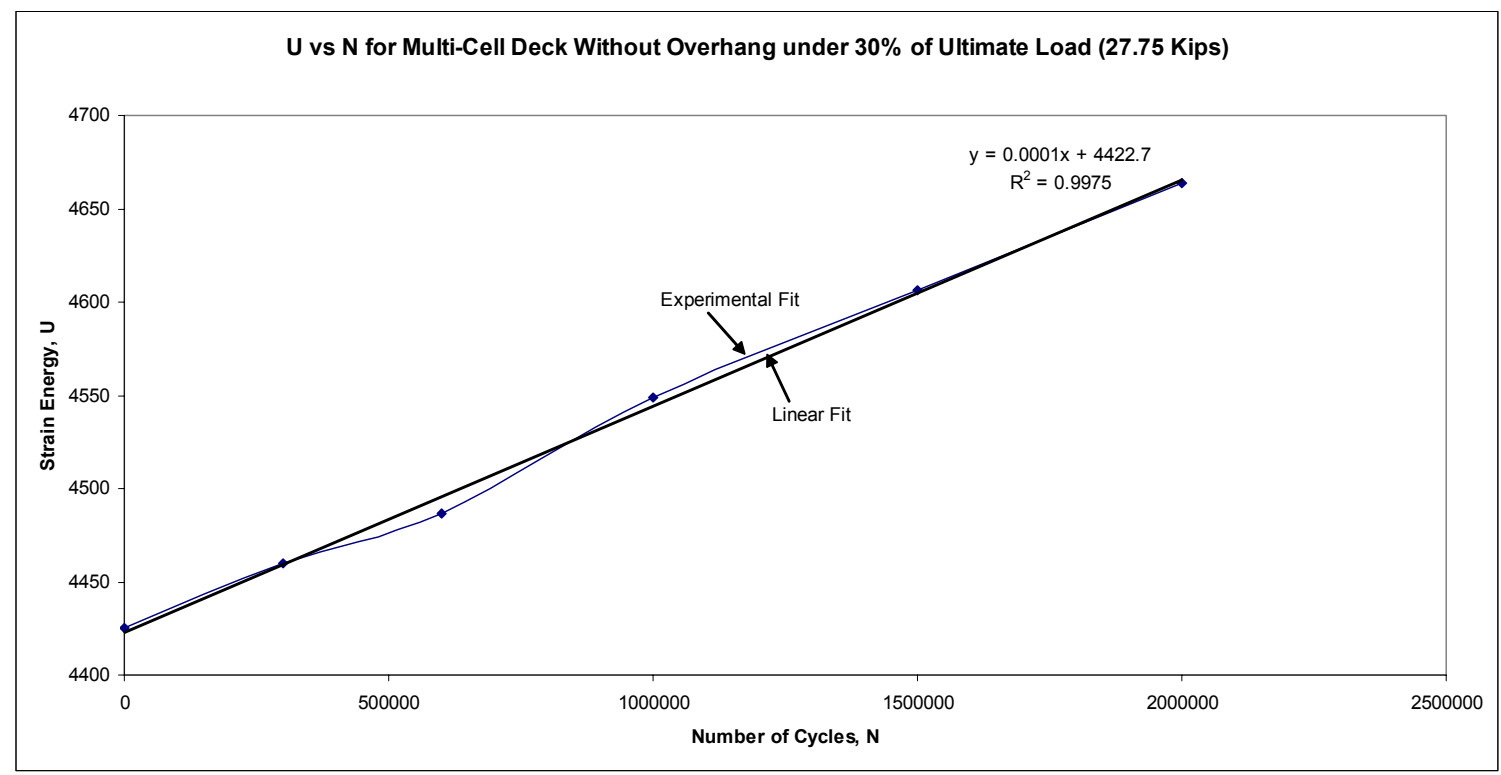

(a) 


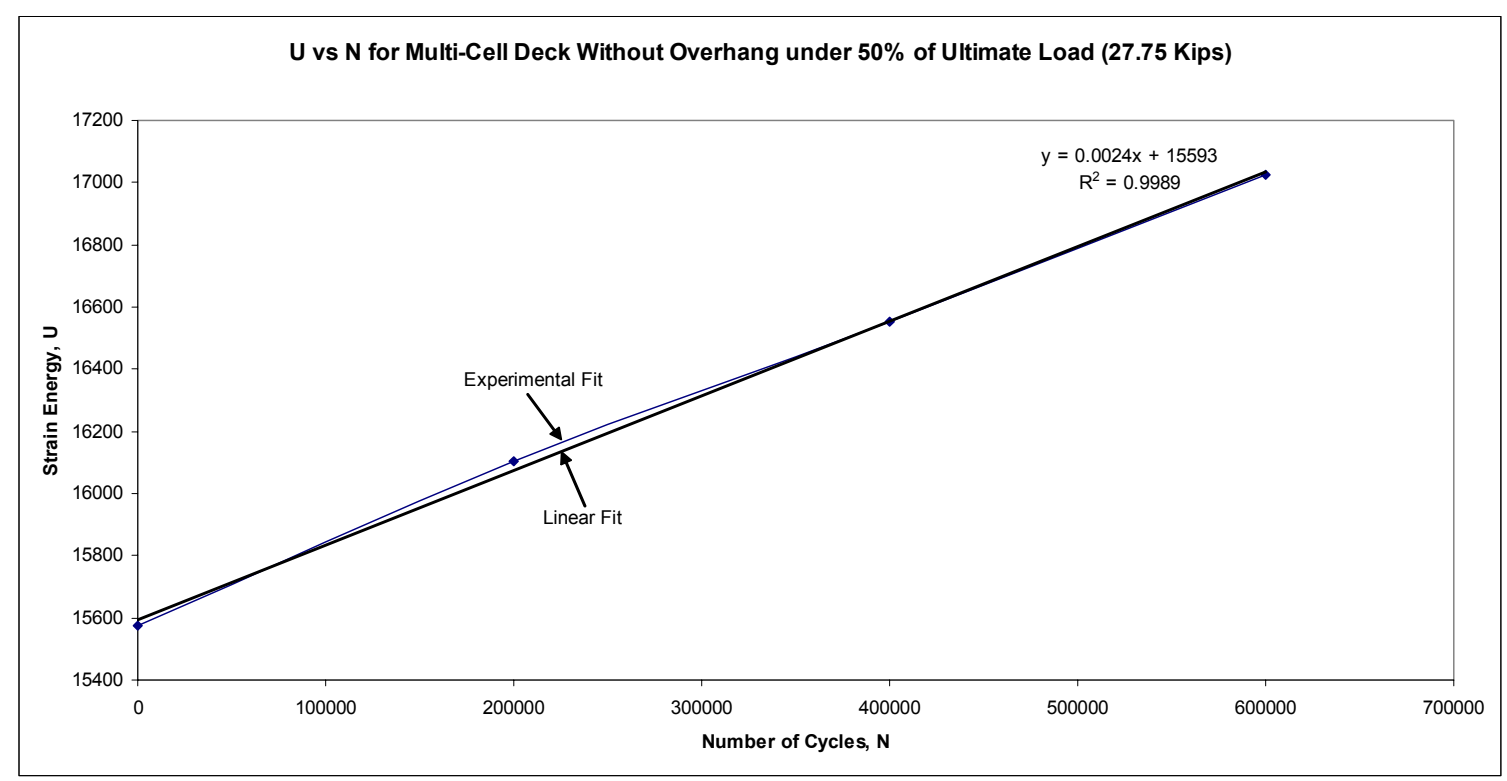

(b)

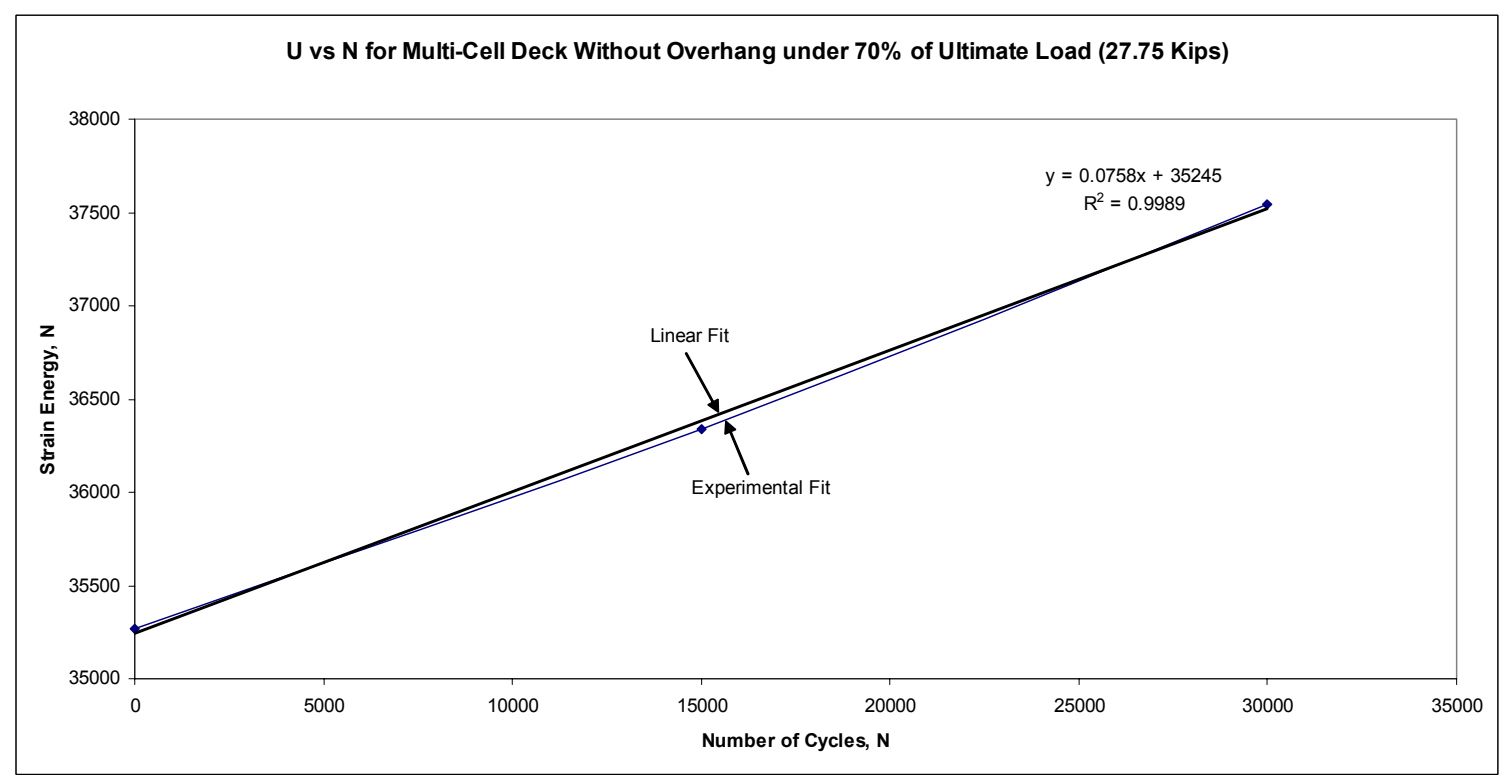

(c)

Figure 4.11 Strain Energy Curves for Multi-Cell Deck (Test 2) 


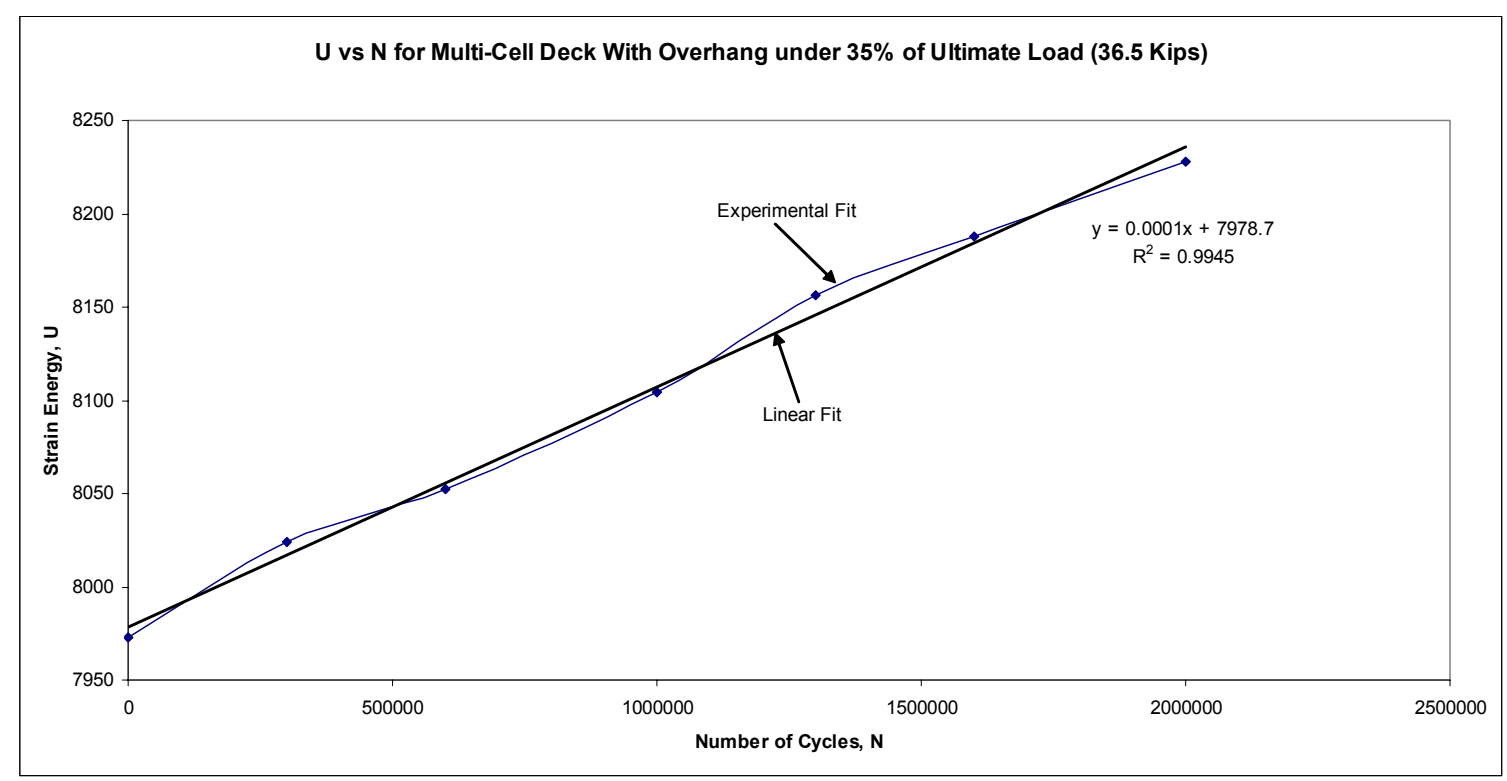

Figure 4.12 Strain Energy Curves for Multi-Cell Deck (Test 1)

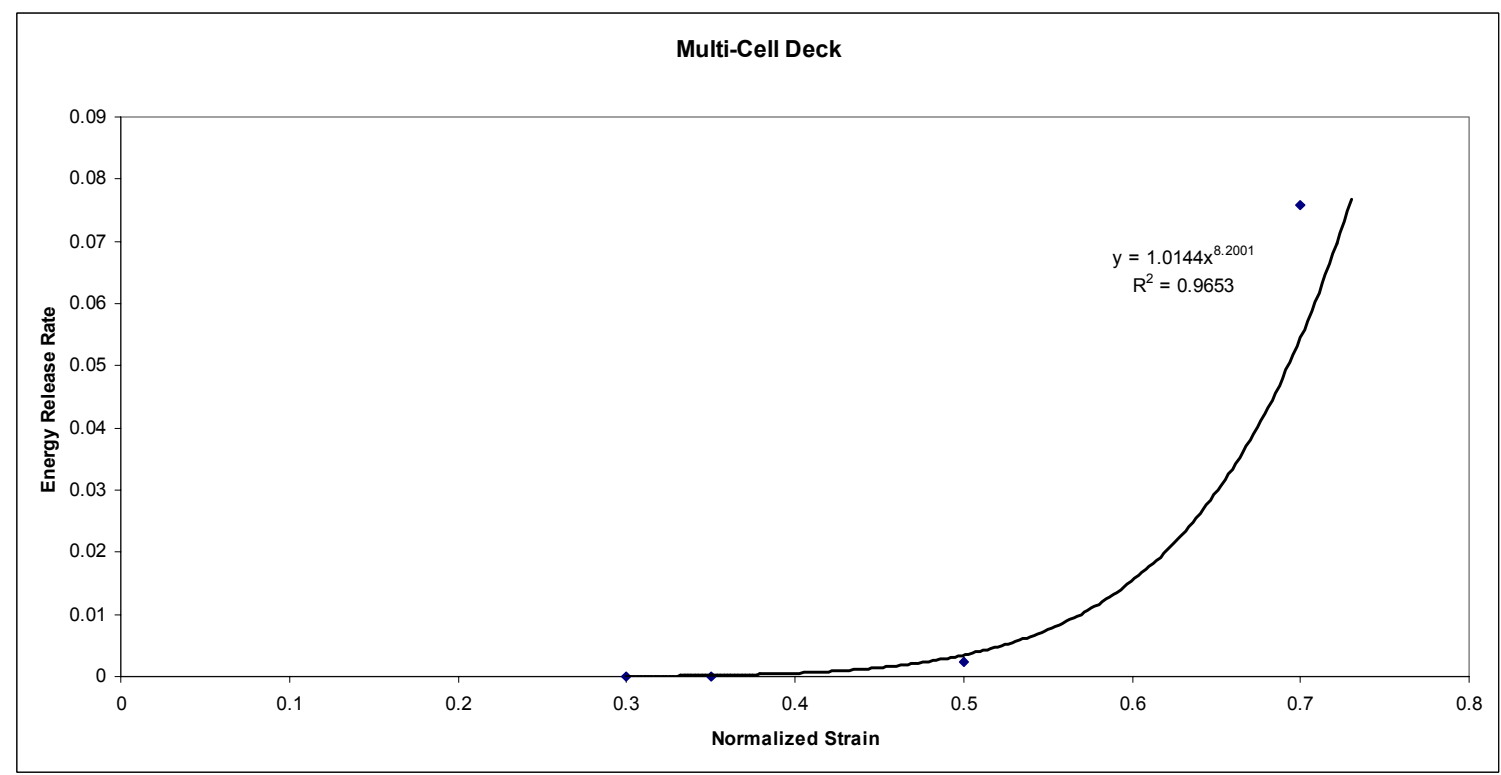

Figure 4.13 Strain Energy Release Rate vs Normalized Strain Curve to Determine

Fatigue Coefficients ' $a$ ' and ' $b$ ' 
Table 4.9 Energy Release Rate of Multi-Cell Deck for Different

Percentages of Ultimate Strain

\begin{tabular}{|c|c|c|}
\hline \% Ultimate Strain & Energy Release Rate & Energy Release Rate/a \\
\hline 0.3 & 0.0001 & 0.00001 \\
\hline 0.35 & 0.0001 & 0.00001 \\
\hline 0.5 & 0.0024 & 0.00236 \\
\hline 0.7 & 0.0758 & 0.0747 \\
\hline
\end{tabular}

Table 4.10 Fatigue Coefficients for Multi-Cell Deck

\begin{tabular}{|c|c|c|}
\hline \multirow{2}{*}{ Multi-Cell Deck } & $\mathrm{a}$ & $\mathrm{b}$ \\
\cline { 2 - 3 } & 1.0144 & 8.2001 \\
\hline
\end{tabular}

\subsection{Conclusions}

\subsubsection{Bending Fatigue tests on Single Cell Deck}

Upon testing the single cell decks under three point bending fatigue, the following conclusions are drawn:

- The cracks initiated in the top flange after certain number of cycles (approximately $10 \%$ of total number of cycles). The number of fatigue cycles depended upon the percentage of ultimate bending strain ranges induced through the MTS machine. The cracks from the top flange progressed towards the bottom flange through the web.

- The strain energy loss per cycle under bending fatigue strain range of $70 \%$ of its ultimate followed the power law $\left(\Delta U=a x^{b}\right.$ where $\Delta U$ is the energy release rate, $\mathrm{x}$ is the normalized strain, ratio of applied strain to ultimate strain, ' $a$ ' and ' $b$ ' are 
the fatigue coefficients) as the bending fatigue under $50 \%$ and $30 \%$ of the ending fatigue strain range of its ultimate value.

- The crack growth on one side was longer than on the other side of the load patch which is positioned at the geometric centroid of the beam. This may be attributed to lack of perfect fabric symmetry in the cross-section about its vertical axis, leading to lateral torsional buckling of the FRP module.

- The failure of the deck was initiated through the delamination because of the fiber-matrix bond failure in the top flange of the FRP deck module. The bond failure is attributed to top flange overhang sliced along the module span length.

- The number of cycles to failure of a single cell deck for $30 \%, 50 \%$ and $70 \%$ of ultimate load was 2.62 million, 1524, 208 respectively. The reason for this may be the bond failure between fiber and matrix as the decks were cut from multi-cell deck.

- The normalized fatigue coefficient, $\mathrm{a} / \mathrm{Uo}$, was found to decrease with the increase in applied strain range. This was concluded observing the trend of power law.

- The experimental and fatigue lives were correlated well with predicted fatigue lives using power law.

\subsubsection{Bending Fatigue Tests on Multi-Cell Deck}

- Multi-cell deck with overhang under fatigue strain range of $35 \%$ of its ultimate didn't exhibit cracking up to 2 million cycles. It only exhibited 3\% decrease in stiffness. 
- The multi-cell deck without overhang failed after 71190 fatigue cycles with the applied percentage strain of $70 \%$ after it had run for 2 million cycles with $30 \%$ and additional one million cycles with $50 \%$ of ultimate strain.

- $\quad$ From the trend observed through power law it was found that the normalized fatigue coefficient, a/Uo, was found to decrease with the increase in applied strain range for multi-cell deck also.

- The multi-cell deck failed due to delamination in the deck and also buckling on one side of the patch load. The buckling on one side is due to higher crack propagation on the side of buckling in the top flange than the other side from the center of patch load. 


\section{CHAPTER 5}

\section{CONCLUSIONS AND RECOMMENDATIONS}

\section{$5.1 \quad$ CONCLUSIONS}

\subsubsection{Fatigue Test on GFRP Composite Materials under Coupon Level}

Based on the test data of GFRP composite coupons made of unidirectional fibers, bidirectional fibers, the following conclusions are drawn:

1. Strain Energy Release Rate:

- The strain energy loss per cycle from $2-5 \%$ to $90 \%$ of the FRP composite's fatigue life was found to be approximately $50 \%$ of the strain energy induced at the mean fatigue load level (Table 3.3).

- $\quad$ The strain energy release rate was found to decrease with the decrease in the applied mean strain that was inducing fatigue (Table 3.3).

2. Fiber Volume Fraction:

- $\quad$ For all fatigue strain ranges fiber volume fraction increases the number of cycles to failure decreases. This is attributed to the interfacial bond failure between fibers and resin because resin thickness decreases as the fiber volume fraction increases. 
3. Strain Range:

- Number of cycles to failure decreases exponentially with the increase in strain range because the strain energy release rate increases exponentially with strain range in all the test specimens under this program.

4. Manufacturing:

- The fatigue coefficient ' $b$ ' was found to be with in the range of 10-13 for pultrusion process which is evident from earlier studies (Reference 37).

5. Fiber Architecture:

- The energy release rate is lower for unidirectional composites than for bidirectional composites because of overlapping of fibers leading to stress concentration.

6. Fatigue Coefficients:

- The fatigue coefficient ' $b$ ' depends on pliability of the FRP material or component which is a function of resin, shape, voids and other parameters. As can be seen from Table 3.4, 'b' is lower for bidirectional composites than for unidirectional composites.

- It was observed through the power law that the normalized fatigue coefficient, a/Uo (APPENDIX A), was found to decrease with an increase in the applied strain range. 


\subsubsection{Bending Fatigue Tests on Single Cell Deck}

Upon testing the single cell decks under three point bending fatigue, the following conclusions are drawn:

- Bending cracks were initiated in the top flange after certain number of fatigue cycles. The number of fatigue cycles depended upon the bending strain range which is a function of ultimate static bending strain. The cracks initiated at the top flange as it was cut from multi-cell deck and progressed towards the bottom flange through the web.

- The strain energy loss per cycle under bending fatigue strain range of $30 \%, 50 \%$ and $70 \%$ of its ultimate strain followed the power law ( $\Delta U=a x^{b}$ where $\Delta U$ is the energy release rate, $x$ is the normalized strain, ratio of applied strain to ultimate strain, 'a' and ' $b$ ' are the fatigue coefficients).

- The failure of the deck was initiated through the delamination of top flange because of the fiber-matrix bond failure in the top flange of the FRP deck module. The bond failure is attributed to cutting/slicing of the top flange along the module span length.

- The number of cycles to failure of a single cell deck for $30 \%, 50 \%, 70 \%$ of ultimate load was 2.62 million, 1524, 208 respectively. The reason for this may be the bond failure between fiber and matrix as the decks were cut from multi-cell deck.

- The normalized fatigue coefficient, a/Uo (APPENDIX A), was found to decrease with the increase in applied strain range. This was concluded observing the trend of power law. 
- The experimental and fatigue lives were correlated well with predicted fatigue lives using power law.

\subsubsection{Bending Fatigue Tests on Multi-Cell Deck}

- Multi-cell decks with overhang under fatigue strain range of 35\% of its ultimate strain didn't exhibit cracking up to 2 million cycles. It only exhibited $3 \%$ decrease in stiffness.

- $\quad$ The multi-cell deck without overhang failed after 71,190 fatigue cycles with the applied percentage strain of $70 \%$ after it had run for 2 million cycles with $30 \%$ and additional one million cycles with $50 \%$ of ultimate strain.

- The crack growth on one side was longer than the crack growth on the other side of the load patch, which is positioned at the geometric centroid of the beam. This may be attributed to lack of perfect fabric symmetry in the cross-section about its vertical axis, leading to lateral torsional buckling of the FRP module as it progressively loses its bending stiffness under increasing number of cycles.

- The strain energy release rate trend revealed that the normalized fatigue coefficient, a/Uo (APPENDIX A) decreased with the increase in applied strain range for multi-cell deck also.

- The multi-cell deck failed due to delamination in the deck and also buckling on one side of the patch load. The buckling on one side is due to higher crack propagation on the side of buckling in the top flange than the other side from the center of patch load. 


\subsection{Recommendations}

- Research can be extended by experimenting fatigue life of composites manufactured from different process such as hand lay-up, VARTM, vacuum bag molding, etc. at coupon level to better understand the effect of fatigue coefficients 'a' and 'b'.

- $3 \mathrm{D}$ stitched composite plates can be manufactured by using pultrusion process with varying pitch and test for fatigue to compare the results of unidirectional and bidirectional pultruded composite plates studied in this research.

- Specimens have to be prepared from various resin systems such as polyester, epoxy, carbon, aramid as different resins are used for the applications based on their functional and cost requirements.

- As composites are used in many offshore, elevated and aggressive temperatures, the specimens can be tested for fatigue response in various service conditions.

- Fatigue tests can be performed on honeycomb, sandwich panels, etc. and also on different geometric shapes such as hexagonal plus half-depth trapezoidal sections, triangular sections, etc.

- The performance of FRP joints under fatigue loads can be evaluated under fatigue.

- Finite element analysis can be performed to simulate the fatigue behavior of composites and the results can be compared with the experimental data. 


\section{REFERENCES}

1. Reifsnider K L, "Introduction: Fatigue of Composite Materials", In: Fatigue of Composite Materials, Reifsnider K L (Ed.), Composite Materials Series 4, Elsevier Science Publishers B. V., 1991.

2. Joris Degrieck and Wim Van Paepegem, "Fatigue Damage Modelling of Fibre-Reinforced Composite Materials: Review”, Applied Mechanics reviews, 54(4), 279-300.

3. Hashin $\mathrm{Z}$ and Rotem A, "A fatigue criterion for fiber reinforced composite materials, Journal of composite materials 33(7), 448-464, 1973.

4. Reifsnider KL ang Gao Z, "A micromechanics model for composites under fatigue loading, International Journal of fatigue 13(2), 149-156, 1991.

5. Harris B, "Fatigue behavior of polymer-based composites and life prediction methods", AIB-Vincotte Leerstoel, 2 maart 1995, Belgium, National Fonds Voor Wetenschappelijk Onderzoek, 28 p, 1985.

6. Philippidis TP and Vassilopoulos AP, "Fatigue strength prediction under multiaxial stress", Journal of Composite Materials 33(17), 1578-1599, 1999.

7. Hwang W and Han KS, "Cumulative damage models and multi-stress fatigue life prediction", Journal of Composite Materials 20, 125-153, 154-165, 1986a, 1986b.

8. Sidoroff F and Subagio B, "Fatigue damage modeling of composite materials from bending tests. In: Matthews FL, Buskell NCR, Hodgkinson JM, and Morton J (eds.), Sixth International Conference on Composite Materials (ICCM-VI) \& Second European Conference on Composite Materials (ECCM-II): Volume 4, Proceedings, 20-24 July 1987, London, UK, Elsevier, PP. 4.32-4.39, 1987. 
9. Whitworth HA, "Modeling stiffness reduction of graphite epoxy composite laminates, Journal of Composie Materials 21, 362-372.

10. Brondsted P, Anderson SI, and Lilholt $\mathrm{H}$, "Fatigue damage accumulation and lifetime prediction of GFRP materials under block loading and stochastic loading. In: Anderson SI Brondsted P, Lilholt H, Lystrup Aa, Rheinlander JT, Sorenson BF, and Toftegaard H (eds), Polymeric Composites- Expanding the Limits, Proceedings of the $18^{\text {th }}$ Riso international Symposium on Materials Science, 1-5 September 1997, Roskilde, Denmark, Riso International Laboratory, pp. 269-278.

11. Halphin JC, Jerina KL, and Johnson TA, "Characterization of composites for the purpose of reliability evaluation", In: Analysis of the test methods for high modulus fibers and composites, ASTM STP 521, pp. 5-64, 1973.

12. Daniel IM and Charewicz A, "Fatigue damage mechanisms and residual properties of graphite/epoxy laminates, Eng Fracture Mech 25(5/6), 793-808, 1986.

13. Whitworth HA, "Evaluation of the residual strength degradation in composite laminates under fatigue loading”, Composite Struct 40(2), 95-101, 2000.

14. Ya0 WX and Himmel N, "A new cumulative fatigue damage model for fiberreinforced plastics, Composites Sci Tech 60, 59-64, 2000.

15. Bergmann HW and Prinz R, "Fatigue life estimation of graphit epoxy laminates under consideration of delamination growth, Int J Numer Methods Eng 27, 323-341, 1989.

16. Feng X, Gilchrist MD, Kinloch AJ, and Matthews FL, "Development of a method for predicting the fatigue life of CFRP components. In: Degallax S, Bathias C, and fougeres R (eds.), International Conference on fatigue of composites. Proceedings, 
Paris, France, pp. 407-414, 3-5 June 1997.

17. Talreja R, "Stiffness properties of composite laminates with matrix cracking and interior delamination, Eng Fracture Mech 25(5/6), 751-762, 1986.

18. Talreja R, "Damage mechanics of composite materials based on thermodynamics with interior variables. In: Cardon AH and Verchery G (eds.), Durability of polymer based composite systems for structural applications. Proceedings of the International Colloquium, Brussels, Belgium, Elsevier, pp. 65-79, 27-31 August 1990.

19. Y. Setiadi, P.-Y. B. Jar, T. Kuboki, and J.-J. R. Cheng, "Fatigue Damage Development of Fibre-Reinforced Polymers (FRPs) with Random In-Plane Reinforcement, University of Alberta, Edmonton, AB, Canada.

20. Ho Sung Kim and Jianping Zhang, "Fatigue Damage and life Prediction of Glass/Vinyl ester Composites”, Journal of reinforced plastics and composites, Vol. 20, No. 10, 834-848 (2001).

21. Cornelia E. Demers, "Tension-Tension Axial Fatigue of E-Glass Fiber-Reinforced Polymeric Composites: Fatigue Life Diagram”, Construction and Building Materials, Elsevier Publishers, December 1997.

22. Z. Khan, F. A. Al-Sulaiman, J. K. Farooqi and M. Younas, "Fatigue Life Predictions in Woven Carbon Fabric/Polyester Composites based on Modulus Degradation”, Journal of Reinforced Plastics and Composites, Vol. 20, No. 05/2001.

23. J. N. Yang, D. L. Jones, S. H. Yang and A. Meskini, “A Stiffness Degradation Model for Graphite/Epoxy Laminates”, Journal of Composite Materials, Vol. 24-July 1990.

24. Z. Fawaz and Ellyin, "Fatigue failure Model for Fibre-Reinforced Materials under 
General Loading Conditions", Journal of Composite Materials, Vol. 28, No. 15/1994.

25. A. Poursartip, M. F. Ashby and P. W. R. Beaumont, "The Fatigue Damage Mechanics of a Carbon Fibre Composite Laminate: I-Development of the Model", Composite Science and Technology, Elsevier Applied Science Publishers Ltd., England, 1986.

26. T. Kevin O’Brien and Kenneth L. Reifsnider, "Fatigue Damage Evaluation through Stiffness Measurements in Boron-Epoxy Laminates", Journal of Composite Materials, Vol. 15, January 1981, P. 55.

27. Jitendra S. Tate and Ajith D. Kelkar, "Fatigue Behavior of VARTM Manufactured Bi-axial Braided Composites", Proceedings of IMECE'03, 2003 International Mechanical Engineering Congress and RD \& D Exposition, Washington D. C. , November 15-21, 2003.

28. Natarajan V, "Fatigue Response of Fabric Reinforced Polymeric Composites", M. S. Thesis, Department of Mechanical and Aerospace Engineering, West Virginia University, Morgantown, WV., December 2003.

29. Deepthi Punyamurthula, "Structural Performance of Low-Profile FRP Composite Cellular Modules", M. S. Thesis, Department of Mechanical and Aerospace Engineering, West Virginia University, Morgantown, WV, 2004.

30. Kumar P, K Chandrashekhara and Nanni A, "Structural Performance of a FRP Bridge Deck”, ASCE Journal of Composites for Construction, March 2001.

31. Stephenson L, Lopez-Anido R, Howdyshell P, "Durability of Modular FRP Bridge Decks Under Cycling Loading”, in Durability of Fiber Reinforced Composites for 
Construction, Edited by Benmorkane B, Rahman H. Proceedings of International Conference CDCC, 1998.

32. Banerjee R, Lockwood J, Day S, "Design, Fabrication and Installation of a Low Profile Composite Bridge Deck” KSI.

33. Kwon S C, G. Durell, Dutta P K, Lopez-Anido R, "Fatigue Evaluation of FRP Composite Bridge Deck Systems under Extreme Temperatures", in Durability of Fiber Reinforced Composites for Construction, Edited by Benmokrane B, ElSalakawy E, Proceedings of International Conference CDCC, 2002.

34. GangaRao H V S, Howdyshell P A, Lopez-Anido R and Trovillion J C, "Development of Advanced Design of Composite Structural Components", USACERL Technical Report, July 1998.

35. M. J. Salkind, "Fatigue of Composites", Composite Materials: Testing and Design (Second Conference), ASTM STP 497, American Society for Testing and Materials, 1972, PP. 143-169.

36. Wim Van Paepegem, Joris Degrieck, "Modelling strategies for fatigue Damage Behavior of Fibre-Reinforced Polymer Composites”, European Journal of Mechanical and Environmental Engineering, 46(4), 217-227.

37. Venkatakrishnan Natarajan, Hota V.S. GangaRao, Vimala Shekar, "Fatigue Response of Fabric Reinforced Polymeric Composites”, Journal of Composites, 2005.

38. Marttin, R., "Delamination Fatigue", Edited by Harris, Bryan. 'Fatigue in Composites', Science and technology of the fatigue responses of FRP, Woodhead publishing limited, Cambridge, England, 2004. 
39. Whitworth H. A., "Modeling Stiffness Reduction of Graphite/Epoxy Composite Laminates", Journal of Composite Materials, Vol. 21, April 1987.

40. Hahn HT and Kim RY, "Proof Testing of Composite Materials", J Composite Mat 9, $1975,297-311$. 


\section{APPENDIX A Normalized Coefficient (a/Uo) Results for GFRP Composites at Coupon Level and Component Level}

1. Unidirectional Coupons (10"* $1 " * 0.125 ”)$ :

\begin{tabular}{|c|c|c|c|}
\hline$\% \varepsilon_{u l t}$ & $\mathrm{a}$ & Uo & $\mathrm{a} / \mathrm{Uo}$ \\
\hline 35 & \multirow{4}{*}{3.0713} & 30.4 & 0.1 \\
\hline 43 & & 45.8 & 0.06 \\
\hline 52 & & 67 & 0.04 \\
\hline 61 & & 92.2 & 0.03 \\
\hline
\end{tabular}

2. Unidirectional Coupons $(10 " * 0.5 " * 0.5 ”)$ :

\begin{tabular}{|c|c|c|c|}
\hline$\% \varepsilon_{u l t}$ & $\mathrm{a}$ & Uo & $\mathrm{a} / \mathrm{Uo}$ \\
\hline 40 & \multirow{6}{*}{1.9845} & 47.1 & 0.042 \\
\hline 50 & & 73.6 & 0.027 \\
\hline 52 & & 79.6 & 0.025 \\
\hline 60 & & 106 & 0.019 \\
\hline 61 & & 109.5 & 0.018 \\
\hline 70 & & 144.2 & 0.014 \\
\hline
\end{tabular}

3. Bidirectional Coupons (10"* $0.5 " * 0.5 ")$ :

\begin{tabular}{|c|c|c|c|}
\hline$\% \varepsilon_{u l t}$ & $\mathrm{a}$ & Uo & $\mathrm{a} / \mathrm{Uo}$ \\
\hline 30 & \multirow{5}{*}{0.4873} & 18 & 0.027 \\
\hline 40 & & 32 & 0.015 \\
\hline 50 & & 50 & 0.01 \\
\hline 60 & & 72 & 0.007 \\
\hline 70 & & 98 & 0.005 \\
\hline
\end{tabular}


4. 3D Stitched Composites (10"* 1 "* $0.12 ")$ :

\begin{tabular}{|c|c|c|c|}
\hline$\% \varepsilon_{u l t}$ & a & Uo & $\mathrm{a} / \mathrm{Uo}$ \\
\hline 30 & \multirow{5}{*}{2.9862} & 23 & 0.13 \\
\hline 39 & & 39.6 & 0.07 \\
\hline 48 & & 60 & 0.05 \\
\hline 53 & & 73 & 0.04 \\
\hline 60 & & 94 & 0.03 \\
\hline
\end{tabular}

\section{Single Cell Deck:}

\begin{tabular}{|c|c|c|c|}
\hline$\% \varepsilon_{\text {ult. }}$ & a & Uo & a/Uo \\
\hline 30 & & & 1.16 \\
\hline 50 & \multirow{3}{*}{1424.9} & 1223 & 0.42 \\
\hline 70 & & 3398 & 0.21 \\
\hline
\end{tabular}

6. Multi-Cell Deck:

\begin{tabular}{|c|c|c|c|}
\hline$\% \varepsilon_{\text {ult. }}$ & $\mathrm{a}$ & Uo & $\mathrm{a} / \mathrm{Uo}$ \\
\hline 30 & & & \\
\hline 35 & \multirow{4}{*}{1.0144} & 8250 & 0.0003 \\
\hline 50 & & 12775 & 0.00001 \\
\hline \multirow{nnn}{nnn}{} & & 13750 & 0.000063 \\
\hline & & 19250 & 0.00003 \\
\hline
\end{tabular}




\section{APPENDIX B Fatigue Test on 3D Stitched GFRP Fabric}

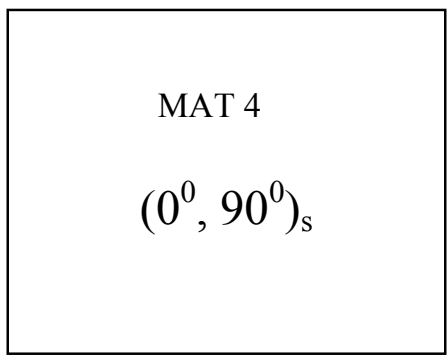

*MAT 4- 3 D Stitched GFRP Composite Material

Fiber Architecture of 3D Stitched Fabric

The $3 \mathrm{D}$ stitched fabric was manufactured using compression molding

process.

\section{Properties of MAT 4}

\begin{tabular}{|c|c|}
\hline Material ID & MAT 4 \\
\hline Fiber/Resin & Glass/Vinyl ester \\
\hline Fiber direction & 3D stitched fabrics \\
\hline Fiber Volume Fraction & 0.45 \\
\hline Width (inches) & 0.12 \\
\hline Plate thickness (inches) & 7500 \\
\hline Ultimate Load (lb) & 3.61 \\
\hline Longitudinal Modulus (psi) & 18564 \\
\hline Failure Strain $(\mu$ strains) & 66 \\
\hline Ultimate Strength (ksi) & Compression molding \\
\hline Manufacturing process &
\end{tabular}




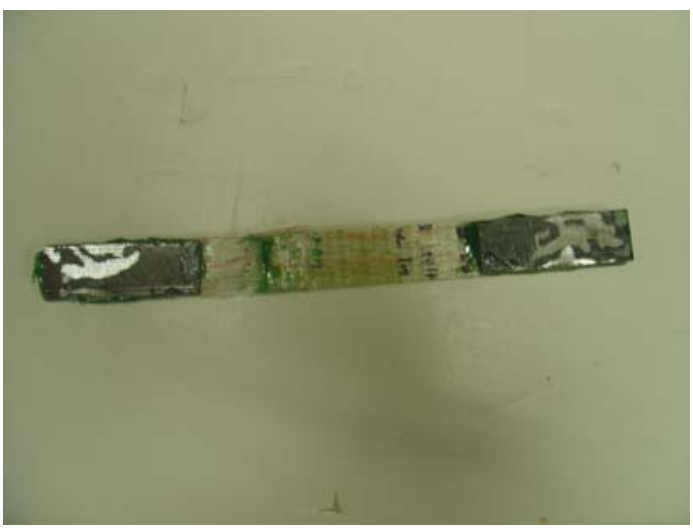

Tension-Tension Fatigue Failure Mode of MAT 4

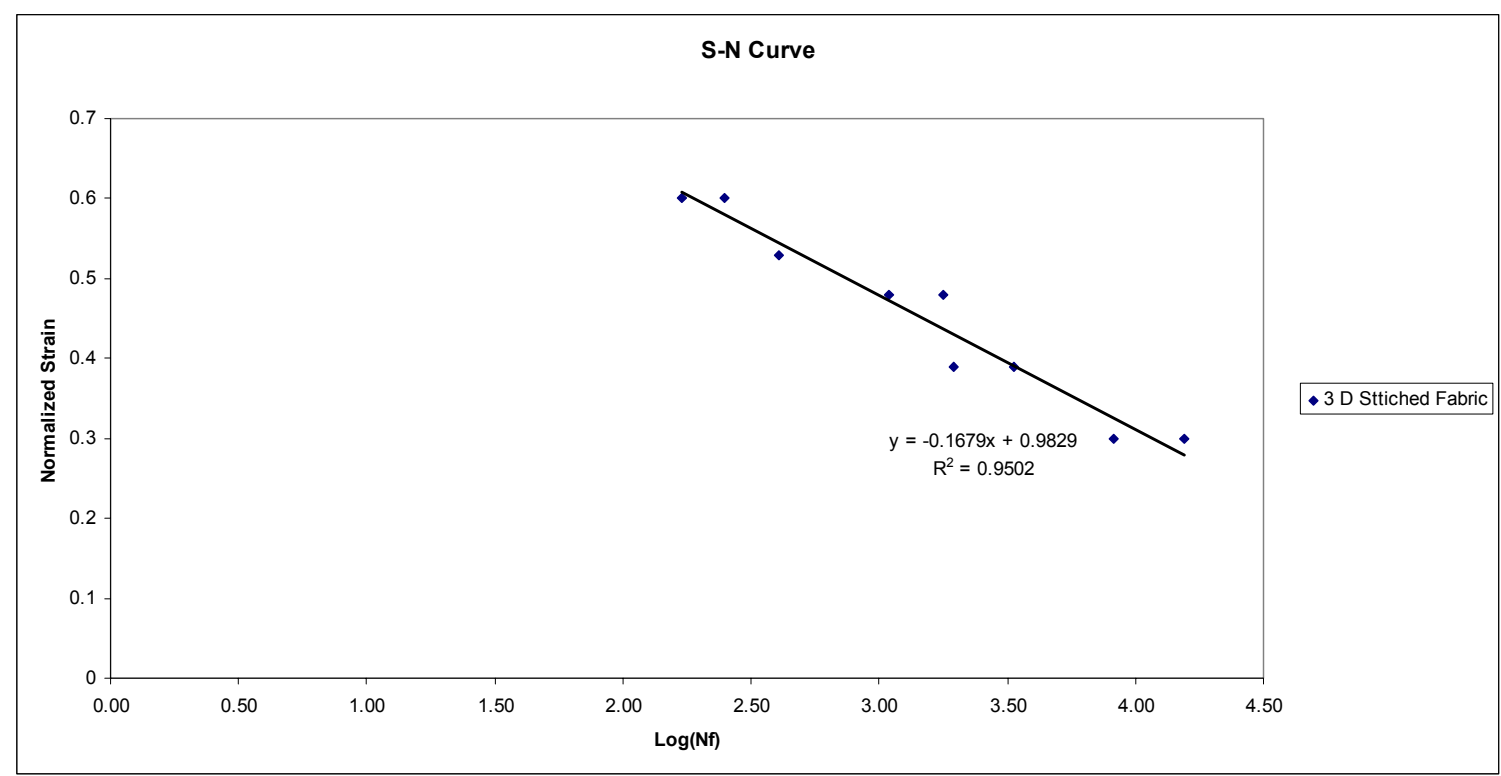

S-N Curve for MAT 4 
Summary of Fatigue Test Results for MAT 4

\begin{tabular}{|c|c|c|c|c|}
\hline \multicolumn{5}{|c|}{ MAT 4} \\
\hline Specimen No. & $\begin{array}{c}\text { Specimen } \\
\text { Dimension }\end{array}$ & $\begin{array}{l}\text { Load Range } \\
\text { (lbs) }\end{array}$ & $\% \varepsilon_{u l t .}$ & $\begin{array}{l}\text { Cycles to } \\
\text { Failure }\end{array}$ \\
\hline 1 & \multirow{9}{*}{$10 " * 1 " * 0.12 "$} & $200-2250$ & 30 & 15420 \\
\hline 2 & & $200-2250$ & 30 & 8180 \\
\hline 3 & & $200-2925$ & 39 & 1962 \\
\hline 4 & & $200-2925$ & 39 & 3364 \\
\hline 5 & & $200-3600$ & 48 & 1783 \\
\hline 6 & & $200-3600$ & 48 & 1098 \\
\hline 7 & & $200-3975$ & 53 & 407 \\
\hline 8 & & $200-4500$ & 60 & 170 \\
\hline 9 & & $200-4500$ & 60 & 248 \\
\hline
\end{tabular}




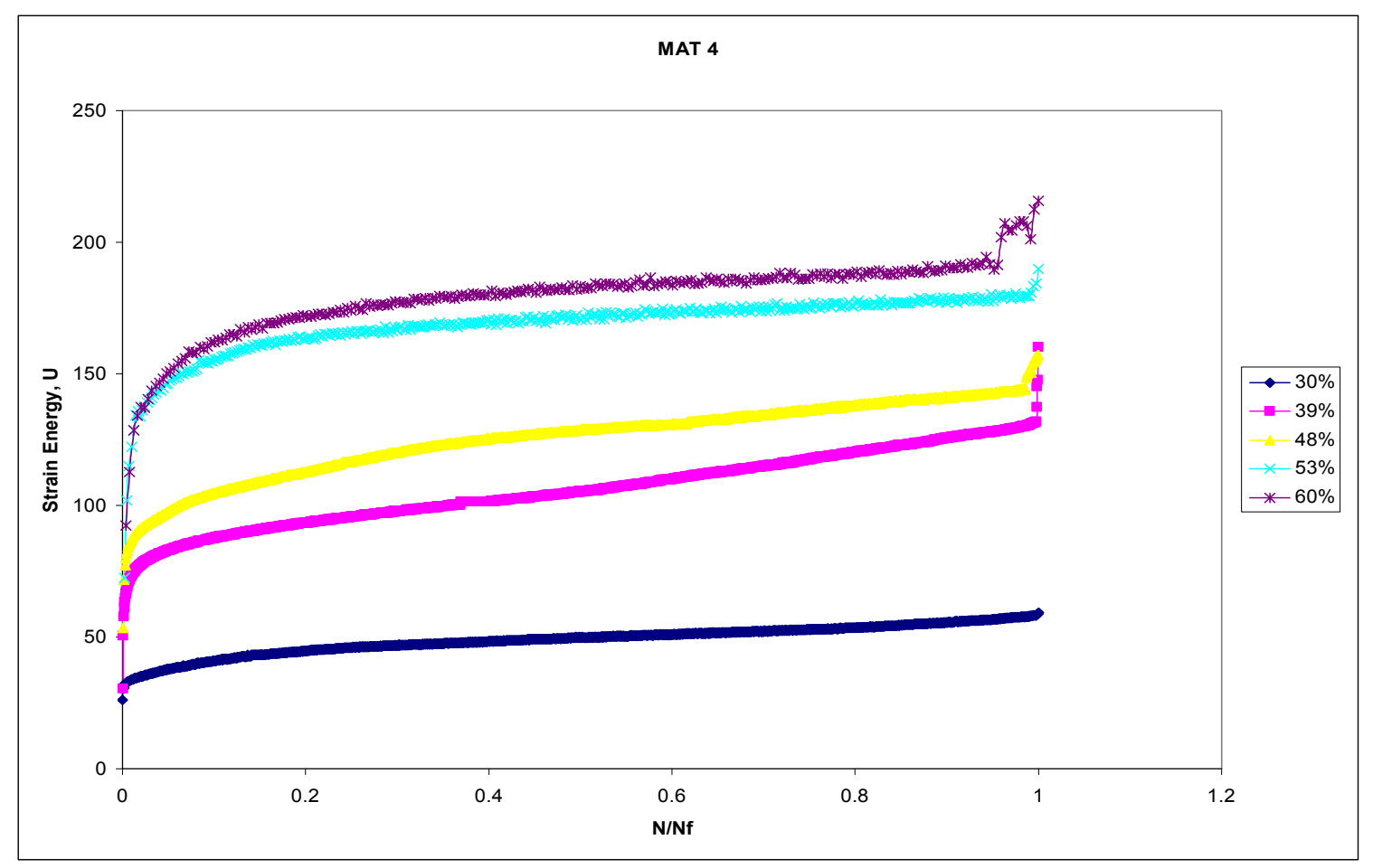

(a)

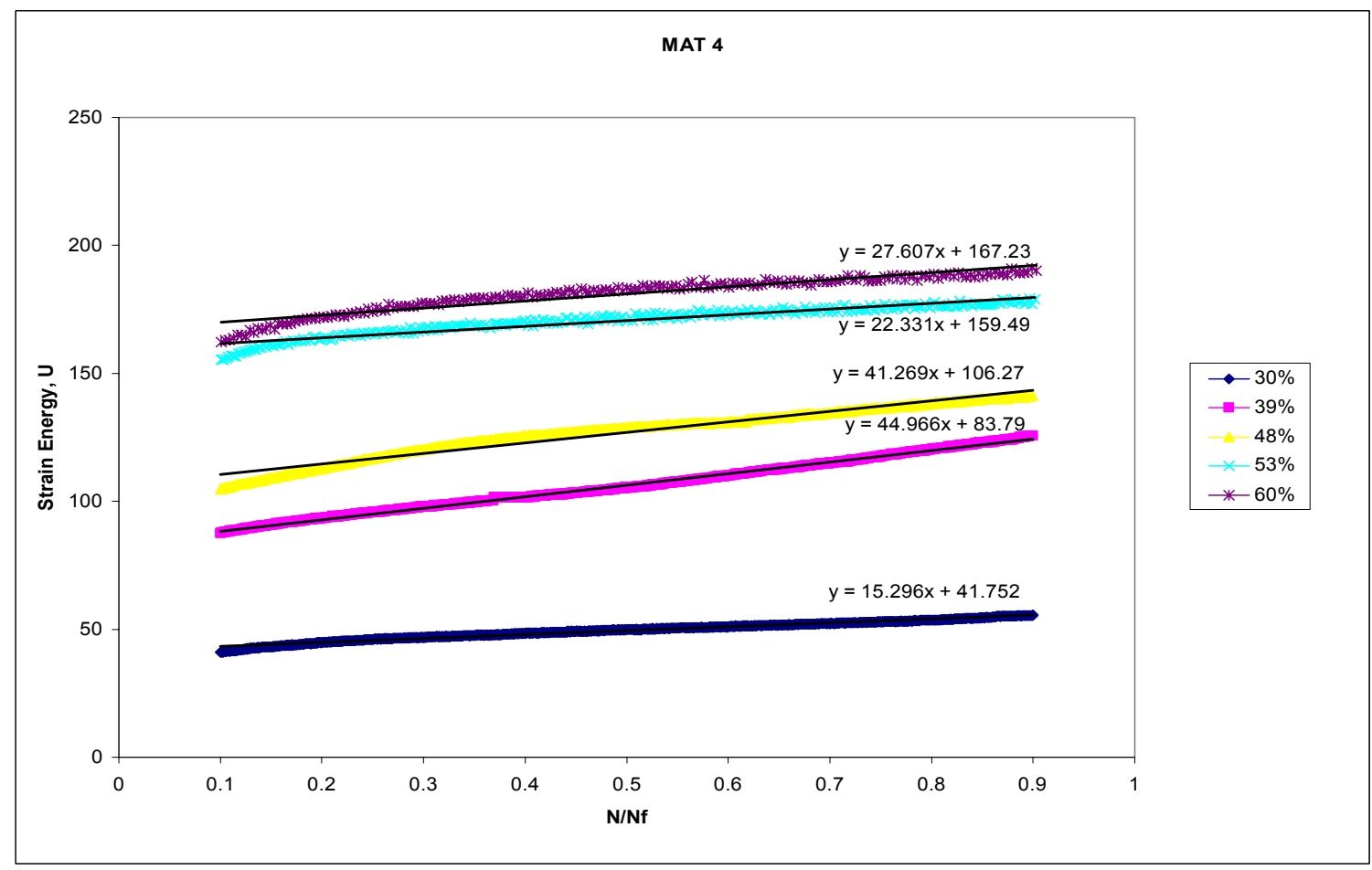

(b)

Strain Energy Curves for MAT 4 
Summary of Strain Energy Results for MAT 4

\begin{tabular}{|c|c|c|c|c|c|}
\hline \multicolumn{7}{|c|}{ MAT 4 } \\
\hline $\begin{array}{c}\text { Specimen } \\
\text { No. }\end{array}$ & $\% \varepsilon_{\text {ult. }}$ & $\begin{array}{c}\mathrm{U} \text { at } 0 \\
\text { cycles, lb-in }\end{array}$ & $\begin{array}{c}\mathrm{U} \text { at } \\
\mathrm{N} / \mathrm{N}_{\mathrm{f}}=0.9, \\
\mathrm{lb}-\mathrm{in}\end{array}$ & $\begin{array}{c}\text { \% increase } \\
\text { in U from } \\
\text { cycle 1 to } \\
\mathrm{N} / \mathrm{N}_{\mathrm{f}}=0.9\end{array}$ & $\begin{array}{c}\text { Energy } \\
\text { Release Rate } \\
\text { (Slope of } \\
\mathrm{U} \text { vs N), } \\
\text { lb-in }\end{array}$ \\
\hline 1 & 30 & 36 & 55 & 53 & 0.0009 \\
\hline 2 & 30 & 38 & 56 & 47 & 0.0013 \\
\hline 3 & 39 & 85 & 126 & 49 & 0.0232 \\
\hline 4 & 39 & 66 & 100 & 51 & 0.0146 \\
\hline 5 & 48 & 112 & 166 & 49 & 0.0241 \\
\hline 6 & 48 & 95 & 141 & 48 & 0.301 \\
\hline 7 & 53 & 122 & 179 & 47 & 0.0455 \\
\hline 8 & 60 & 130 & 193 & 48 & 0.147 \\
\hline 9 & 60 & 129 & 191 & 48 & 0.0836 \\
\hline & & & \multicolumn{4}{|c|}{ Avg. 48.89} \\
\hline
\end{tabular}

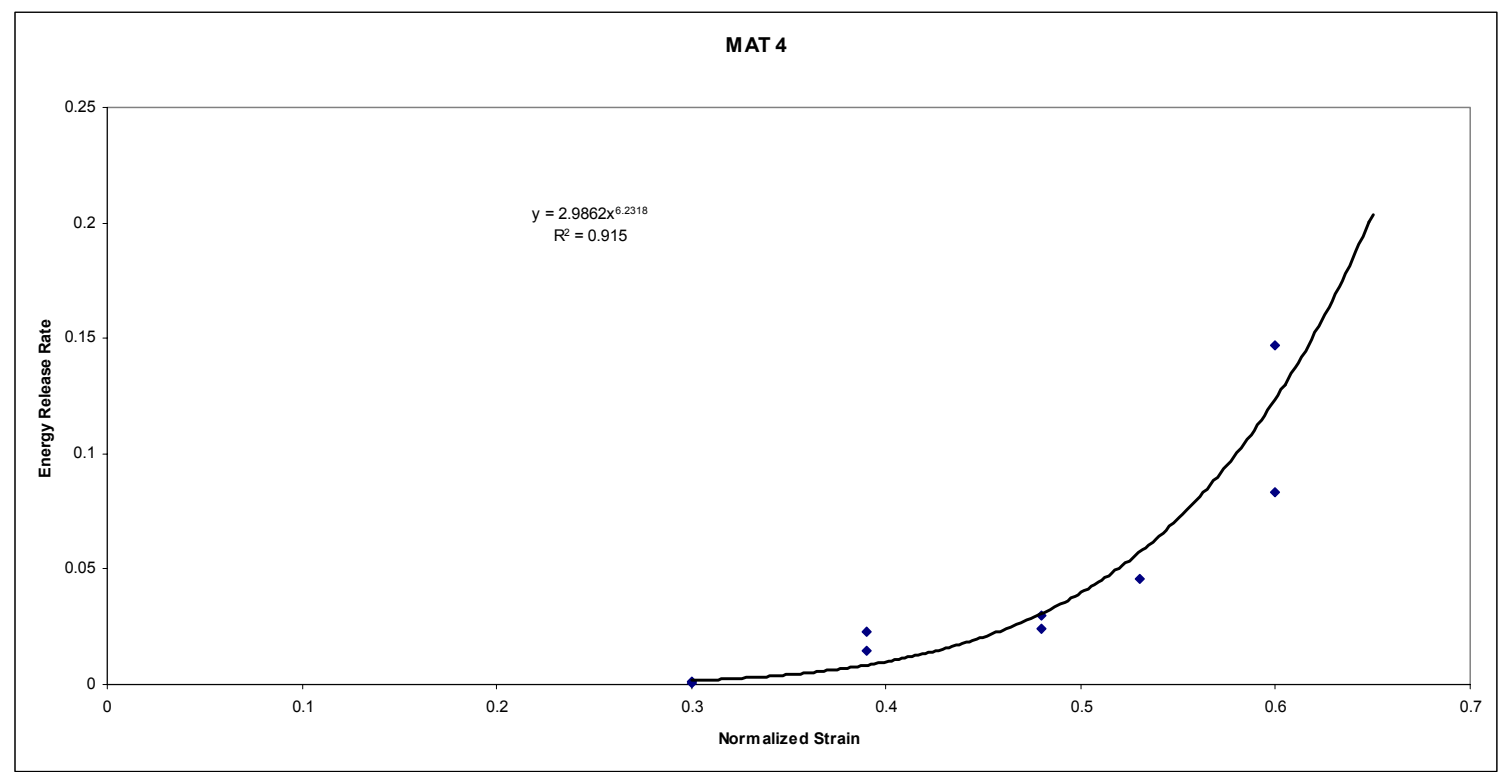

Variation of Strain Energy Release Rate with Normalized Strain for MAT 4 
Fatigue Coefficients for MAT 4

\begin{tabular}{|c|c|c|}
\hline \multirow{2}{*}{ Material } & \multicolumn{2}{|c|}{ Fatigue Coefficients } \\
\cline { 2 - 3 } & $\mathrm{a}$ & $\mathrm{b}$ \\
\hline MAT 4 & 2.9862 & 6.2318 \\
\hline
\end{tabular}

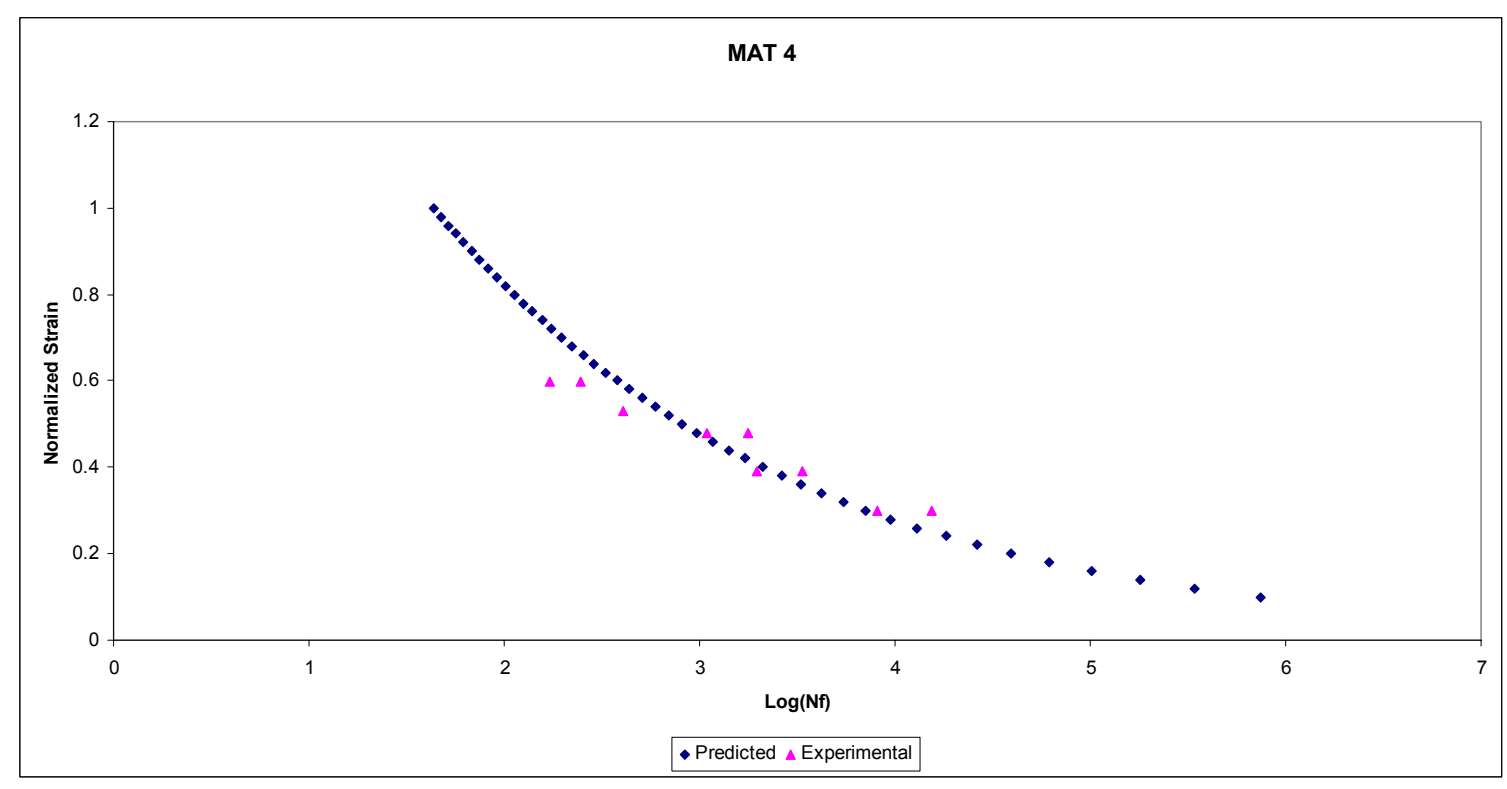

Comparision of Experimental and Predicted Fatigue Lives for MAT 4 


\section{APPENDIX C Comparision of Strain Energy Loss between GFRP Coupons and Carbon Fabric Coupons}

In this study as mentioned earlier the percentage increase in strain energy from $2-5 \%$ to $\mathrm{N} / \mathrm{N}_{\mathrm{f}}=90 \%$ was found to $50 \%$. In that $50 \%, 34 \%-40 \%$ increase was found in stage I and 6-10\% increase was found in stage II. This is compared with the Carbon fiber based composite coupons. Since strain energy is inversely proportional to stiffness the percentage decrease in stiffness was considered as approximately equal to percentage increase in strain energy loss when compared with carbon based composite coupons. It was found that for Carbon fabric/polyester composite coupons the percentage increase was found to be $7.7 \%$ from start of fatigue to stage I, $7.8 \%$ in stage II and $4.6 \%$ in stage III and a total of $18 \%$ from start of fatigue test to specimen failure ${ }^{22}$. Based on Whitworth for a Graphite/Epoxy composite laminates the percentage increase in strain energy was $4.6 \%$ in stage I, $5.7 \%$ in stage II, $9.6 \%$ in stage III and a total of $19 \%$ from 0 cycles to the last value noted at predetermined number of cycles $^{39}$. 


\section{APPENDIX D Application of Strain Energy Model}

A Quasi-Isotropic T-300 carbon fiber-epoxy laminate is subjected to 100,000 cycles at $382 \mathrm{MPa}$ after which the stress level is increased to $437 \mathrm{MPa}$. Estimate the number of cycles the laminate will survive at the second stress level. Median fatigue lives at $382 \mathrm{MPa}$ and $437 \mathrm{MPa}$ are 252, 852 and 19822 cycles respectively. The ultimate static strength of the material is $545 \mathrm{MPa}$.

Sol: Assuming strain energy model is valid for carbon fiber-epoxy laminate under the same limits as mentioned for glass fiber-vinyl ester composite.

Condition 1:

Maximum fatigue strain (mean strain $+50 \%$ of strain range) is less than $70 \%$ of the static ultimate strain $^{37}$

Condition 2:

Mean fatigue strain should be less than $30 \%$ of the ultimate static strain to avoid creep strain effects and creep rupture under fatigue ${ }^{37}$

Assuming mean fatigue strain $=29 \%$

$$
\begin{aligned}
& \varepsilon_{\text {max. }}=0.29 \varepsilon_{\text {static }}+0.5 \varepsilon_{\text {range }}<0.7 \varepsilon_{\text {static }} \\
& \varepsilon_{\text {max. }}=0.29\left(\frac{\sigma_{\text {ult. }}}{E}\right)+0.5\left(\frac{\sigma_{\text {range }}}{E}\right)<0.7\left(\frac{\sigma_{\text {ult. }}}{E}\right) \\
& \varepsilon_{\max .}=0.29+0.5\left(\frac{\sigma_{\text {range }}}{\sigma_{\text {ult. }}}\right)<0.7
\end{aligned}
$$

For $\sigma_{\text {max } .1}=382 \mathrm{MPa}, 0.29+0.5(382 / 545)=0.64<0.7$

For $\sigma_{\text {max } .2_{2}}=437 \mathrm{MPa}, 0.29+0.5(437 / 545)=0.695<0.7$ 
To find ' $b$ '

Using power law, $\left(\frac{d U}{d N}\right)=a\left(\frac{\varepsilon_{\text {max. }}}{\varepsilon_{u l t .}}\right)^{b}=0.5\left(\frac{U_{0}}{N_{f}}\right)$

For Tension-Tension fatigue, $U_{0}=\left(\frac{P_{\max .}{ }^{2} l}{2 A E}\right)=\left(\frac{\sigma^{2} A l}{2 E}\right)$

Using Equation (1) for $382 \mathrm{MPa}$ and $437 \mathrm{MPa}$

$$
b=\left(\frac{\log \left(\frac{U_{0_{1}} N_{f_{2}}}{U_{0_{2}} N_{f_{1}}}\right)}{\log \left[\frac{\varepsilon_{\text {max.1 }}}{\varepsilon_{\text {max.2 }}}\right]}\right)
$$

Canceling equal terms

$$
b=\left(\frac{\log \left(\frac{\sigma_{\text {max. }}^{2} N_{f_{2}}}{\sigma_{\text {max } \cdot 2}^{2} N_{f_{1}}}\right)}{\log \left(\frac{0.29 \sigma_{u l t .+} 0.5 \sigma_{\text {max. }}}{0.29 \sigma_{u l t .+} 0.5 \sigma_{\text {max.2 }}}\right)}\right)
$$

Substituting the values

$$
b=\left(\frac{\log \left(\frac{382^{2} * 18922}{437^{2} * 252852}\right)}{\log \left(\frac{0.29 * 545+0.5 * 382}{0.29 * 545+0.5 * 437}\right)}\right)=39.4
$$

Expressing 'a' in terms of $U_{0}$

Using Equation (1)

$$
\begin{aligned}
& \frac{0.5 * U_{0}}{18922}=a\left(\frac{0.29(545)+0.5(437)}{545}\right)^{39.4} \\
& a=\frac{U_{0_{2}}}{0.01693}
\end{aligned}
$$


As the strain energy loss is linear the difference of energy between two stresses is also linear

Therefore $\left(\frac{d U}{d N}\right)_{1}-\left(\frac{d U}{d N}\right)_{2}=\left(a *\left(\frac{\varepsilon_{\text {max. }}}{\varepsilon_{\text {ult. }}}\right)_{1}^{b}\right)-\left(a *\left(\frac{\varepsilon_{\max }}{\varepsilon_{u l t .}}\right)_{2}^{b}\right)$

$\frac{0.5 * U_{0_{1}}}{N_{f_{1}}}-\frac{0.5 * U_{0_{2}}}{N_{f_{2}}}=\left(a *\left(\frac{\varepsilon_{\text {max. }}}{\varepsilon_{\text {ult. }}}\right)_{1}^{b}\right)-\left(a *\left(\frac{\varepsilon_{\text {max. }}}{\varepsilon_{u l t .}}\right)_{2}^{b}\right)$

Using Equation (2) and canceling equal terms

$U_{0_{1}}=\left(\frac{\sigma_{0_{1}}}{\sigma_{0_{2}}}\right)^{2} * U_{0_{2}}$

Substituting (3) and (5) in (4)

$\frac{0.5 *\left(\frac{382}{437}\right)^{2}}{100,000}-\frac{0.5}{N_{f_{2}}}=\left(\frac{1}{0.01693}\right) *\left(\left(\frac{0.29 * 545+0.5 * 382}{545}\right)^{39.4}-\left(\frac{0.29 * 545+0.5 * 437}{545}\right)^{39.4}\right)$

$N_{f_{2}}=10,434$ Cycles which are less than number of cycles determined experimentally.

From this it can be stated that the theory is safe and valid. 